\author{
Universidade de SÃo PAUlo \\ Faculdade de EConomia, Administração e Contabilidade de Ribeirão Preto \\ Departamento DE ECONOMia \\ Programa de Pós-GraduaÇão em Economia - Área: Economia Aplicada
}

FELIPE DOS SANTOS COSTA

Repasse cambial para os preços de importação e ao atacado da indústria brasileira: uma análise via Global VAR

Orientador: Prof. Dr. Sérgio Kannebley Júnior

Ribeirão Preto 
Prof. Dr. Vahan Agopyan

Reitor da Universidade de São Paulo

Prof. Dr. André Lucirton Costa

Diretor da Faculdade de Economia, Administração e Contabilidade de Ribeirão Preto

Prof. Dr. Sérgio Kannebley Júnior

Chefe do Departamento de Economia

Prof. Dr. Sérgio Naruhiko Sakurai

Coordenador do Programa de Pós-Graduação em Economia 
FELIPE DOS SANTOS COSTA

\title{
Repasse cambial para os preços de importação e ao atacado da indústria brasileira: uma análise via Global VAR
}

Dissertação de mestrado apresentada ao Programa de Pós-Graduação em Economia - Área: Economia Aplicada da Faculdade de Economia, Administração e Contabilidade de Ribeirão Preto da Universidade de São Paulo para obtenção do título de Mestre em Ciências.

Orientador: Prof. Dr. Sérgio Kannebley Júnior

\author{
Versão Corrigida \\ (versão original disponível na Faculdade de Economia, Administração e \\ Contabilidade de Ribeirão Preto)
}

Ribeirão Preto 
Autorizo a reprodução e divulgação total ou parcial deste trabalho, por qualquer meio convencional ou eletrônico, para fins de estudo e pesquisa, desde que citada a fonte.

COSTA, Felipe dos Santos.

Repasse cambial para os preços de importação e ao atacado da indústria brasileira: uma análise via Global VAR / Felipe dos Santos Costa - Ribeirão Preto, SP, 2019.

110 p.: il.; $30 \mathrm{~cm}$

Dissertação de mestrado apresentada ao Programa de PósGraduação em Economia - Área: Economia Aplicada da Faculdade de Economia, Administração e Contabilidade de Ribeirão Preto da Universidade de São Paulo, para obtenção do título de Mestre em Ciências. - Universidade de São Paulo

Orientador: Kannebley Júnior, Sérgio

1. Repasse cambial. 2. Setores. 3. GVAR. 
Aos meus pais. 



\section{AGRADECIMENTOS}

Uma vez que nenhum homem é uma ilha, muitos serão citados aqui. Primeiramente, gostaria de expressar minha incomensurável gratidão aos meus pais, Rosangela e Vladimir, que apostaram até o que não podiam em mim, e que tanto sacrificaram para que eu pudesse chegar até aqui. Essa conquista é tão de vocês quanto minha.

Ao meu caro orientador, Sérgio Kannebley, por ser não apenas um mentor, mas um verdadeiro amigo, durante todo o mestrado, e também ao Diogo Prince, que tão solicitamente respondeu as mais inúmeras dúvidas que tive durante as rodadas de estimação e que também, rapidamente, tornou-se um mentor e amigo para a vida. Meu muito obrigado a ambos é certamente pouco perante a confiança que vocês depositaram em mim.

Ao Professor Márcio Laurini por todo conhecimento e inspiração que me foram transmitidos durante as disciplinas do mestrado, e pelas valiosas contribuições na qualificação, pré-defesa e defesa. E aos professores Emerson Marçal e Mauro Rodrigues por também terem aceitado meu convite para participar da minha defesa e pelas contribuições importantíssimas.

Aos meus amigos e colegas de épocas tensas de estudo, Laura (minha duplinha), Diego, Giulia, Renata, Raytza, Francielly, Thiago, Marcos, Quinaud, Danizinho, Vitoca e Victor. Sem vocês, passar pelo mestrado não seria possível. Obrigado pelo apoio e amizade durante a caminhada.

Aos melhores veteranos que alguém poderia ter, em especial, Denize, Giba, Lívia, Lucas Reis, Lucas Souza e Ricardo.

Aos melhores calouros desse Brasil: André, Felipe Basso, Gabriel, Henrique, Igor, Lívia, Lucas Gerez, Paolo, Patrícia, Rafinha, William e todos os demais. E claro, à membra honorária do PPGE, Ana Luíza.

Às minhas queridas Ana Carolina, Camila, Juliana e Tainá pelo apoio, mesmo que à distância. E, em especial, ao meu amigo Thiago pelo nosso mútuo suporte durante o mestrado, mas por principalmente me ajudar a encontrar meu eixo quando me sentia perdido. Vocês são maior presente que a graduação me deu e que espero levar por toda a vida.

A todos os professores do PPGE/FEARP/USP com os quais tive contato seja em sala de aula seja em atividade acadêmica de outra natureza, em especial aos professores Alex Ferreira e Luciano Nakabashi que depositaram tamanha confiança que foram as monitorias de Macroeconomia I da pós-graduação.

A todos os técnicos e funcionários da FEARP/USP, especialmente do Serviço de Pós-Graduação (vocês são demais!). 
Por fim, mas não menos importante, gostaria de agradecer a um grupo de pessoas que me inspirou a fazer o mestrado e buscar ser um profissional tão excelente como todos são. A todos os amigos que fiz na MCM/LCA/E2, em especial ao Leandro e à Sarah; e aos Professores Fernando Postali e Paula Pereda.

Ao IBRE/FGV pela cessão dos dados necessários tornando possível esta pesquisa.

À CAPES pelo apoio financeiro concedido ao longo do mestrado. O presente trabalho foi realizado com o apoio da Coordenação de Aperfeiçoamento de Pessoal de Nível Superior Brasil (CAPES) - Código de Financiamento 001. 


\section{RESUMO}

COSTA, F. S. Repasse cambial para os preços de importação e ao atacado da indústria brasileira: uma análise via Global VAR. Dissertação (Mestrado) - Faculdade de Economia, Administração e Contabilidade de Ribeirão Preto, Universidade de São Paulo, Ribeirão Preto, 2019.

O repasse de choques cambiais, ou de custos produtivos em geral, para os preços é um problema chave para o controle da inflação pela autoridade monetária, sendo seu entendimento uma das ferramentas para tomadas de decisão de políticas. Na literatura, já se argumentou que a estimação do repasse cambial usando dados agregados pode levar a uma superestimação do grau de transmissão dos choques e que a heterogeneidade das diferentes atividades levam a decisões de precificação e transferência de custos diferenciadas para cada uma. Utiliza-se então o Global VAR para estimar um modelo multi-setores, usando os preços de importação e ao atacado dos setores da indústria de transformação brasileira, além do câmbio e preço do petróleo como variáveis globais, levando-se em conta os canais de transmissão de choques entre ambos preços como entre setores, buscando capturar possíveis efeitos transbordamento. Os resultados aqui obtidos estão em consonância com a literatura nacional e internacional, sendo que os preços de importação apresentam um repasse de cerca de $80 \%$ no primeiro trimestre seguido ao choque, reduzindo para $73 \%$ após vinte trimestres, enquanto que para o atacado de cerca de $11 \%$ a $22 \%$ após um e vinte trimestres do choque, respectivamente. Em vista do método utilizando, estimou-se também o grau de repasse de choques de custo vindo do preço do petróleo para os preços de importação e ao produtor, sendo que após um trimestre do choque a transmissão era de $18 \%$ e $6 \%$, e após vinte, $29 \%$ e $9 \%$, respectivamente.

Palavras-chave: Repasse cambial. Setores. GVAR. 



\section{ABSTRACT}

COSTA, F. S. Exchange rate pass-through to Brazilian industry import and producer prices: a Global VAR analysis. Dissertation (Master Degree) - School of Economics, Business and Accounting at Ribeirão Preto, University of São Paulo, Ribeirão Preto, 2019.

The pass-through of exchange rate shocks, as well as production costs in general, to prices is a key issue to the maintenance of price stability by the monetary authority. Understanding the phenomenon is essential to policy decisions. Previous works in the field have argued that estimating the degree of exchange rate pass-through (ERPT) using aggregated country data may lead to an overestimated rate of transmission of the shock. Moreover, the heterogeneity of the multiple activities which compose the economic system leads to different responses to the shock from each one of those. The Global VAR was used to estimate a multi-sector model for import and producer prices of the manufacturing industry sectors. Nominal exchange rate and oil price are included as global exogenous variables. Such methodology is capable to capture the direct shock transmission to both prices of all sectors of the industry, besides spillover effects from one sector to another. The results show ERPT coefficients similar to those found in the literature, specifically import prices have a degree of ERPT of $80 \%$ one quarter after the shock, and $73 \%$ twenty quarters after, while producer prices have a shock transmission of $11 \%$ and $22 \%$ after one and twenty quarters after the shock, respectively. Since oil prices had been used as a global variable which is made possible by the framework used, besides the fact that it represents an important fraction of production cost for some activities, the degree of pass-through of its shock is also calculated. Import prices show a degree of oil price pass-through of $18 \%$ after one quarter, and $29 \%$ after twenty, while producer prices show a pass-through of $6 \%$ after one quarter and $9 \%$ after twenty quarters.

Keywords: Exchange rate pass-through. Sectors. GVAR. 



\section{LISTA DE ILUSTRAÇÕES}

Figura 4.1 - Função de resposta ao impulso a choque cambial . . . . . . . . . . . . . . 64

Figura 4.2 - Função de resposta ao impulso generalizada dos preços de importação a choque positivo no câmbio $\ldots \ldots \ldots \ldots 6$

Figura 4.3 - Função de resposta ao impulso generalizada dos preços ao atacado a choque positivo no câmbio . . . . . . . . . . . . . . 66

Figura 4.4 - Função de resposta ao impulso ao choque no preço do petróleo . . . . . . . 67

Figura 4.5 - Função de resposta ao impulso generalizada dos preços de importação a choque positivo no preço do petróleo . . . . . . . . . . . . 68

Figura 4.6 - Função de resposta ao impulso generalizada dos preços ao atacado a choque positivo no preço do petróleo . . . . . . . . . . . . . . . . . . 69

Figura 4.7 - Repasse cambial agregado aos preços de importação e ao atacado doméstico 71

Figura 4.8 - Repasse agregado de choque positivo sobre o preço do petróleo sobre os preços de importação e ao atacado . . . . . . . . . . . . . . . . 78

Figura A.1 - Variações YoY \% dos índices ponderados dos preços das importações dos Estados Unidos . . . . . . . . . . . . . . . . . . . . . . . . . 96

Figura A.2 - Variações YoY \% das projeções para os índices de preços das importações dos Estados Unidos . . . . . . . . . . . . . . . . . . . . . . 101

Figura C.1 - Dinâmica do repasse do choque cambial para os preços de importação 107

Figura C.2 - Dinâmica do repasse do choque cambial para os preços ao atacado $\ldots$. . . 108

Figura C.3 - Dinâmica do repasse do choque do preço do petróleo para os preços de importação . . . . . . . . . . . . . . . . . . . . . . . 109

Figura C.4 - Dinâmica do repasse do choque do preço do petróleo para os preços ao

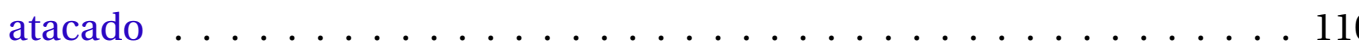




\section{LISTA DE TABELAS}

Tabela 1.1 - Estimativas de coeficientes setoriais de repasse cambial . . . . . . . . . 24

Tabela 3.1 - Setores da indústria de transformação . . . . . . . . . . . . . . . . . . 54

Tabela 4.1 - Ordem dos modelos VARX* setoriais $\ldots \ldots \ldots$. . . . . . . . . . 60

Tabela 4.2 - Número de relações de cointegração por setor . . . . . . . . . . . . . . 61

Tabela 4.3 - Teste de exogeneidade fraca . . . . . . . . . . . . . . . . . 62

Tabela 4.4 - Repasse cambial aos preços de importação para os setores da indústria 72

Tabela 4.5 - Coeficiente de correlação de posto de Spearman . . . . . . . . . . . . . 73

Tabela 4.6 - Repasse cambial aos preços ao atacado para os setores da indústria . . . 76

Tabela 4.7 - Repasse de choque do preço do petróleo aos preços de importação dos setores da indústria brasileira $\ldots \ldots \ldots \ldots \ldots$

Tabela 4.8 - Repasse de choque do preço do petróleo aos preços ao atacado dos setores da indústria brasileira . . . . . . . . . . . . . . . . 80

Tabela B.1 - Estimativas dos vetores cointegração dos modelos setoriais VARX* . . . . . 105 


\section{SUMÁRIO}

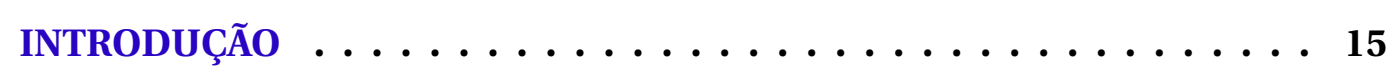

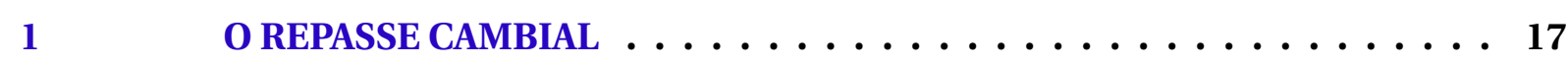

$1.1 \quad$ A teoria do repasse cambial $\ldots \ldots \ldots \ldots \ldots$

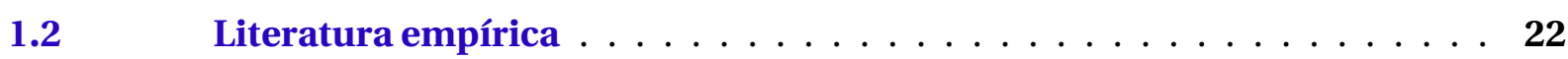

1.2.1 O repasse de choques do preço do petróleo $\ldots \ldots \ldots \ldots$

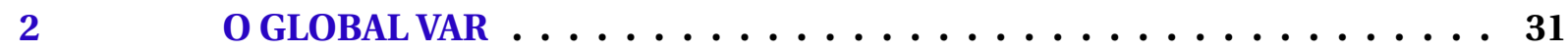

$2.1 \quad$ Modelando setores e interconexões $\ldots \ldots \ldots \ldots$

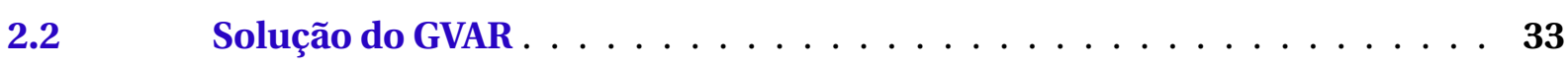

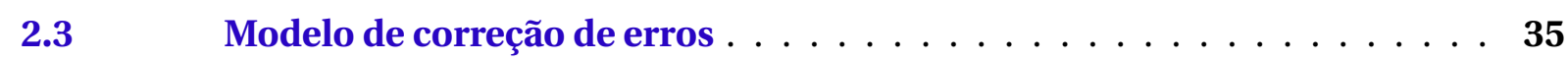

2.4 Introdução de variáveis globais ao GVAR $\ldots \ldots \ldots \ldots \ldots$

$2.5 \quad$ Teste de exogeneidade fraca $\ldots \ldots \ldots \ldots \ldots \ldots$

2.6 Análise de resposta ao impulso $\ldots \ldots \ldots \ldots \ldots \ldots$

2.6.1 A função de resposta ao impulso generalizada $\ldots \ldots \ldots \ldots \ldots \ldots$

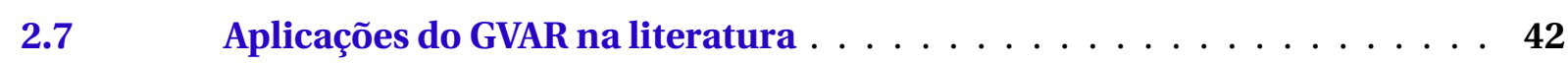

3 DADOS E ESTRUTURA DE ESTIMAÇÃO $\ldots \ldots \ldots \ldots$

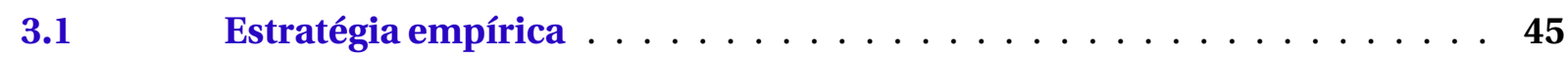

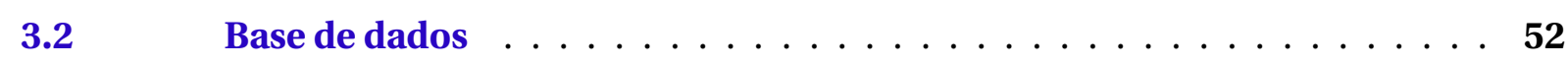

$3.3 \quad$ A ponderação dos setores $\ldots \ldots \ldots \ldots \ldots \ldots$

$3.4 \quad$ Estimação do repasse cambial $\ldots \ldots \ldots \ldots \ldots$

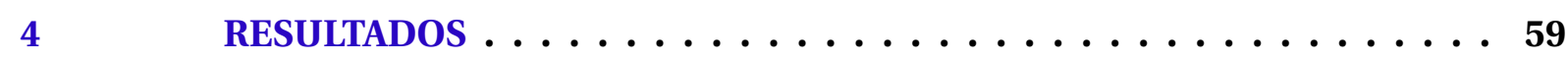

$4.1 \quad$ Estimação do GVAR $\ldots \ldots \ldots \ldots \ldots \ldots$

4.2 Estimação da função de resposta ao impulso generalizada . . . . . . . . 63

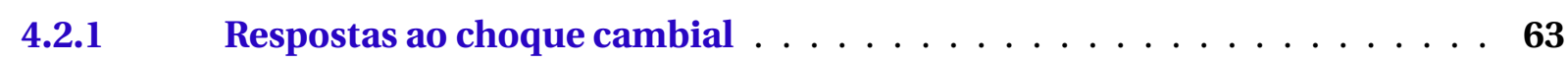

4.2.2 Respostas ao choque no preço do petróleo $\ldots \ldots \ldots$. . . . . . . . 67

Estimativa de repasse $\ldots \ldots \ldots \ldots \ldots \ldots \ldots$ 
4.3.1 Estimativas de repasse cambial $\ldots \ldots \ldots \ldots \ldots$

4.3.2 Estimativas de repasse de choques no preço do petróleo . . . . . . . . 77

CONCLUSÃo ........................ 83

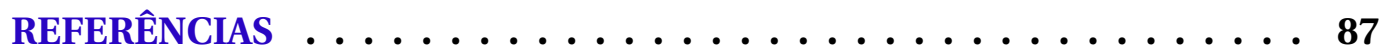

$\begin{array}{ll}\text { APENNDICES } & 93\end{array}$

APÊNDICE A - RECONSTRUÇÃO DAS SÉRIES DE ÍNDICE DE PREÇOS DE IMPORTAÇÃO DOS ESTADOS UNIDOS . . . . . . . . 95

APÊNDICE B - RESULTADOS DA ESTIMAÇÃO DOS VETORES DE COINTEGRAÇÃO SETORIAIS . . . . . . . . . . . . 105

APÊNDICE C - COEFICIENTES DO REPASSE DOS CHOQUES CAMBIAIS E AOS PREÇOS DO PETRÓLEO . . . . . . . . . . . . 107 


\section{INTRODUÇÃO}

Nos anos que se seguiram ao acordo de Bretton Woods, a adoção do câmbio flexível era considerada benéfica, uma vez que se constatava que as moedas haviam desviado de suas taxas de equilíbrio durante a vigência do acordo (MENON, 1995). Todavia, apesar do entusiasmo inicial com adoção do sistema de câmbio flexível, a expectativa do ajuste taxa de câmbio nominal das diversas moedas existentes como um fator de equilíbrio do comércio internacional não se concretizou, uma vez que se observou resistência dos saldos comerciais dos países apesar das flutuações cambiais. Segundo Menon (1995), a explicação é que o ajuste dos preços das importações não ocorre como deveria com a variação cambial, o que na literatura se refere como a questão do repasse cambial (exchange rate pass-through).

No caso brasileiro, uma economia de passado altamente inflacionário e que adotou o regime de metas de inflação com câmbio flutuante, este é um preço fundamental devido a sua influência na formação dos demais preços dentro da economia. Assim, para a autoridade monetária, o entendimento acerca de como os preços se comportam frente a flutuações cambiais é de suma importância diante de seu papel de garantidor da estabilidade do poder de compra.

Em vista da importância de exercícios que busquem verificar o grau de transmissão dos choques cambiais, na literatura, trabalhos utilizaram desde modelos de equilíbrio parcial, até aqueles de equilíbrio geral dinâmico (utilizando desde de índices de preços agregados para os respectivos países ou desagregados setorialmente). Por sua vez, alguns trabalhos fazendo uso de informações detalhadas de comércio internacional, seja no nível da firma (e.g. Gopinath, Itskhoki e Rigobon (2010), Auer e Schoenle (2016)) ou do produto (e.g. Cao, Dong e Tomlin (2015), Pennings (2017)), foram capazes de verificar o papel de hipóteses acerca da estrutura de mercado e comportamento da firma, como efeito da escolha de moeda de precificação, tamanho do market share etc., sobre o grau de repasse cambial utilizando métodos econométricos comuns aos estudos atuais em Organização Industrial Empírica, o que não era possível anteriormente a partir de índices de preço.

Apesar deste encaminhamento da literatura, dados agregados ainda são muito utilizados na pesquisa sobre o comportamento do repasse cambial, em vista da pouca disponibilidade de microdados. Deste modo, novos trabalhos empíricos na área estão em busca de métodos econométricos que tragam novas informações a partir dos dados disponíveis (e.g. Forbes, Hjortsoe e Nenova (2018)). O presente trabalho busca contribuir para a literatura apresentando o método de Global Vector Autoregression (GVAR) de Pesaran, Schuermann e Weiner (2004) como alternativa para estimar o grau de repasse cambial. Mais especificamente, será estimado o grau de repasse para os preços de importação e ao produtor (também denotados como preços ao atacado) dos setores da indústria de transformação brasileira. 
O arcabouço do GVAR permite que se estime, a partir de modelos individuais, os sistemas de determinação de preços de importação e ao produtor de cada um dos setores da indústria de transformação, considerando a determinação conjunta das variáveis dos setores. Cada modelo setorial é estimado condicionalmente a todos os demais, uma vez que os erros do modelo de um está correlacionado, a um nível limitado, com os erros de todos os dos demais setores. Além disso, permite-se a existência de variáveis globais que são capazes de afetar todas unidades da indústria simultaneamente. Com as ligações entre os setores e as variáveis globais, o GVAR é capaz de aproximar fatores comuns não-observáveis aos setores e incorporá-los à estimação .

Assim, o GVAR se mostra como uma ferramenta é capaz de incorporar o fatores comuns e, dada a estimação dos modelos setoriais condicionados aos demais, captar efeitos transbordamento de um setor para outro, frente a choques sistêmicos, como é o cambial. Desta forma, o objetivo com uso do método é ser capaz de considerar relações intersetoriais, incorporando componentes comuns que afetem toda indústria de transformação.

Poucas são as aplicações multi-setoriais do GVAR, já que o foco maior de seu uso tem sido para modelar sistemas multi-países, ao passo que também inexiste a utilização da metodologia com o propósito de estimar coeficientes de repasse cambial. A única contribuição encontrada dentro desta literatura que utiliza o GVAR é Razafindrabe (2016), cujo objetivo é a estimação de um modelo multi-países de equilíbrio geral dinâmico para conduzir análises de repasse cambial. O autor utiliza o GVAR apenas para estimar o estado-estacionário das variáveis de seu modelo.

Para o cálculo das elasticidades de preços a choques, segue-se a literatura ao utilizar a análise resposta ao impulso (e.g. Belaisch (2003) e Faruqee (2006)). Os coeficientes obtidos indicam, como registrado na literatura, que os preços de importação têm alto coeficiente de repasse cambial (para alguns setores, a transferência é maior do que o choque), enquanto os preços ao produtor sofrem impacto reduzido. Após cinco anos passados do choque, o grau de repasse para os preços de importação é de 72,7\%, e ao produtor de 21,8\%. Ademais, em virtude da possibilidade de inserção de variáveis globais no modelo, foi considerada a variável de preço do petróleo, dada sua importância no processo de determinação de preços. Um choque positivo sobre tal preço mostrou um repasse médio de $28,6 \%$ e $8,9 \%$ para preços de importação e ao atacado, respectivamente.

Este trabalho está estruturado em quatro capítulos, além desta introdução, conclusão e apêndices. No Capítulo 1, apresenta-se a revisão da literatura, tanto do desenvolvimento teórico sobre o tema, como de suas aplicações empíricas. No Capítulo 2, apresenta-se a metodologia de estimação, ou seja, o GVAR. No Capítulo 3 são apresentados a estratégia empírica e os dados. E, por fim, no Capítulo 4 estão os resultados. 


\section{O REPASSE CAMBIAL}

Na literatura econômica, dá-se o nome de repasse cambial (ou exchange rate passthrough) para a elasticidade dos preços à taxa de câmbio nominal, o que segundo Cao, Dong e Tomlin (2015) é o grau com que movimentos da taxa de câmbio nominal são transmitidos aos preços de importação e, então, ao preços aos consumidores internos (firmas ou famílias). Uma das principais hipóteses sobre a relação entre preços e câmbio, segundo Burstein e Gopinath (2014), é paridade do poder de compra (PPC) relativa, sendo que segundo esta, quando cotadas na mesma moeda, as variações de preços em diferentes localidades seriam iguais.

Todavia, desvios de tal hipótese são observados nos dados, o que pode advir de diferenças nos custos para fornecer um bem para diversos lugares ou porque firmas diferenciam seus preços de acordo com o destino, ao variar o markup (BURSTEIN; GOPINATH, 2014). Segundo Burstein e Gopinath (2014), a investigação da relação dos preços e o câmbio é informativa acerca da estrutura de mercado em que se opera, da demanda e da segmentação de mercado entre países. Além disso, há vantagem de se basear neste tipo choque (cambial), pois é de simples argumentação a validade da hipótese de sua exogeneidade às ações da firma, bem como de fácil mensuração e exibe variação no tempo considerável.

Goldberg e Hellerstein (2008) afirmam, complementarmente, que os choques cambiais são importantes na identificação de variáveis não observadas, como o markup e os custos marginais. Deste modo, a taxa de câmbio tem um papel duplo na literatura: o de objeto de investigação, bem como de auxílio para a identificação dos parâmetros de interesse do modelo estrutural.

O comportamento dos preços é tal que este não é como o que seria previsto pela PPC. Segundo Auer e Schoenle (2016), a evidência internacional sobre o comportamento de precificação das firmas é de que o repasse de choques de custos ${ }^{1}$ aos preços de importação é incompleto, mesmo no longo prazo. Adicionalmente, tal incompletude é ainda mais pronunciada sob os preços ao consumidor doméstico, uma vez que o grau do repasse é ainda menor para este, segundo evidência coletada por Burstein e Gopinath (2014).

\subsection{A teoria do repasse cambial}

Dornbusch (1987) observando que o repasse de choques cambiais aos preços são incompletos, para explicar a fonte deste fenômeno passa então assumir a hipótese de que há imperfeição de mercado no comércio internacional. Nesta linha, argumenta então a favor da aplicação de modelos de Organização Industrial para a problemática. Tais modelos

\footnotetext{
${ }^{1}$ Yang (1997) afirma que mudanças cambiais são vistas pela firma exportadora como um choque de custos.
} 
mostraram-se frutíferos na teoria de comércio, uma vez que tal modelagem é capaz de explicar o ajuste dos preços em termo do grau de concentração do mercado, a homogeneidade da produção e o market share relativo entre firmas domésticas e estrangeiras ${ }^{2}$. $\mathrm{O}$ autor busca entender o ajuste dos preços relativos advindo de movimentos da taxa de câmbio desenvolvendo três modelos de organização industrial (sendo um modelo de oligopólio, outro de competição monopolística, e por fim um de diferenciação de produto).

Considerando primeiramente apenas o papel da estrutura de mercado, o modelo de Cournot proposto por Dornbusch (1987), com produtos homogêneos e custo marginal constante, o número de firmas estrangeiras é relevante uma vez que, em tal formulação, a elasticidade do preço de equilíbrio à taxa de câmbio $\left(e_{P, E}\right)$ é dada por

$$
e_{P, E}=\frac{\partial P}{\partial E} \frac{E}{P}=\left(\frac{n^{*}}{N}\right)\left(\frac{E W^{*}}{P}\right)
$$

em que $n^{*}$ é número de firmas estrangeiras, $N$ é o número todas de empresas que atuam no mercados (domésticas ou estrangeiras), $W^{*}$ são salários estrangeiros na moeda do país de origem, $E$ é a taxa de câmbio, e $P$ é o preço da indústria (destaca-se que $E W^{*}$ representa, neste modelo, o custo marginal na moeda do país importador). Observe que na formulação de Dornbusch (1987), E é o preço de uma unidade da moeda estrangeira medido em dólares.

Assim, com uma apreciação do dólar (queda de $E$ ), o custo da firma estrangeira cai em tal moeda, sendo que o declínio do preço em dólares é maior conforme mais competitiva a indústria (isto é, quanto menor o markup do preço sob o custo marginal) e maior a parcela de importações nas vendas totais. No caso de uma apreciação cambial, o repasse cambial é então incompleto, uma vez que a parcela de firmas estrangeiras é menor do que o total de firmas no mercado (market share é menor que um). Desta forma, o modelo de Cournot que não considera diferenciação de preços ou de produtos é capaz de representar o fenômeno de repasse cambial incompleto, pois como argumenta Menon (1995) isso ocorre pois na construção desse modelo apenas as $n^{*}$ firmas estrangeiras serão, de fato, afetadas pela variação cambial.

Ainda com relação à estrutura do mercado, Froot e Klemperer (1989) desenvolvem um modelo dinâmico em que a demanda futura da firma é determinada pelo seu atual market share, de modo que a taxa de câmbio esperada afeta o valor atribuído ao tamanho do market share futuro, o que modifica a estratégia de precificação das firmas. Os autores afirmam que os preços dos importados podem ser mais sensíveis à taxa de câmbio esperada do que à corrente. Esta afirmação está em linha com Fisher (1989) que aponta que, tanto a expectativa, quanto a realização do câmbio, são importantes para a precificação, sendo que em particular o passado parece impactar menos nas decisões estratégicas do que a expectativa com relação aos movimentos cambiais.

\footnotetext{
${ }^{2}$ Note que esta característica difere do grau de concentração do mercado já mencionado, uma vez que pode ser que o mercado não seja concentrado por um única empresa, mas tenha um maior número de empresas domésticas ou estrangeiras, o que afeta o grau de repasse também.
} 
Froot e Klemperer (1989) argumentam que, se há expectativa de mudança permanente na taxa de câmbio do país de destino, como uma depreciação, por exemplo, os custos presentes e futuros das firmas estrangeiras caem (quando expressos na moeda do país importador), levando firmas estrangeiras a competirem mais vigorosamente neste mercado e, sem ambiguidade, reduzirão seus preços abaixo do nível atual, buscando tomar uma maior fatia do mercado para si. Por sua vez, movimentos temporários, como uma depreciação temporária, por exemplo, farão com que as firmas deixem suas margens de lucro crescerem, investindo em outras frentes, ao invés de buscar maior parcela do mercado.

Fisher (1989) argumenta que, apesar de compatíveis com a evidência empírica, modelos que consideram produtos homogêneos e ausência de restrição na capacidade de produção parecem pouco verossímeis, uma vez que já no final da década de 1980 observava-se no comércio internacional o aumento da presença de bens diferenciados e o fluxo crescente de comércio. Em mesma linha, Goldberg e Hellerstein (2008) afirmam que as hipóteses de preferências representadas por um função utilidade do tipo Constant Elasticity of Substitution (CES), e de competição baseada em um modelo de Cournot são hipóteses difíceis de serem defendidas, pois apesar de gerarem repasse cambial incompleto, não se aplicam bem ao contexto em que há um maior conjunto de setores dentro da economia (isso porque espera-se que bens não sejam homogêneos e a elasticidade de substituição entre eles não seja constante). Além disso, Fisher (1989) argumenta que não deveria ser esperado que firmas de indústrias diferentes, com estruturas de mercado particulares, tenham o mesmo grau de repasse cambial.

No que diz respeito à afirmação de Fisher (1989) sobre a possível heterogeneidade do grau de repasse cambial em diferentes setores, Dornbusch (1987) já trazia a ideia de que cada atividade teria seu comportamento melhor representado por um modelo teórico diferente. Por exemplo, Dornbusch (1987) sugere que o modo de precificação da indústria de manufaturados seria melhor explicado por modelos de competição monopolística (e.g. modelo de Dixit-Stiglitz) ou de diferenciação de produto (e.g. modelo de Salop), uma vez que estes seriam bens mais complexos e, por isso, com baixo de grau de substitutibilidade e maior poder de precificação, sendo capazes de absorver maior parte do choque cambial. Em contrapartida, setores de bens mais básicos têm produtos mais similares e substituíveis entre si, de modo que seu comportamento poderia ser representado por um modelo de oligopólio à lá Cournot, em que apesar das firmas possuírem poder de mercado, os bens produzidos por elas são homogêneos entre si. Em seu estudo, Hooper e Mann (1989) argumentam que seu enfoque se dá apenas nos preços de importações da indústria manufatureira, pois esses são mais prováveis de exibir as características explicadas pela teoria que se baseia na literatura de organização industrial, além de tais bens representarem $80 \%$ das importações dos Estados Unidos.

Como pode ser observado nestes primeiros trabalhos cujo objetivo era o desenvolvi- 
mento de modelos teóricos para explicar o comportamento dos preços a um choque câmbio, muito tratou-se das causas microeconômicas do fenômeno, como elasticidade da demanda, estruturas de mercado, natureza da competição, grau de diferenciação de produtos etc. (BACHE, 2006; CHOUDHRI; HAKURA, 2006). Todavia, como destacado por Bache (2006), muita atenção tem sido dada ao tópico por outro ramo da pesquisa econômica que é o da Nova Macroeconomia Aberta (New Open Economy Macroeconomics, NOEM), que é um classe de modelos dinâmicos estocásticos de equilíbrio geral (Dynamic Stochatisc General Equilibrium, DSGE) para economias abertas que consideram competição imperfeita e rigidez nominal de preços.

Segundo Bache (2006), os modelos DSGE tornaram-se populares para realizar análises de política considerando a Crítica de Lucas (1976). Destaca-se também que, na literatura de NOEM, vários fatores foram identificados como potenciais influenciadores do repasse cambial, dentre eles estão: o grau de rigidez dos preços, a escolha de moeda de precificação das firmas, a perspectiva de persistência do câmbio, a margem de distribuição, responsividade da elasticidade da demanda ao câmbio, além do peso que bens intermediários importados têm para a produção doméstica.

Trabalhos importantes no desenvolvimento da literatura de NOEM partem da ideia apresentada pelo modelo redux de Obstfeld e Rogoff (1995), no qual a LPU se verifica pois todos os bens transacionados são definidos na moeda do produtor (producer currency pricing, PCP). Nesse caso, o preço do produto na moeda do importador responde proporcionalmente às variações do câmbio nominal, ou seja, o repasse dos choques cambiais é imediato e completo, compatível com a visão tradicional de economia aberta como no modelo de Mundell-Fleming-Dornbusch e com o modelo de referência Novo Keynesiano para pequenas economias abertas de Galí e Monacelli (2005). Seguindo o modelo de Obstfeld e Rogoff (1995), e tendo como base estudos que verificam a prática de princing-to-market por indústrias exportadores de diversas localidades, Betts e Devereux (1996) partem do pressuposto que de que a prática de PTM é combinada com a rigidez dos preços, os quais são definidos na moeda do local de destino, para assim construir um modelo de equilíbrio geral no qual preços não respondem a movimentos cambiais gerados por choques monetários.

Betts e Devereux (1996) e Betts e Devereux (2000) consideram então que firmas tendem a precificar na moeda de destino, não ajustando preços frente a variações cambiais, de modo que os desvios observados da LPU ocorrem pois os preços de muitos bens apresentam estabilidade de preço na moeda local ou de destino. Assim, os autores buscaram explicar o repasse incompleto devido à segmentação do mercado internacional e por preços serem temporariamente rígidos na moeda do comprador, que é hipótese de local currency princing (LCP), a qual tais autores ajudaram a cunhar. Sob tal hipótese, o modelo implica em um tipo de rigidez de preços que leva o repasse cambial de curto prazo para zero (BACHE, 2006).

Outro trabalho que foi inovador ao buscar explicações macroeconômicas para o 
fenômeno do repasse cambial incompleto foi Taylor (2000), que encontrou inspiração na redução verificada do repasse de flutuações de custos pelas firmas, com este declínio sendo caracterizado como uma redução no poder de precificação das firmas em contexto de declínio de inflação em diversos países. Neste artigo, desenha-se um modelo com firmas sob contratos escalonados e competição monopolística a fim de explicar a relação entre o repasse e a inflação. Taylor (2000) mostra que como firmas definem seus preços por diversos períodos, a sua resposta a um aumento de custos depende se estas mudanças são percebidas como persistentes. Assim, aponta-se que ambientes altamente inflacionários tendem a ter aumentos de custos persistentes, o que faz com que tal ambiente tenda também a elevar o quanto firmas repassem da variação dos custos para seus preços, inclusive os choques cambiais.

Com tal arcabouço, foram desenvolvidos modelos de NOEM que buscaram combinar a hipótese de LCP com modelos de precificação que são funções do tempo. Por exemplo, trabalhos utilizaram modelos de contratos escalonados de Taylor (1980) (e.g. Bergin e Feenstra (2001)) ou de ajuste aleatório de preços de Calvo (1983) (e.g. Choudhri, Faruqee e Hakura (2005)). Levando em conta estas características, Bache (2006) afirma que um traço chave desses modelos é que as regras ótimas de precificação são forward-looking, ou seja, preços dependem das expectativas das variáveis que são dominantes no modelo.

As expectativas passam a ter um importante papel nos modelos Novo Keynesianos em resposta à crítica apresentada por Lucas (1976), que são a base para os modelos de NOEM. Aqui uma das hipóteses chave para tal característica do modelo é a de LCP de Betts e Devereux (1996) e Betts e Devereux (2000), já que em seus modelos os preços são definidos no período anterior o que faz com que todos os preços de importação sejam pré-determinados. Dado o papel das expectativas das variáveis do modelo para a definição dos preços de importação, segundo Bache (2006) isto implica que o repasse cambial será endógeno ao regime de política monetária, característica presente em modelos como de Taylor (2000) e Gagnon e Ihrig (2004) ${ }^{3}$. Adicionalmente, segundo Bache (2006), outra característica desses modelos é predizer que o repasse para os preços de importação é gradual, sendo que o tamanho e a velocidade do repasse depende da expectativa de persistência do choque.

Outros trabalhos desta literatura deram destaques para outras características que influenciam na definição do preço e do repasse de um choque de custos. Corsetti e Dedola (2005) estendem a estrutura básica de NOEM assumindo que custos de distribuição aos consumidores requerem recurso local e não-transacionável, de modo que custos de distribuição criam uma diferença entre os preços de bens importados "nas docas" e vendidos aos consumidores, o que tem efeito de redução do grau de repasse. Por sua vez, Gopinath, Itskhoki e Rigobon (2010) desenvolvem modelo dinâmico com rigidez nominal para escolha endógena da moeda de precificação ${ }^{4}$.

\footnotetext{
${ }^{3} \mathrm{O}$ papel da política monetária sob a definição do tamanho do repasse cambial foi investigado, empiricamente, dentre outros por Gagnon e Ihrig (2004) e Choudhri e Hakura (2006).

${ }^{4}$ Em um desenvolvimento mais recente acerca do tema da moeda de precificação, Casas et al. (2017)
} 


\subsection{Literatura empírica}

A literatura teórica que buscou aprofundar-se nos aspectos microeconômicos do repasse cambial desde seu início buscou, a partir dos dados, mostrar a validade dos modelos propostos. Uma vez que se partia da ideia de equilíbrio parcial, como feito por trabalhos citados como Dornbusch (1987) e Hooper e Mann (1989), tinha-se como hipótese principal a exogeneidade do variável de câmbio para assim validar a estimação do ficou conhecida na literatura como "regressão de repasse cambial" (exchange rate pass-through regression) ${ }^{5}$.

$$
\Delta p_{n, t}=\alpha_{n}+\sum_{k=0}^{T} \beta_{n, k} \Delta e_{n, t-k}+\gamma_{n} \mathbf{X}_{n, t}+\varepsilon_{n, t}
$$

Hooper e Mann (1989) estimam por Mínimos Quadrados Ordinários (MQO) que, no curto prazo, cerca de $20 \%$ da variação cambial é repassada aos preços de importação de bens manufaturados para os Estados Unidos, enquanto que, no longo prazo, este número vai para algo entre 50\% e 60\%. Yang (1997), que se baseia em um modelo Dixit-Stiglitz, também utilizando MQO, encontra repasse incompleto e variável para os preços de importação entre os setores avaliados da indústria manufatureira dos Estados Unidos, obtendo um grau médio de repasse de aproximadamente $32 \%$, no curto prazo, e de $42 \%$ no longo ${ }^{6}$. Yang (1997) explica que o diferencial do repasse cambial entre os setores devido a fatores como grau de competição, substitutibilidade dos produtos e parcelas do mercado atendidas por empresas domésticas ou estrangeiras. Assim, o repasse será maior conforme mais diferenciados forem os bens e maior a elasticidade do custo marginal à quantidade produzida.

Um estudo relevante para a literatura que faz uso da regressão de repasse é o de Campa e Goldberg (2005), que buscam não apenas estimar a elasticidade dos preços de importação, como também analisar seu comportamento e as suas fontes de heterogeneidade (o que é feito a partir de regressões que consideram o grau de repasse cambial como variável dependente e medem os efeitos de outras variáveis sobre ele). Ao estimarem o grau de repasse aos preços de importação agregados para os países da Organização para Cooperação e Desenvolvimento Econômico (OCDE) por MQO, encontram, na média, elasticidades de $46 \%$ e $64 \%$ no curto e longo prazos, respectivamente. Ademais, identificam que o repasse é menor para produtos manufaturados ( $43 \%$ e $62 \%$ no curto e longo prazos, respectivamente), sendo maior para importações de energia e matérias-primas.

\footnotetext{
desenvolvem um modelo a partir da ideia de que existe uma moeda dominante em que as firmas precificam seus produtos, uma vez que se observa que países precificam seus produtos em dólar, apesar de nenhuma das partes envolvidas ter como moeda o dólar.

${ }^{5} \mathrm{Na}$ discussão sobre o uso da regressão de repasse cambial, a literatura tem um importante destaque em Goldberg e Knetter (1997).

${ }^{6}$ Vale ressaltar que, apesar dos resultados de Hooper e Mann (1989) e Yang (1997) divergirem, o primeiro utiliza uma seleção de países de origem das importações e uma menor desagregação dos dados, não sendo diretamente comparáveis apesar do foco de análise ser a mesma variável.
} 
Corroborando a hipótese feita por Fisher (1989) a respeito da existência de diferentes graus de repasse para setores distintos como já relatado por Yang (1997), Campa e Goldberg (2005) usam tal fator para explicar a queda observada na transmissão de choques cambiais aos preços de importação em diversos países. Discute-se que o declínio observado ocorreu devido a uma mudança na pauta de importações, que passou a conter mais produtos manufaturados, que têm menor grau de repasse, do que outros produtos que apresentam preços mais sensíveis a variações cambiais. Anteriormente, as proporções eram maiores para estes últimos.

Estudos posteriores verificaram a heterogeneidade setorial do repasse cambial em vista de evidências, como as de Yang (1997) e Campa e Goldberg (2005), a respeito dos diferentes graus de repasse para cada uma das atividades existentes na economia ${ }^{7}$. Bhattacharya, Karayalcin e Thomakos (2008) estimam três sistemas de determinação do preços, cada qual contendo uma motivação para entrada de bens importados em um país ${ }^{8}$, sendo que cada um dos três sistemas é estimado por Mínimos Quadrados Condicionais, utilizando dados setoriais dos Estados Unidos, Japão e Reino Unido. As estimativas para os Estados Unidos de Bhattacharya, Karayalcin e Thomakos (2008) estão na Tabela 1.1.

Em estudo setorial para os preços brasileiros de bens importados e ao atacado doméstico, Kannebley Júnior, Reis e Toneto Júnior (2016) preenchem a lacuna existente na literatura empírica para o Brasil, na qual usualmente o repasse cambial é estimado utilizando dados agregados (e.g. Belaisch (2003)). Além disso, utilizam um método de estimação multiequacional, considerando a presença de relações de cointegração entre as variáveis. O grau de repasse cambial é obtido a partir dos coeficientes dos vetores de cointegração dos modelos estimados para cada setor. Por sua vez Gopinath, Itskhoki e Rigobon (2010), utilizando dados de preços de importação dos Estados Unidos no nível das firmas, verificam os diferentes graus de repasse para os setores, desagregando entre importações que são e não são precificadas em dólares. Ambas estimações também estão dispostas na Tabela 1.1, bem como as de Yang (1997).

Campa e Goldberg (2005) também buscaram verificar se as mudanças no grau de repasse tinham outras fontes, e para isso verificaram o quanto variáveis macroeconômicas, como inflação e estoque de moeda, afetam o coeficiente. Encontrou-se que tais variáveis têm papel limitado na determinação no nível de repasse, reforçando para os autores a veracidade de sua explicação, que a queda do tamanho da transmissão dos choques do câmbio aos preços de bens importados ocorrem graças a uma mudança na composição das cestas de importação. Ao contrário de Campa e Goldberg (2005), outros concluem que a hipótese de

\footnotetext{
${ }^{7}$ Outro estudo que testa em suas especificações, a partir do uso de microdados, para verificar se o efeito do câmbio se modifica a depender do setor utilizando variáveis dummy (uma para cada setor da amostra) é Cao, Dong e Tomlin (2015).

${ }^{8}$ No primeiro, os bens importados são considerados como produtos finais vendidos aos consumidores; o segundo considera que os bens finais são produzidos internamente usando insumos nacionais e importados; e, por fim, o terceiro considera que os bens vendidos aos produtores são produzidos usando bens intermediários importados (consideram este caso um um misto dos dois anteriores).
} 


\begin{tabular}{|c|c|c|c|c|c|c|c|c|c|c|}
\hline \multirow{4}{*}{ Setores } & \multicolumn{7}{|c|}{ Preços de importação } & \multicolumn{3}{|c|}{ Preços ao atacado/produtor } \\
\hline & \multicolumn{4}{|c|}{ Curto Prazo } & \multicolumn{3}{|c|}{ Longo Prazo } & \multirow{3}{*}{$\begin{array}{c}\text { Curto Prazo } \\
\text { (2) }\end{array}$} & \multicolumn{2}{|c|}{ Longo Prazo } \\
\hline & \multirow[b]{2}{*}{ (1) } & \multirow[b]{2}{*}{ (2) } & \multicolumn{2}{|r|}{ (3) } & \multirow[b]{2}{*}{ (1) } & \multirow[b]{2}{*}{ (2) } & \multirow[b]{2}{*}{ (4) } & & \multirow[b]{2}{*}{ (2) } & \multirow[b]{2}{*}{ (4) } \\
\hline & & & Dólar & $\begin{array}{l}\text { Demais } \\
\text { moedas }\end{array}$ & & & & & & \\
\hline Alimentos & 0.1875 & 0.354 & 0.24 & 0.83 & 0.2485 & 0.291 & 0.591 & -0.082 & -0.084 & 0.041 \\
\hline Bebidas & - & 0.046 & - & - & - & 0.033 & - & -0.164 & -0.164 & 0.000 \\
\hline Fumo & - & - & - & - & - & - & - & - & - & - \\
\hline Têxtil & 0.2091 & - & 0.41 & 0.94 & 0.3124 & - & 0.719 & - & - & 0.224 \\
\hline Vestuário & 0.1099 & -0.254 & 0.45 & 0.97 & 0.1068 & -0.256 & 0.311 & 0.158 & 0.060 & 0.000 \\
\hline Couro & 0.2845 & - & -0.15 & 0.91 & 0.3144 & - & 0.475 & - & - & - \\
\hline Madeira & 0.0897 & - & -0.08 & 0.85 & 0.0812 & - & 0.447 & - & - & 0.000 \\
\hline Papel e Celulose & - & - & 0.26 & 1.02 & - & - & 0.728 & - & - & 0.234 \\
\hline Derivados de petróleo & & 0.522 & - & - & - & 0.522 & 0.839 & 0.450 & 0.450 & 0.067 \\
\hline Químicos & 0.3754 & 0.105 & 0.27 & 0.64 & 0.5312 & 0.105 & 0.777 & 0.094 & 0.121 & 0.469 \\
\hline Farmoquímicos & - & - & - & - & - & - & 0.224 & - & - & 0.000 \\
\hline Borracha & 0.4285 & 0.038 & 0.21 & 0.53 & 0.5318 & 0.063 & 0.386 & 0.005 & -0.014 & 0.489 \\
\hline Minerais não metálicos & 0.6213 & 0.111 & 0.54 & 0.76 & 0.8843 & -0.134 & 1.000 & 0.028 & 0.035 & 0.200 \\
\hline Metalurgia & 0.1625 & - & - & - & 0.2123 & - & 1.000 & - & - & 0.641 \\
\hline Produtos de metal & 0.2221 & - & 0.21 & 1.35 & 0.3138 & - & 0.724 & - & - & 0.000 \\
\hline Informática & 0.5635 & - & - & - & 0.7559 & - & 0.858 & - & - & 0.495 \\
\hline Máquinas elétricas & 0.2930 & 0.118 & - & - & 0.3914 & -0.189 & 0.730 & - & - & 0.000 \\
\hline Máquinas e equipamentos & - & 0.303 & 0.22 & 0.90 & - & 0.431 & 0.708 & 0.077 & 0.811 & 0.272 \\
\hline Veículos & 0.2144 & - & 0.17 & 0.93 & 0.3583 & - & 0.610 & - & - & 0.324 \\
\hline Outros eq. transporte & & - & - & - & - & - & 0.756 & - & - & 0.078 \\
\hline Móveis & 0.3067 & 0.100 & - & - & 0.3576 & 0.124 & - & 0.027 & 0.081 & - \\
\hline Diversos & 0.2305 & - & 0.19 & 1.06 & 0.2765 & - & - & - & - & - \\
\hline
\end{tabular}

(1): Yang (1997); (2): Bhattacharya, Karayalcin e Thomakos (2008) (estimações para os EUA); (3) Gopinath, Itskhoki e Rigobon (2010); (4): Kannebley Júnior, Reis e Toneto Júnior (2016)

Tabela 1.1 - Estimativas de coeficientes setoriais de repasse cambial

Taylor (2000) que o ambiente inflacionário e, por consequência, a política monetária têm papel fundamental na determinação do repasse cambial aos preços (e.g., para preços aos consumidores, Gagnon e Ihrig (2004) e Choudhri e Hakura (2006)).

Forbes, Hjortsoe e Nenova (2018) ao analisarem estudos empíricos como os discutidos até aqui, afirmam que a estrutura padrão evidenciada em (1.2) não incorpora as muitas maneiras com que os movimentos do câmbio são endogenamente determinados com os preços. Uma alternativa às regressões de repasse cambial amplamente utilizada foi o uso do modelo de Vetor Autorregressivo (Vector Autoregression, VAR) ou de VAR estrutural (Structural VAR, SVAR), além do Vetor de Correção de Erros (Vector Error Correction Model, VECM).

Diversos são os estudos empíricos que utilizaram modelos VAR para tratar a questão do repasse cambial, sendo que grande parte define o repasse como a resposta ao impulso dos preços a um choque exógeno do câmbio (BACHE, 2006). Segundo, Ito e Sato (2008), uma das vantagens do VAR é poder identificar o repasse com um conjunto de preços domésticos que é uma representação da cadeia produtiva, uma vez que vai do nível do exportador estrangeiro ou produtor para o consumidor. Ademais, Ito e Sato (2008) destacam a relevância de levar em conta a cadeia de precificação, uma vez que, ao longo desta, é possível observar o declínio do repasse.

Bache (2006) destaca que na literatura de repasse cambial a preocupação inicial era a 
respeito da transmissão de choques cambiais aos preços de importação, mas estudos buscaram aprofundar o conhecimento do repasse ao longo da cadeia de precificação, estimando-se modelos para preços domésticos ao produtor e ao consumidor. Hooper e Mann (1989) em sua formulação deixam claro a interdependência entre os preços de importação e domésticos, assim como Froot e Klemperer (1989) e Fisher (1989). Esta conexão não é referente apenas à competição existente entre os produtos nacionais e importados, mas também advém da dependência de insumos estrangeiros nos processos produtivos domésticos. Ou seja, é preciso considerar o ambiente competitivo e o papel da cadeia produtiva na precificação. No contexto dos modelos VAR, para obter tal configuração utiliza-se restrições feitas a partir da decomposição de Cholesky (e.g. Choudhri, Faruqee e Hakura (2005), Faruqee (2006) e McCarthy (2007)).

Faruqee (2006) estima o repasse aos preços de importação e ao produtor para a Zona do Euro a partir das funções de resposta ao impulso, normalizando a resposta dos preços ao choque cambial pelo comportamento do câmbio. Observa-se um repasse inicial para os preços de importação de 0,03 que após 18 meses vai para 1,17, enquanto que o dos preços ao produtor vai de zero a 0,17. Para o caso brasileiro, usando dados mensais de 1999 a 2002, Belaisch (2003) estima uma transferência dos choques choques cambiais para os preços gerais de $8 \%$ e $71 \%$, no curto e longo prazos, respectivamente (enquanto que para os preços ao atacado os número são 12\% e 165\%). Ao contrário de Belaisch (2003) e Faruqee (2006), apesar de utilizarem as funções de resposta ao impulso para avaliarem o grau de repasse cambial, Choudhri, Faruqee e Hakura (2005) e McCarthy (2007) não normalizam as respostas do preço pelo comportamento da resposta do câmbio, de modo que estas não podem ser interpretadas como elasticidades.

Outra utilização recorrente na literatura para os modelos VAR é na avaliação das funções de resposta ao impulso dos DSGE, principalmente para verificar respostas à política monetária, sendo esta estratégia também foi aplicada nos trabalhos de NOEM. Segundo Bache (2006, p. 194), como os modelos VAR dependem de um número relativamente pequeno de restrições, suas respostas podem ser consideradas como "fatos estilizados" e espera-se que os DSGE (empiricamente relevantes) sejam capazes de reproduzir o mesmo padrão, de modo que a distância entre as respostas de choques são minimizadas para obtenção de parâmetros estruturais. Choudhri, Faruqee e Hakura (2005) e Faruqee (2006) empregam tal estratégia aos modelos de NOEM com repasse cambial incompleto, sendo que o grau de repasse, como já mencionado, é identificado a partir das respostas ao impulso de diversos preços na economia.

Por sua vez, Bache (2006, Capítulo 5) utiliza dados simulados de um experimento de Monte Carlo a partir de um modelo DSGE para verificar a capacidade de SVARs de estimar o repasse cambial já definido pelo modelo téorico. Neste capítulo, o objetivo da autora é de verificar o quanto a resposta a um choque na paridade de juros descoberta pode ser uma ferramenta capaz de auxiliar na avaliação e estimação de modelos DSGE com repasse 
incompleto ${ }^{9}$. A conclusão a que se chega é que estimativas a partir dos modelos VAR em primeiras diferenças são viesadas para baixo, constatando que estes modelos não são uma boa aproximação para o modelo DSGE, ao passo que VECMs, mesmo que de baixa ordem, parecem mais adequados para replicar o comportamento do modelo teórico.

Recente desenvolvimento na estimação da transmissão dos choques cambiais aos preços foi realizado por Forbes, Hjortsoe e Nenova (2018), a partir da estimação de um modelo SVAR bayesiano (Bayesian SVAR, B-SVAR) para o Reino Unido. Considerando que agentes econômicos tomam decisões baseados no futuro (uma das principais hipóteses da NOEM), as autoras buscam evidenciar que não apenas o choque cambial em si é responsável pelo grau de repasse para os preços, mas também a origem da flutuação cambial. Assim, em sua formulação, esperam mostrar que um choque cambial que advém de mudanças na demanda doméstica, é diferente daquele vindo da demanda externa, ou de política monetária local, por exemplo. Para identificar os diferentes tipos de choque e ser possível analisar o repasse cambial aos preços, Forbes, Hjortsoe e Nenova (2018) utilizam restrições de zeros para o curto e o longo prazo, bem como restrições de sinal, para então considerar o impacto dos seis tipos de choque identificados ${ }^{10}$. Observa-se que uma apreciação cambial de vinda demanda leva a repasse do choque de menos de $40 \%$ após cinco anos nos preços de importação, enquanto que, se vindo da política monetária, tem repasse de mais de $80 \%$. A partir das diferenças nas respostas dos preços a cada tipo de choque, Forbes, Hjortsoe e Nenova (2018) argumentam que tal evidência ilustra a necessidade de considerar a determinação endógena do câmbio nos modelos, e não considerá-lo como uma variável exógena.

Burstein e Gopinath (2014) destacam que, motivados pela existência de heterogeneidade na determinação do repasse cambial entre firmas, pesquisas empíricas recentes passaram a usar microdados detalhados que unem características das firmas e do repasse. Ademais, alguns desses trabalhos também desenvolvem modelos que criam sistemas de demandas mais completos e flexíveis, e que são simulados ou estimados usando microdados e métodos econométricos padrão de Organização Industrial empírica. Estes trabalhos frequentemente também comparam a performance de modelos estruturais que se apoiam em recentes desenvolvimentos vindos da literatura de Organização Industrial, o que é obtido a partir de regressões de formas reduzidas, como feito por Nakamura e Zerom (2010), ou usando modelos de macroeconomia aberta, como em Gopinath, Itskhoki e Rigobon (2010).

Nesta linha de estudos empíricos que buscou aprofundar o entendimento do papel das características das firmas no repasse cambial, houve retomada na literatura da investigação

\footnotetext{
${ }^{9}$ O modelo DSGE desenvolvido em Bache (2006, Capítulo 5) e que serve como processo gerador dos dados incorpora mecanismos que geram repasse cambial incompleto os quais foram propostos na literatura de NOEM, como rigidez de preços devido à hipótese de LCP e presença de custos de distribuição; além de incorporar mecanismos de formação de hábitos de consumo e persistência inflacionária estrutural.

${ }^{10}$ São avaliados choques de oferta, demanda e política monetária domésticos, além de choques exógenos ao câmbio, e choques globais persistentes ou transitórios.
} 
acerca do papel da moeda de precificação dos produtos a serem exportados pelas firmas. Campa e Goldberg (2005) já haviam investigado a testado as hipóteses de PCP e LCP a partir de dados agregado dos preços de importação dos países da OCDE, nos quais ambas foram rejeitas para a maior parte destes países. Retomando a discussão sobre moeda de precificação, a partir de microdados de preços de importação dos Estados Unidos, Gopinath, Itskhoki e Rigobon (2010) estimam que o repasse para bens precificados em dólar é de, aproximadamente, 25\% do choque, enquanto que aqueles precificados nas demais moedas, $95 \%$.

Por sua vez, para verificar o papel da moeda de precificação das exportações canadenses, Cao, Dong e Tomlin (2015) utilizam microdados ao nível do produto, nos quais foram registrados os preços de "porta de fábrica"11 das vendas realizadas por parte das firmas canadenses, não apenas as exportações mas também as domésticas. A estimação é realizada utilizando uma regressão de repasse cambial, consistente com a de Goldberg e Knetter (1997) e Gopinath, Itskhoki e Rigobon (2010), na qual adicionam interações do câmbio com dummies para identificar se a venda é para exportação ou não e se a operação é precificada em dólar. Verifica-se que o grau de repasse cambial para preços de bens que os produtores vendem domesticamente é de 0,185 , ao passo que para os bens exportados e precificados em dólar canadense o repasse é nulo, enquanto que para as exportações precificadas em dólar estadunidense, o repasse vai para 0,909. Frente a tais informações, Cao, Dong e Tomlin (2015) concluem que enquanto as exportações feitas moeda canadense (ou seja, sob PCP) não sofriam variação dos preços recebidos pelas firmas, aquelas realizadas em dólar estadunidense (sob LCP) indicam que as firmas locais ajustam seus preços, medidos em moeda doméstica, para estabilizar aqueles em dólar em vista de flutuações cambiais.

Nakamura e Zerom (2010) buscaram analisar o papel de determinantes do repasse incompleto apontados pela teoria (custos de menu, custos locais e ajuste do markup) a partir dos microdados da indústria do café. Os autores apontam que os custos de menu têm efeito baixo sobre o repasse de longo prazo, apesar de replicarem de modo bem sucedido a dinâmica da transmissão de choques cambiais no curto prazo. Ao contrário do consenso existente em torno da rigidez nominal como explicação de repasse incompleto e gradual, Nakamura e Zerom (2010) destacam o papel do ajuste substancial do markup frente a choques de custo pelas firmas, bem como da existência de custos locais ${ }^{12}$, como fontes determinantes do fenômeno também no longo prazo.

Partindo da formulação de firmas heterogêneas de Atkeson e Burstein (2008), Auer e Schoenle (2016) apresentam evidência sobre como o market share e a resposta dos preços das firmas estrangeiras ao comportamento de precificação de suas concorrentes, também

\footnotetext{
${ }^{11}$ Como os preços são medidos, de acordo com Cao, Dong e Tomlin (2015), na "porta da fábrica", estes são livres de custos de distribuição e transporte. Logo, a comparação com os resultados de outros estudos cujos custos mencionados estão embutidos nos preços deve ser feita com cautela.

${ }^{12}$ Estes são uma parcela dos preços dos bens vendidos internamente, sendo que este componente tende a não ser afetado pelas flutuações do câmbio.
} 
estrangeiras, afetam a decisão de repasse cambial no nível da firma, bem como o modo com que a heterogeneidade da resposta específica da firma afeta o repasse no equilíbrio da indústria. Auer e Schoenle (2016) encontram evidência que as firmas que respondem mais a choques no próprio custo são aquelas que reagem menos aos preços dos seus competidores. Deste modo, quando separam-se as firmas em quantis, de acordo com seus respectivos market shares, a resposta delas aos seus custos tem formato de "U" ( $U$-shaped), enquanto que as respostas aos preços das demais firmas estrangeiras com quem competem tem formato de corcova (hump-shaped). Assim, corroborando a teoria, a parcela de mercado atendida pela firma é significativa para a decisão de precificação. Todavia, as reações tendo sentidos opostos, anulam-se na formulação do preço de equilíbrio, sendo que segundo Auer e Schoenle (2016) ambos os fenômenos são estatisticamente significantes e com mesma importância econômica.

Baseado em uma versão multi-países do modelo de Atkeson e Burstein (2008) e dos microdados fornecidos pelo Bureau of Labor Statistics (BLS), Pennings (2017) mostra que os preços de importação respondem não apenas às taxas de câmbio nominal, mas também ao que o autor chama de "taxa de câmbio dos competidores estrangeiros do produtor". $\mathrm{O}$ exercício é similar ao realizado por Auer e Schoenle (2016), mas que, ao invés de levar em conta choques nos câmbios das demais moedas, observa as mudanças de preços feitas pelos competidores estrangeiros, isso porque há diversos modelos teóricos baseados no fato de que os preços dos competidores são determinantes no comportamento da firma. Deste modo, Pennings (2017) argumenta que, por exemplo, uma apreciação real do iene em relação ao dólar, não afeta apenas o preço do carro japonês vendido nos Estados Unidos, mas também de todos os demais carros importados. Afirma-se que a desconsideração de tal relação é fonte de viés para os resultados do grau de repasse, de modo que as medidas simples de repasse cambial superestimam o grau verdadeiro, uma vez que a taxa de câmbio nominal e a "taxa de câmbio dos competidos estrangeiros do produtor" são positivamente correlacionadas. A partir de seu modelo, Pennings (2017) estima que uma apreciação de 1\% na taxa de câmbio nominal leva a uma elevação de $0,16 \%$ nos preços de importados nos Estados Unidos, enquanto uma apreciação da "taxa de câmbio dos competidores estrangeiros" de $1 \%$ levaria a um aumento de $0,35 \%$ dos preços das importações e de $0,11 \%$ nos preços dos produtores domésticos.

\subsubsection{O repasse de choques do preço do petróleo}

A literatura de repasse cambial frequentemente destaca o papel da taxa de câmbio como sendo também um preço, sendo sua variação interpretada como um choque de custos. Trabalhos empíricos se voltaram para verificar o modo com que flutuações de custos de produção são repassadas para os preços, sendo que um outro preço determinante para as economias ao redor do globo é o dos preços do petróleo. O entendimento e diferenciação do 
repasse deste fenômeno em relação ao do câmbio pode aprofundar o conhecimento acerca do comportamento dos preços de um país.

Na literatura que busca entender os efeitos de variações no preços do petróleo, primariamente a fonte de preocupação está em como um aumento de custos de produção leva a uma redução de produtividade e da demanda doméstica (CASTRO; JIMÉNEZ-RODRÍGUEZ, 2017). Todavia, o entendimento da ligação entre o preço do petróleo e a inflação é bastante importante para as autoridades monetárias em sua busca por estabilidade de preços, uma vez que na literatura é bastante difundida a ideia de que, ao menos parcialmente, choques nos preços do petróleo afetam a inflação (CHEN, 2009).

Os preços do petróleo no mercado internacional são afetados por diversas forças, tanto econômicas como políticas, implicando que tais forças têm papel nos processos de precificação ao longo de todo o globo. Logo, dada a importância desta commodity, ela terá também papel de destaque nas políticas realizadas pelos mais diversos países. No Brasil, a relevância do estudo de impactos de flutuações no preço do petróleo também está ligada ao papel do Estado no processo do refino do petróleo, pois este fica a cargo de uma empresa estatal, sendo seu preço considerado como um preço administrado.

Hooker (2002) ao estimar uma Curva de Phillips para os Estados Unidos encontram uma quebra estrutural no repasse dos choques do preço do petróleo, sendo que, a partir dela, o repasse passaria a ter um grau mais baixo. Por sua vez, Chen (2009) estima o coeficiente de repasse variante no tempo para 19 países industrializados ${ }^{13}$, trazendo mais informações acerca do comportamento do coeficiente de transmissão do choque. Com seu método de estimação, Chen (2009) identifica que a redução do repasse do choques de preço do petróleo pode ser explicada por fatores como apreciação da moeda doméstica do país, política monetária mais ativa (em resposta a aumentos da taxa de inflação), e maior abertura comercial (similar à Forbes, Hjortsoe e Nenova (2018)). Chen (2009) afirma que não obtém evidência que suporte a hipótese de Taylor (2000) de que, em um ambiente de baixa inflação, há redução do repasse dos choques.

Castro e Jiménez-Rodríguez (2017) buscam deixar claro que a apesar da teoria econômica muito ter se preocupado com os impactos produtivos de um choque dos preços do petróleo, não há estudo que analise como este choque é repassado para a cadeia de preços a um nível desagregado. Adicionalmente, os autores ressaltam a importância dessa informação não apenas para a previsão dos preços futuros como para realização de política monetária apropriada. Castro e Jiménez-Rodríguez (2017) ao calcularem as respostas ao impulso acumuladas de cada setores, observam que apenas alguns se destacam (com respostas acumuladas acima de $10 \%$, chegando no máximo a $20 \%$ ), que são aqueles que dependem mais da commodity em seus processos produtivos. Ao contrário, os demais setores apresentam resposta

\footnotetext{
${ }^{13}$ Em exercício preliminar, Chen (2009) estima uma Curva de Phillips, encontrando repasse de choques do preço do petróleo, em média, para os preços aos consumidores de 0,005 e 0,166, no curto e longo prazos.
} 
acumulada quase nula.

Haja vista o papel de flutuações cambiais e do preço do petróleo para a economia, e tendo à disposição uma ferramenta de estimação que busca incorporar fatores não considerados por outras metodologias padrão da literatura, busca-se verificar os efeitos dos choques cambiais e no mercado petrolífero sobre os preços brasileiros. Então, a estimação dos coeficientes de repasse de choques será realizada setorialmente, seguindo trabalhos como Yang (1997), Bhattacharya, Karayalcin e Thomakos (2008), Kannebley Júnior, Reis e Toneto Júnior (2016) e Castro e Jiménez-Rodríguez (2017), a partir da estimação do Global Vector Autoregression de Pesaran, Schuermann e Weiner (2004). 


\section{O GLOBAL VAR}

O Global Vector Autoregression surge da necessidade de um método de modelar a economia global, mas que não possuísse as limitações de métodos já conhecidos, como do vetor autorregressivo (vector autoregression, VAR) irrestrito para o qual tal estimação não seria factível, dado o número de parâmetros. Com esse intuito, Pesaran, Schuermann e Weiner (2004) propõem tal metodologia de estimação global em duas partes.

Neste procedimento, primeiramente, estimam-se os modelos específicos individuais para países ou regiões relacionando as variáveis macroeconômicas de interesse para cada país com o que chamam de "foreign specific variables", variáveis construídas para imitar o padrão comercial do país de interesse e consideradas como fracamente exógenas (neste trabalho, estas serão denominadas como variáveis externas específicas). Em seguida, os modelos individuais são empilhados e resolvidos simultaneamente como um único modelo VAR de alta dimensão, ou seja, um VAR global.

Um fato importante a mencionar é que a abordagem de Pesaran, Schuermann e Weiner (2004), apesar de assumir exogeneidade fraca para as variáveis externas específicas, não fornece justificativa teórica para o seu uso na modelagem. Uma primeira tentativa para isto foi realizada por Dées et al. (2007), que deriva os modelos para as unidades do corte transversal como uma aproximação de um modelo de fator globais comuns (CHUDIK; PESARAN, 2016). A partir deste tipo de formulação, é possível justificar o uso do GVAR para a obtenção de um modelo que é capaz de considerar, além de fatores globais observáveis que afetem o sistema, como o preço do petróleo, fatores globais não observáveis e que fazem parte dos canais de transmissão de choques dentro de um sistema.

A informação supracitada é de relevância para o presente trabalho, pois o exercício proposto para a estimação do repasse cambial aos preços tem justamente a finalidade de considerar os fatores comuns entre os setores da economia brasileira. Deste modo, o efeito estimado do choque do câmbio sobre os preços deverá abarcar não somente os efeitos de tal choque dentro das variáveis do setor, mas também sobre o componente comum que é não observado, além de efeitos transbordamento.

Neste trabalho, o GVAR será aplicado para um problema inédito em tal literatura, que é a estimação dos graus de repasse cambial dos setores da indústria de transformação brasileira. Esta seção tem papel de apresentar os aspectos metodológicos do GVAR, sem aplicálo diretamente ao problema; o que será feito na seção seguinte. Todavia, deixa -se definido desde já que as unidades do corte transversal são os setores da indústria de transformação, aos quais serão referidos cada um dos modelos VAR individuais

Primeiramente, serão construídos os modelos individuais de cada setor; em seguida é mostrada a solução do modelo GVAR; as propriedades de cointegração; o uso de variáveis 
globais ou unidades dominantes; além de explicitar o teste de exogeneidade fraca usado. Por fim, são discutidas as ferramentas de análise, em especial as funções de resposta ao impulso utilizadas.

\subsection{Modelando setores e interconexões}

O modelo global é construído assumindo-se que este contém $N$ unidades no corte transversal indexadas por $i=1,2, \ldots, N$, sendo que para cada setor considera-se que suas variáveis sejam relacionadas com aquelas do restante da indústria. Para este fim, cada setor será então representado por um modelo VAR aumentado por variáveis fracamente exógenas, denotados como modelos VARX*.

Para cada setor há um vetor $k_{i} \times 1$ do que são denominadas variáveis internas específicas (à unidade $i$ do corte transversal), denotadas por $\mathbf{x}_{i, t}$. Estas são relacionadas com as chamadas variáveis externas específicas, inseridas no modelo setorial por um vetor $k_{i}^{*} \times 1, \mathbf{x}_{i, t}^{*}$, que nada mais são do que médias ponderadas das variáveis específicas de todos os demais setores do corte transversal. Estas variáveis têm, de acordo com Chudik e Pesaran (2016), a capacidade de aproximarem os fatores globais não-observados do sistema, uma vez que provam que estes fatores podem ser estimados a partir de combinações linares das médias das variáveis observadas $\mathbf{x}_{i t}$ das unidades do corte transversal. Além disso, podem-se inserir as chamadas variáveis globais (fracamente) exógenas. Pode-se então escrever um modelo VARX* $(1,1)$ simplificado dado por:

$$
\mathbf{x}_{i, t}=\mathbf{a}_{i 0}+\mathbf{a}_{i 1} t+\boldsymbol{\Phi}_{i 1} \mathbf{x}_{i, t-1}+\Lambda_{i 0} \mathbf{x}_{i t}^{*}+\Lambda_{i 1} \mathbf{x}_{i, t-1}^{*}+\boldsymbol{\varepsilon}_{i, t}, t=0,1, \ldots, T, i=0,1, \ldots, N
$$

sendo $\Phi_{i 1}$ a matriz $k_{i} \times k_{i}$ de coeficientes das defasagens de $\mathbf{x}_{i t}, \Lambda_{i 0}$ e $\Lambda_{i 1}$ matrizes $k_{i} \times k_{i}^{*}$ de coeficientes associados às variáveis externas específicas $\mathbf{x}_{i t}^{*}$, e $\varepsilon_{i t}$ uma matriz $k_{i} \times 1 \mathrm{de}$ choques idiossincráticos do setor $i$.

Assume-se que tais choques idiossincráticos $\boldsymbol{\varepsilon}_{i t}$ não são serialmente correlacionados, cuja matriz de médias $k_{i} \times 1$ é $\mathbf{0}$ e matriz de covariância não-singular denotada por $\Sigma_{i i}=$ $\left(\sigma_{i i, \ell s}\right)$, sendo um elemento típico dessa matriz $\sigma_{i i, \ell s}=\operatorname{cov}\left(\varepsilon_{i \ell t}, \varepsilon_{i s t}\right)$, ou seja,

$$
\boldsymbol{\varepsilon}_{i t} \sim \text { i.i.d. }\left(\mathbf{0}, \Sigma_{i i}\right)
$$

Além disso, permite-se que os erros idiossincráticos sejam correlacionados no corte transversal a um nível limitado ${ }^{14}$, o que ocorre devido às inter-ligações entre as variáveis externas $\mathbf{x}_{i t}^{*}$ com as demais do sistema econômico, $\left(\mathbf{x}_{0 t}, \mathbf{x}_{1 t}, \ldots, \mathbf{x}_{i-1, t}, \mathbf{x}_{i+1, t}, \ldots, \mathbf{x}_{N t}\right)$.

\footnotetext{
${ }^{14}$ Segundo Pesaran, Schuermann e Weiner (2004), a limitação da correlação entre os erros das unidades do corte tranversal é devido à natureza da dependência entre as variáveis externas específicas ao setor, $\mathbf{x}_{i t}^{*}$, e as variáveis do restante do sistema a ser estimado.
} 
Ademais, o modelo pode também conter, além das variáveis externas específicas, o que Pesaran, Schuermann e Weiner (2004) chamam de variáveis comuns globais $\left(\mathbf{d}_{t}\right)$, como por exemplo, choques dos preços do petróleo, que implicam em importantes choques de custos para diversos setores. Note que tantos as variáveis externas específicas como as globais são inseridas no modelo sob a hipótese de exogeneidade fraca, pois supõe-se que estas afetem as variáveis em $\mathbf{x}_{i t}$, mas o inverso não é válido.

Segundo Pesaran, Schuermann e Weiner (2004), o modelo GVAR é capaz de captar as relações de inter-dependência a partir de três canais:

1. Dependência contemporânea de $\mathbf{x}_{i t} \mathbf{e m} \mathbf{x}_{i t}^{*}$, bem como sobre seus valores defasados;

2. Dependência das variáveis específicas em variáveis globais (fracamente) exógenas;

3. Dependência contemporânea não-nula de choques no setor $i$ sobre choques no setor $j$, medido via matriz covariâncias $\Sigma_{i j}=E\left(\boldsymbol{\varepsilon}_{i t} \boldsymbol{\varepsilon}_{j t}^{\prime}\right)$.

Tendo em vista o modelo específico para cada unidade $i$ do GVAR, a estimação do modelo inicia-se por estes, que são estimados individualmente condicionados ao restante dos modelos setoriais, todos representados por modelos VAR aumentados. Na seção seguinte, mostra-se como esses modelos individuais são empilhados e o modelo é solucionado como um único VAR de alta dimensão, configurando a segunda parte do processo de estimação.

\subsection{Solução do GVAR}

Para a construção do modelo GVAR a partir dos modelos VARX* que representam individualmente cada um dos setores da indústria de transformação, segue-se a notação de Chudik e Pesaran (2016) que consideram para cada $i$ um modelo $\operatorname{VARX}{ }^{*}\left(p_{i}, q_{i}\right)$, mas aqui incluindo os termos determinísticos:

$$
\mathbf{x}_{i t}=\mathbf{a}_{i 0}+\mathbf{a}_{i 1} t+\sum_{\ell=1}^{p_{i}} \boldsymbol{\Phi}_{i \ell} \mathbf{x}_{i, t-\ell}+\boldsymbol{\Lambda}_{i 0} \mathbf{x}_{i t}^{*}+\sum_{\ell=1}^{q_{i}} \boldsymbol{\Lambda}_{i \ell} \mathbf{x}_{i, t-\ell}^{*}+\boldsymbol{\varepsilon}_{i t},
$$

para $i=1,2, \ldots, N$, $\operatorname{com} \Phi_{i \ell}$ para $\ell=1,2, \ldots, p_{i}, \boldsymbol{\Lambda}_{i \ell}$ para $\ell=1,2, \ldots, q_{i}$, cujas ordens são $k_{i} \times k_{i}$ e $k_{i} \times k_{i}^{*}$, respectivamente.

Definindo para cada setor $i$ um vetor $\mathbf{z}_{i t}=\left(\mathbf{x}_{i t}, \mathbf{x}_{i t}^{*}\right)^{\prime}$, de ordem $\left(k_{i}+k_{i}^{*}\right) \times 1$, é possível reescrever (2.2) como

$$
\mathbf{A}_{i 0} \mathbf{z}_{i t}=\mathbf{a}_{i 0}+\mathbf{a}_{i 1} t+\sum_{\ell=1}^{p} \mathbf{A}_{i \ell} \mathbf{z}_{i, t-\ell}+\boldsymbol{\varepsilon}_{i t}
$$

onde

$$
\mathbf{A}_{i 0}=\left(\mathbf{I}_{k_{i}},-\boldsymbol{\Lambda}_{i 0}\right), \mathbf{A}_{i, \ell}=\left(\boldsymbol{\Phi}_{i \ell}, \boldsymbol{\Lambda}_{i \ell}\right), \text { para } \ell=1,2, \ldots, p
$$


$\operatorname{com} p=\max _{i}\left(p_{i}, q_{i}\right)$. Tais matrizes possuem dimensão $k_{i} \times\left(k_{i}+k_{i}^{*}\right)$, além de $\mathbf{A}_{i 0}$ ter posto completo $k_{i}$. Ademais defini-se que $\boldsymbol{\Phi}_{i \ell}=\mathbf{0}$ para $\ell>p_{i}$ e $\boldsymbol{\Lambda}_{i \ell}=\mathbf{0}$ para $\ell>q_{i}$.

Em seguida, mostra-se que as variáveis internas específicas podem ser unidas em um vetor $k \times 1$ denominado como vetor global, $\mathbf{x}_{t}=\left(\mathbf{x}_{0 t}^{\prime}, \mathbf{x}_{1 t}^{\prime}, \ldots, \mathbf{x}_{N, t}^{\prime}\right)^{\prime}$, em que $k=\sum_{i=0}^{N} k_{i}$ é o número de variáveis endógenas no modelo global. Pesaran, Schuermann e Weiner (2004) ressaltam que para a construção deste vetor não é relevante a ordenação dos setores ou das variáveis de cada um deles dentro dos respectivos vetores de variáveis internas específicas, uma vez que a análise é invariante a tal configuração. Isto é um fator que auxilia na análise do modelo, uma vez que não é preciso impor restrições de ordenação como para um modelo SVAR, por exemplo.

Por sua vez, o vetor $\mathbf{z}_{i t}=\left(\mathbf{x}_{i t}^{\prime}, \mathbf{x}_{i t}^{*^{\prime}}\right)^{\prime}$ de cada setor pode ser escrito como uma combinação das variáveis internas específicas que compõem o vetor global $\mathbf{x}_{t}$, uma vez que $\mathbf{x}_{i, t}^{*}$ é uma combinação linear das variáveis internas específicas dos setores do sistema que compõem $\mathbf{x}_{t}$. Escreve-se $\mathbf{z}_{i t}$ como

$$
\mathbf{z}_{i t}=\left(\begin{array}{l}
\mathbf{x}_{i t} \\
\mathbf{x}_{i t}^{*}
\end{array}\right)=\mathbf{W}_{i} \mathbf{x}_{t}, i=0,1,2, \ldots, N,
$$

sendo $\mathbf{W}_{i}$ é a uma matriz $\left(k_{i}+k_{i}^{*}\right) \times k$ de constantes fixas definidas em função dos pesos setoriais das variáveis endógenas do modelo, a qual é dada pela matriz de coeficientes técnicos obtidos através da matriz de insumo produto brasileira ${ }^{15}$. Assim,

$$
\mathbf{A}_{i 0} \mathbf{W}_{i} \mathbf{x}_{t}=\mathbf{a}_{i 0}+\mathbf{a}_{i 1} t+\sum_{\ell=1}^{p} \mathbf{A}_{i \ell} \mathbf{W}_{i} \mathbf{x}_{t-\ell}+\boldsymbol{\varepsilon}_{i t},
$$

em que $\mathbf{A}_{i 0} \mathbf{W}_{i}$ e $\mathbf{A}_{i \ell} \mathbf{W}_{i}$ têm ambas dimensão $k_{i} \times k, \forall \ell=1,2, \ldots, p$.

Empilhando tais equações, obtém-se

$$
\mathbf{G}_{0} \mathbf{x}_{t}=\mathbf{a}_{0}+\mathbf{a}_{1} t+\sum_{\ell=1}^{p} \mathbf{G}_{\ell} \mathbf{x}_{t-\ell}+\boldsymbol{\varepsilon}_{t}
$$

sendo

$$
\mathbf{G}_{0}=\left(\begin{array}{c}
\mathbf{A}_{1,0} \mathbf{W}_{1} \\
\mathbf{A}_{2,0} \mathbf{W}_{2} \\
\vdots \\
\mathbf{A}_{N, 0} \mathbf{W}_{N}
\end{array}\right), \mathbf{G}_{\ell}=\left(\begin{array}{c}
\mathbf{A}_{1, \ell} \mathbf{W}_{1} \\
\mathbf{A}_{2, \ell} \mathbf{W}_{2} \\
\vdots \\
\mathbf{A}_{N, \ell} \mathbf{W}_{N}
\end{array}\right), \boldsymbol{\varepsilon}_{t}=\left(\begin{array}{c}
\boldsymbol{\varepsilon}_{0 t} \\
\boldsymbol{\varepsilon}_{1 t} \\
\vdots \\
\boldsymbol{\varepsilon}_{N t}
\end{array}\right)
$$

$\mathrm{e}$

$$
\mathbf{a}_{0}=\left(\begin{array}{c}
\mathbf{a}_{10} \\
\mathbf{a}_{20} \\
\vdots \\
\mathbf{a}_{N 0}
\end{array}\right), \mathbf{a}_{1}=\left(\begin{array}{c}
\mathbf{a}_{11} \\
\mathbf{a}_{21} \\
\vdots \\
\mathbf{a}_{N 1}
\end{array}\right)
$$

\footnotetext{
${ }^{15}$ A construção da matriz de pesos a partir do uso da matriz de insumo produto será discutida no capítulo seguinte.
} 
Dessa forma, Pesaran, Schuermann e Weiner (2004) afirmam que a matriz $\mathbf{G}_{0}$ de dimensão $k \times k$ em geral terá posto completo e, portanto, será não-singular. Dadas tais informações, pode-se afirmar que a matriz será invertível e o modelo GVAR terá como solução

$$
\mathbf{x}_{t}=\mathbf{G}_{0}^{-1} \mathbf{a}_{0}+\mathbf{G}_{0}^{-1} \mathbf{a}_{1} t+\sum_{\ell=1}^{p} \mathbf{G}_{0}^{-1} \mathbf{G}_{\ell} \mathbf{x}_{t-\ell}+\mathbf{G}_{0}^{-1} \boldsymbol{\varepsilon}_{t},
$$

de modo que tal forma reduzida pode ser escrita como

$$
\mathbf{x}_{t}=\mathbf{b}_{0}+\mathbf{b}_{1} t+\sum_{\ell=1}^{p} \mathbf{F}_{\ell} \mathbf{x}_{t-\ell}+\mathbf{u}_{t}
$$

para $t=1,2, \ldots, T, T+1, \ldots, T+n$, em que $n \in[0,+\infty)$ é o horizonte de previsão, $\mathbf{b}_{1}=\mathbf{G}_{0}^{-1} \mathbf{a}_{i}$ para $i=0,1, \mathbf{F}_{\ell}=\mathbf{G}_{0}^{-1} \mathbf{G}_{\ell}$ para $\ell=1,2, \ldots, p, \mathrm{e} \mathbf{u}_{t}=\mathbf{G}_{0}^{-1} \boldsymbol{\varepsilon}_{t}$.

\subsection{Modelo de correção de erros}

Além de fornecer uma representação para os modelos VARX* das unidades do corte transversal, Pesaran, Schuermann e Weiner (2004) permitem a existência de cointegração entre as variáveis de $\mathbf{z}_{i t}$. Primeiramente, a representação de vetor de correção de erros de (2.1) é dada por

$$
\Delta \mathbf{x}_{i, t}=\mathbf{a}_{i 0}+\mathbf{a}_{i 1} t-\left(\mathbf{I}_{k_{i}}-\boldsymbol{\Phi}_{i 1}\right) \mathbf{x}_{i, t-1}+\left(\boldsymbol{\Lambda}_{i 0}+\boldsymbol{\Lambda}_{i 1}\right) \mathbf{x}_{i, t-1}^{*}+\Lambda_{i 0} \Delta \mathbf{x}_{i t}^{*}+\boldsymbol{\varepsilon}_{i, t}
$$

para $i=0,1, \ldots, N$ e tendo em mente que $\mathbf{z}_{i t}=\left(\mathbf{x}_{i j}^{\prime}, \mathbf{x}_{i t}^{* \prime}\right)^{\prime}$, podemos reescrever (2.9) como

$$
\begin{aligned}
\Delta \mathbf{x}_{i, t} & =\mathbf{a}_{i 0}+\mathbf{a}_{i 1} t+\left(-\left(\mathbf{I}_{k_{i}}-\boldsymbol{\Phi}_{i 1}\right), \boldsymbol{\Lambda}_{i 0}+\boldsymbol{\Lambda}_{i 1}\right) \mathbf{z}_{i, t-1}+\boldsymbol{\Lambda}_{i 0} \Delta \mathbf{x}_{i t}^{*}+\boldsymbol{\varepsilon}_{i, t} \\
& =\mathbf{a}_{i 0}+\mathbf{a}_{i 1} t-\left(\mathbf{I}_{k_{i}}-\boldsymbol{\Phi}_{i 1},-\boldsymbol{\Lambda}_{i 0}-\boldsymbol{\Lambda}_{i 1}\right) \mathbf{z}_{i, t-1}+\boldsymbol{\Lambda}_{i 0} \Delta \mathbf{x}_{i t}^{*}+\boldsymbol{\varepsilon}_{i, t}
\end{aligned}
$$

e sendo que $\mathbf{A}_{i 0}=\left(\mathbf{I}_{k_{i}},-\boldsymbol{\Lambda}_{i 0}\right)$ e $\mathbf{A}_{i 1}=\left(\boldsymbol{\Phi}_{i 1}, \boldsymbol{\Lambda}_{i 1}\right)$, facilmente obtém-se que

$$
\mathbf{A}_{i 0}-\mathbf{A}_{i 1}=\left(\mathbf{I}_{k_{j}},-\boldsymbol{\Lambda}_{i 0}\right)-\left(\boldsymbol{\Phi}_{i 1}, \boldsymbol{\Lambda}_{i 1}\right)=\left(\mathbf{I}_{k_{i}}-\boldsymbol{\Phi}_{i 1},-\boldsymbol{\Lambda}_{i 0}-\boldsymbol{\Lambda}_{i 1}\right) .
$$

Logo,

$$
\Delta \mathbf{x}_{i, t}=\mathbf{a}_{i 0}+\mathbf{a}_{i 1} t-\left(\mathbf{A}_{i 0}-\mathbf{A}_{i 1}\right) \mathbf{z}_{i, t-1}+\Lambda_{i 0} \Delta \mathbf{x}_{i t}^{*}+\boldsymbol{\varepsilon}_{i, t}
$$

sendo que as propriedades de correção de erro para o setor $i$ são resumidas pela matriz

$$
\boldsymbol{\Pi}_{i}=\mathbf{A}_{i 0}-\mathbf{A}_{i 1}
$$

a qual contém não apenas, para o modelo de cada setor, as variáveis internas específicas $\left(\mathbf{x}_{i t}\right)$ como as externas $\left(\mathbf{x}_{i t}^{*}\right)$ também.

Note que a matriz $\Pi_{i}$, cuja dimensão é $k_{i} \times\left(k_{i}+k_{i}^{*}\right)$ e com posto denotado por $r_{i} \leq k_{i}$, determina o número de relações de "longo prazo" entre $\mathbf{x}_{i t}$ e $\mathbf{x}_{i t}^{*}$ (PESARAN; SCHUERMANN; 
WEINER, 2004), sendo que o vetor que representa as relações de cointegração contém todas as variáveis que compõem $\mathbf{z}_{i t}$. Desse modo, tem-se que $\boldsymbol{\Pi}_{\boldsymbol{i}}=\boldsymbol{\alpha}_{i} \boldsymbol{\beta}_{i}^{\prime}$, sendo que $\boldsymbol{\alpha}_{i}$ é a loading matrix $k_{i} \times r_{i}$, e $\boldsymbol{\beta}_{i}$ é a matriz de vetores de cointegração $\left(k_{i}+k_{i}^{*}\right) \times r_{i}$

Para fins de ilustração, a generalização para o caso de um $\operatorname{VARX}^{*}\left(p_{i}, q_{i}\right)$, como em Chudik e Pesaran (2016), para o respectivo modelo em sua forma de correção de erros é dada por

$$
\begin{array}{r}
\Delta \mathbf{x}_{i t}=\mathbf{a}_{i 0}+\mathbf{a}_{i 1} t+\boldsymbol{\Lambda}_{i 0} \Delta \mathbf{x}_{i t}^{*}-\boldsymbol{\Pi}_{i} \mathbf{z}_{i, t-1}+\sum_{\ell=1}^{p} \mathbf{H}_{i \ell} \Delta \mathbf{z}_{i, t-1}+\boldsymbol{\varepsilon}_{i t}, \\
\boldsymbol{\Pi}_{i}=\mathbf{A}_{i 0}-\sum_{\ell=1}^{p} \mathbf{A}_{i \ell} \mathbf{e} \mathbf{H}_{i \ell}=-\left(\mathbf{A}_{i, \ell+1}+\mathbf{A}_{i, \ell+2}+\cdots+\mathbf{A}_{i, \ell+p}\right) .
\end{array}
$$

Assim, bem como realizado para o modelo VARX* para cada setor $i$, pode-se reescrever a representação de correção de erros (2.10) utilizando (2.4) da seguinte forma:

$$
\begin{gathered}
\mathbf{A}_{i 0} \Delta \mathbf{z}_{i t}=\mathbf{a}_{i 0}+\mathbf{a}_{i 1} t-\left(\mathbf{A}_{i 0}-\mathbf{A}_{i 1}\right) \mathbf{z}_{i, t-1}+\boldsymbol{\varepsilon}_{t}, \\
\mathbf{A}_{i 0} \mathbf{W}_{i} \Delta \mathbf{x}_{t}=\mathbf{a}_{i 0}+\mathbf{a}_{i 1} t-\left(\mathbf{A}_{i 0}-\mathbf{A}_{i 1}\right) \mathbf{W}_{i} \mathbf{x}_{t-1}+\boldsymbol{\varepsilon}_{t} .
\end{gathered}
$$

Então, o modelo global dado por (2.6) tem sua forma de correção de erros dada por

$$
\mathbf{G}_{0} \Delta \mathbf{x}_{\mathbf{t}}=\mathbf{a}_{0}+\mathbf{a}_{1} t-\left(\mathbf{G}_{0}-\mathbf{G}_{1}\right) \mathbf{x}_{t-1}+\boldsymbol{\varepsilon}_{t}
$$

sendo que, de maneira similar, o número de relações de longo prazo do modelo global é determinado pelo posto de $\mathbf{G}_{0}-\mathbf{G}_{1}=\tilde{\boldsymbol{\alpha}} \tilde{\boldsymbol{\beta}}^{\prime}$, em que $\tilde{\boldsymbol{\beta}}$ é a matriz $k \times r$ de cointegração global, $\operatorname{com} r=\sum_{i=0}^{N} r_{i}$ e $k=\sum_{i=0}^{N} k_{i}$.

$$
\tilde{\boldsymbol{\alpha}}=\left(\begin{array}{cccc}
\boldsymbol{\alpha}_{0} & \mathbf{0} & \ldots & \mathbf{0} \\
\mathbf{0} & \boldsymbol{\alpha}_{1} & \ldots & \mathbf{0} \\
\vdots & \vdots & \ddots & \vdots \\
\mathbf{0} & \mathbf{0} & \ldots & \boldsymbol{\alpha}_{N}
\end{array}\right), \tilde{\boldsymbol{\beta}}=\left(\mathbf{W}_{0}^{\prime} \boldsymbol{\beta}_{0}, \mathbf{W}_{1}^{\prime} \boldsymbol{\beta}_{1}, \ldots, \mathbf{W}_{N}^{\prime} \boldsymbol{\beta}_{N}\right)
$$

Pesaran, Schuermann e Weiner (2004) frisam que os resultados são condicionados à escolha das matrizes $\mathbf{W}_{i}$, de maneira que, em princípio, é possível obter um número variável de relações de cointegração no modelo global para diferentes escolhas de tal matriz.

\subsection{Introdução de variáveis globais ao GVAR}

Em Pesaran, Schuermann e Weiner (2004) e Dées et al. (2007), a introdução de variáveis globais, ou também nomeadas como variáveis comuns (uma vez que são comuns a todos dos modelos VARX* setoriais), é feito de maneira usual, sendo estas adicionadas assim como são 
inseridas variáveis exógenas em modelos VAR ou VEC. Todavia, neste caso, diferencia-se pelo fato de que tais variáveis exógenas são inseridas nos vetores de cointegração.

Utilizando a notação de Dées et al. (2007), descreve-se a especificação de um modelo $\operatorname{VARX}^{*}(2,2)$ como

$$
\begin{array}{r}
\mathbf{x}_{i t}=\mathbf{a}_{i 0}+\mathbf{a}_{i 1} t+\boldsymbol{\Phi}_{i 1} \mathbf{x}_{i, t-1}+\boldsymbol{\Phi}_{i 2} \mathbf{x}_{i, t-2}+\Upsilon_{i 0} \mathbf{d}_{t}+\Upsilon_{i 1} \mathbf{d}_{t-1}+\Upsilon_{i 2} \mathbf{d}_{t-2}+ \\
+\Lambda_{i 0} \mathbf{x}_{i t}^{*}+\Lambda_{i 1} \mathbf{x}_{i, t-1}^{*}+\Lambda_{i 2} \mathbf{x}_{i, t-2}^{*}+\boldsymbol{\varepsilon}_{i t},
\end{array}
$$

cuja forma de correção de erros é dada por

$$
\Delta \mathbf{x}_{i t}=\mathbf{c}_{i 0}-\boldsymbol{\alpha}_{i} \boldsymbol{\beta}_{i}^{\prime}\left[\boldsymbol{\zeta}_{i, t-1}-\gamma_{i}(t-1)\right]+\Upsilon_{i 0} \Delta \mathbf{d}_{t}+\boldsymbol{\Lambda}_{i 0} \Delta \mathbf{x}_{i t}^{*}+\Upsilon_{i 1} \Delta \mathbf{d}_{t-1}+\boldsymbol{\Gamma}_{i} \Delta \mathbf{z}_{i, t-1}+\boldsymbol{\varepsilon}_{i t},
$$

sendo $\zeta_{i, t-1}=\left(\mathbf{z}_{i, t-1}^{\prime}, \mathbf{d}_{t-1}^{\prime}\right)$. Neste caso, $\boldsymbol{\alpha}_{i}$ é uma matriz $k_{i} \times r_{i}$ é $\boldsymbol{\beta}_{i}$ é $\left(k_{i}+k_{i}^{*}+m_{d}\right) \times r_{i}$, com $m_{d}$ representando o número de variáveis comuns inseridas no modelo.

Com tal representação, $\boldsymbol{\beta}_{i}$ pode ser particionada como $\boldsymbol{\beta}_{i}=\left(\boldsymbol{\beta}_{i x}^{\prime}, \boldsymbol{\beta}_{i x *}^{\prime}, \boldsymbol{\beta}_{i d}^{\prime}\right)$, em conformidade $\operatorname{com} \zeta_{i t}=\left(\mathbf{x}_{i t}^{\prime}, \mathbf{x}_{i t}^{* \prime}, \mathbf{d}_{t}^{\prime}\right)$ e o termo de correção de erro podendo ser escrito como $\boldsymbol{\beta}_{i}^{\prime}\left(\boldsymbol{\zeta}_{i, t-1}-\gamma_{i} t\right)=\boldsymbol{\beta}_{i x}^{\prime} \mathbf{x}_{i t}+\boldsymbol{\beta}_{i x *}^{\prime} \mathbf{x}_{i t}^{*}+\boldsymbol{\beta}_{i d}^{\prime} \mathbf{d}_{t}+\left(\boldsymbol{\beta}_{i}^{\prime} \gamma_{i}\right) \mathbf{t}$. Segundo Dées et al. (2007), tal representação deixa claro que a metodologia permite que exista cointegração de $\mathbf{x}_{i t} \operatorname{com} \mathbf{x}_{i t}^{*}$ e $\mathbf{d}_{t}$.

Chudik e Pesaran (2016) afirmam que, além da introdução das variáveis globais como fatores observáveis comuns às unidades do corte transversal, estas podem ser inseridas na forma de unidades dominantes como definido por Chudik e Pesaran (2013). Os autores descrevem que a unidade dominante (dominant unit) influencia o restante das variáveis do modelo, tanto direta como indiretamente, sendo que seu efeito não desaparece conforme $N \rightarrow \infty$.

Segundo Chudik e Pesaran (2013), a unidade dominante funciona como um fator dinâmico nas regressões das unidades que são consideradas não-dominantes e induz relações de ordem infinita entre as unidades dominantes e não-dominantes ${ }^{16}$. Nesta linha, Chudik e Pesaran (2016) afirmam que os modelos de cada setor são aumentados pelo vetor de variáveis $\boldsymbol{\omega}_{t}$ e seus valores defasados, em adição às variáveis externas específicas.

Chudik e Pesaran (2016) derivam a solução do modelo GVAR que considera a existência de uma unidade dominante, o que é relevante para as variáveis globais inseridas. Considerando aqui o caso genérico de $\operatorname{um} \operatorname{VARX}^{*}\left(p_{i}, q_{i}\right)$,

$$
\mathbf{x}_{i t}=\sum_{\ell=1}^{p_{i}} \boldsymbol{\Phi}_{i \ell} \mathbf{x}_{i, t-\ell}+\boldsymbol{\Lambda}_{i 0} \mathbf{x}_{i t}^{*}+\sum_{\ell=1}^{q_{i}} \boldsymbol{\Lambda}_{i \ell} \mathbf{x}_{i, t-\ell}^{*}+\mathbf{D}_{i 0} \boldsymbol{\omega}_{t}+\sum_{\ell=1}^{s_{i}} \mathbf{D}_{i 0} \boldsymbol{\omega}_{t-\ell}+\boldsymbol{\varepsilon}_{i t}
$$

para $i=1,2, \ldots, N$, com as variáveis $\omega_{t} \mathbf{e} \mathbf{x}_{i t}^{*}$ também tratadas como fracamente exógenas para fins de estimação ${ }^{17}$.

\footnotetext{
${ }^{16}$ No modelo GVAR a ser estimado neste trabalho, não existirá um setor dominante, mas sim as variáveis globais comporão a dita dominant unit.

${ }^{17}$ Uma vez que nem todos os coeficientes $\left\{\mathbf{D}_{i \ell}\right\}$ das variáveis comuns certamente serão estatisticamente significantes, aqueles que não o forem podem ser excluídos para assim obter-se um modelo mais parcimonioso (CHUDIK; PESARAN, 2016).
} 
Por sua vez, o modelo marginal para as variáveis dominantes pode ser estimado com ou sem retroalimentação das variáveis de $\mathbf{x}_{t}$. Desconsiderando a retroalimentação, o modelo marginal é representado por

$$
\boldsymbol{\omega}_{t}=\sum_{\ell=1}^{p_{\omega}} \boldsymbol{\Phi}_{\omega \ell} \boldsymbol{\omega}_{t-\ell}+\boldsymbol{\eta}_{\omega t},
$$

cuja forma de correção de erros é dada abaixo:

$$
\Delta \boldsymbol{\omega}_{t}=-\boldsymbol{\alpha}_{\omega} \boldsymbol{\beta}_{\omega}^{\prime} \boldsymbol{\omega}_{t-1}+\sum_{\ell=1}^{p_{\omega}-1} \mathbf{H}_{\omega \ell} \Delta \boldsymbol{\omega}_{t-\ell}+\boldsymbol{\eta}_{\omega t}
$$

$\operatorname{com} \boldsymbol{\alpha}_{\omega} \boldsymbol{\beta}_{\omega}^{\prime}=\sum_{\ell=1}^{p_{\omega}} \boldsymbol{\Phi}_{\omega \ell}, \mathbf{H}_{\omega \ell}=-\left(\boldsymbol{\Phi}_{\omega, \ell+1}+\boldsymbol{\Phi}_{\omega, \ell+2}+\cdots+\boldsymbol{\Phi}_{\omega, \ell+p_{\omega}-1}\right)$ para $\ell=1,2, \ldots, p_{\omega}-1^{18}$

Adicionalmente, para permitir a existência de efeitos de retroalimentação vindos das variáveis do GVAR para a unidade dominante via médias das unidades do corte transversal ${ }^{19}$, ou seja, uma variação em $\mathbf{x}_{t}$ que teve origem em $\omega_{t}$ passa a ter efeito sobre este, o modelo VAR (2.18) é aumentado pelas defasagens de $\mathbf{x}_{\omega t}^{*}=\mathbf{W}_{\omega} \mathbf{x}_{t}$

$$
\boldsymbol{\omega}_{t}=\sum_{\ell=1}^{p_{\omega}} \boldsymbol{\Phi}_{\omega \ell} \boldsymbol{\omega}_{t-\ell}+\sum_{\ell=1}^{q_{\omega}} \boldsymbol{\Lambda}_{\omega \ell} \mathbf{x}_{\omega, t-\ell}^{*}+\boldsymbol{\eta}_{\omega t} .
$$

Segundo Chudik e Pesaran (2016), assumindo que não há cointegração entre as variáveis comuns, $\omega_{t}$, e as médias das unidades do corte transversal, $\mathbf{x}_{\omega, t-\ell}^{*},(2.20)$ pode ser escrito como

$$
\Delta \boldsymbol{\omega}_{t}=-\boldsymbol{\alpha}_{\omega} \boldsymbol{\beta}_{\omega}^{\prime} \boldsymbol{\omega}_{t-1}+\sum_{\ell=1}^{p_{\omega}-1} \mathbf{H}_{\omega \ell} \Delta \boldsymbol{\omega}_{t-\ell}+\sum_{\ell=1}^{q_{\omega}-1} \mathbf{B}_{\omega \ell} \Delta \mathbf{x}_{\omega, t-\ell}^{*}+\boldsymbol{\eta}_{\omega t}
$$

sendo que $\mathbf{B}_{\omega \ell}=-\left(\boldsymbol{\Lambda}_{\omega, \ell+1}+\boldsymbol{\Lambda}_{\omega, \ell+2}+\cdots+\boldsymbol{\Lambda}_{\omega, \ell+q_{\omega}-1}\right)$, e podendo ser estimado por mínimos quadrados. É importante notar que em (2.21) as variáveis médias não possuem seus valores contemporâneos inseridos.

Assim como feito anteriormente, os modelos condicional (2.17) e marginal (2.21) podem também ser combinados para assim solucionar o modelo global, bem como já foi feito. Desse modo, Chudik e Pesaran (2016) definem o vetor $\mathbf{y}_{t}=\left(\boldsymbol{\omega}_{t}^{\prime}, \mathbf{x}_{t}^{\prime}\right)^{\prime} \operatorname{de}$ ordem $\left(k+m_{\omega}\right) \times 1$, contendo então todas as variáveis observáveis do modelo. Unindo os modelos setoriais (2.17) com o modelo para as variáveis comuns dado por (2.20), o modelo GVAR é então escrito como

$$
\mathbf{G}_{y, 0} \mathbf{y}_{t}=\sum_{\ell=1}^{p} \mathbf{G}_{y, \ell} \mathbf{y}_{t-\ell}+\boldsymbol{\varepsilon}_{y t}
$$

sendo que o resíduo agora é decomposto como $\boldsymbol{\varepsilon}_{y t}=\left(\boldsymbol{\varepsilon}_{t}^{\prime}, \boldsymbol{\eta}_{\omega t}^{\prime}\right)^{\prime}$, e

$$
\mathbf{G}_{y, 0}=\left(\begin{array}{cc}
\mathbf{I}_{m_{\omega}} & \mathbf{0}_{m_{\omega} \times k} \\
\mathbf{D}_{0} & \mathbf{G}_{0}
\end{array}\right), \mathbf{G}_{y, \ell}=\left(\begin{array}{cc}
\boldsymbol{\Phi}_{\omega \ell} & \boldsymbol{\Lambda}_{\omega \ell} \tilde{\mathbf{W}}_{\omega} \\
\mathbf{D}_{\ell} & \mathbf{G}_{\ell}
\end{array}\right), \text { para } \ell=1,2, \ldots, p,
$$

\footnotetext{
${ }^{18}$ A representação deixa clara a possibilidade de existência de relações de cointegração entre as variáveis que compõem a unidade dominante do GVAR.

${ }^{19}$ Note que aqui as médias ponderadas não são as variáveis externas específicas.
} 
$\operatorname{com} \mathbf{D}_{\ell}=\left(\mathbf{D}_{1 \ell}^{\prime}, \mathbf{D}_{2 \ell}^{\prime}, \ldots, \mathbf{D}_{N \ell}^{\prime}\right)^{\prime}$, para $\ell=0,1, \ldots, p, p=\max _{i}\left\{p_{i}, q_{i}, s_{i}, p_{\omega}, q_{\omega}\right\}$, e os autores definem que $\mathbf{D}_{i \ell}=\mathbf{0}$ para $\ell>s_{i}, \boldsymbol{\Phi}_{\omega \ell}=\mathbf{0}$ para $\ell>p_{\omega}$, e $\boldsymbol{\Lambda}_{\omega \ell}=\mathbf{0}$ para $\ell>q_{\omega}$.

Por fim, é necessário que a matriz $\mathbf{G}_{y, 0}$ seja invertível, o que é verdade se, e somente se, $\mathbf{G}_{0}$ é invertível ${ }^{20}$. Supondo a existência de $\mathbf{G}_{0}^{-1}$, a inversa de $\mathbf{G}_{y, 0}$ é dada por

$$
\mathbf{G}_{y, 0}^{-1}=\left(\begin{array}{cc}
\mathbf{I}_{m_{\omega}} & \mathbf{0}_{m_{\omega} \times k} \\
-\mathbf{G}_{0}^{-1} \mathbf{D}_{0} & \mathbf{G}_{0}^{-1}
\end{array}\right),
$$

que é bloco diagonal, mostrando a causalidade das variáveis dominantes. Multiplicando ambos os lados de (2.22) por (2.24), obtém-se o modelo GVAR para $\mathbf{y}_{t}$ :

$$
\mathbf{y}_{t}=\sum_{\ell=1}^{p} \mathbf{F}_{y, \ell} \mathbf{y}_{t-\ell}+\mathbf{G}_{y, 0}^{-1} \boldsymbol{\varepsilon}_{y, t}
$$

em que $\mathbf{F}_{y, \ell}=\mathbf{G}_{y, 0}^{-1} \mathbf{G}_{y, \ell} \ell=1,2, \ldots, p$

\subsection{Teste de exogeneidade fraca}

Como discutido anteriormente, a inserção das variáveis externas específicas ou globais se dá partindo do pressuposto que tais variáveis podem ser consideradas fracamente exógenas $^{21}$. Mais especificamente, como descrito por Dées et al. (2007), a hipótese principal da estratégia de estimação do GVAR é que as variáveis externas específicas e as globais são fracamente exógenas aos parâmetros de longo prazo do modelo condicional (2.16), .

Haja vista a importância de tal hipótese para a estimação, esta é testada utilizando a abordagem de Johansen (1992) e Harbo et al. (1998). A pressuposição é testada a partir da significância dos termos de correção de erros em uma regressão auxiliar para as variáveis externas específicas. Para cada $l$-ésimo elemento de $\mathbf{x}_{i t}^{*}$ é realizada a regressão

$$
\Delta x_{i j, l}^{*}=\mu_{i l}+\sum_{j=1}^{r_{i}} \gamma_{i j, l} E C M_{i, t-1}^{j}+\sum_{k=1}^{s_{i}} \varphi_{i k, l} \Delta \mathbf{x}_{i, t-k}+\sum_{m=1}^{n_{i}} \vartheta_{i m, l} \Delta \tilde{\mathbf{x}}_{i, t-m}^{*}+\varepsilon_{i t, l}
$$

em que $E C M_{i, t-1}^{j}, j=1,2, \ldots, r_{i}$ são os termos de correção de erro estimados que correspondem às $r_{i}$ relações de cointegração identificadas para o $i$-ésimo setor, e $\tilde{\mathbf{x}}_{i, t-m}^{*}=\left(\Delta \mathbf{x}_{i t}^{*}, \Delta p_{t}^{o}\right)^{\prime}$.

Deste modo, o teste de exogeneidade fraca é um teste F cuja hipótese nula conjunta é que $\gamma_{i j, l}=0, j=1,2, \ldots, r_{i}$ para (2.26). Ademais, as defasagens utilizadas para o teste, $s_{i}$ e $n_{i}$, não precisam ser iguais ao número de defasagens do modelo VARX* para cada setor.

\footnotetext{
${ }^{20}$ Pesaran (2015) fornece solução para derivar o modelo caso tal matriz seja singular.

${ }^{21}$ Para discussão sobre exogeneidade fraca, ver Johansen (1992) e Harbo et al. (1998).
} 


\subsection{Análise de resposta ao impulso}

Uma das mais importantes ferramentas utilizadas em modelos multivariados de séries temporais é a análise resposta ao impulso, a qual pode ser considerada como o produto de um experimento conceitual em que o interesse é no efeito do choque ocorrido em $t$ sobre a economia em $t+n$ (PESARAN, 2015, p. 584). Para o estudo do repasse cambial esta ferramenta é especialmente importante, pois é possível verificar os efeitos de um choque cambial sobre os preços por meio de tal análise.

No caso do modelo GVAR, é importante recordar a existência de interdependências entre unidades do corte transversal (aqui os setores da indústria de transformação brasileira), o que permite verificar os efeitos dos choques, por exemplo, no setor de metalurgia sobre o de veículos automotores. Todavia, esta característica combinada à alta dimensão do modelo global dificultam a identificação dos choques.

Assim, para realizar tal análise é preciso que as correlações que existem entre os diferentes choques, tanto dentro do próprio setor como entre eles, sejam consideradas de maneira apropriada. A literatura tradicional de modelos VAR trata tal problema da correlação entre variáveis por meio das chamadas respostas ao impulso ortogonalizadas (orthogonalized impulse responses, OIRs) de Sims (1980).

Neste procedimento, supondo que o processo gerador dos dados é (2.8), que conta com $k=\sum_{i=0}^{N} k_{i}$ erros específicos a cada unidade $i$ do corte transversal, sendo que neste caso não existem variáveis comuns incluídas no modelo. Suponha que existam $k$ choques estruturais distintos para este caso. As respostas ao impulso são computadas a partir de choques ortogonalizados, $\boldsymbol{\xi}_{t}$, ao invés dos choques originais, $\boldsymbol{\varepsilon}_{t}{ }^{22}$, sendo que $\boldsymbol{\xi}_{t}=\mathbf{P}^{-1} \boldsymbol{\varepsilon}_{t}$, em que $\mathbf{P}$ é uma matriz $k \times k$ obtida pela decomposição de Cholesky da matriz de covariâncias, $\operatorname{cov}\left(\xi_{t}\right)=\Sigma$, ou seja,

$$
\mathbf{P P}^{\prime}=\Sigma
$$

Dessa forma, por construção, $E\left(\xi_{t} \xi_{t}^{\prime}\right)=I_{k}$ e o vetor $k \times 1$ das funções de resposta ao impulso ortogonalizada (OIR) é dado por:

$$
\begin{aligned}
\mathbf{g}_{\xi j}(h) & =E\left(\mathbf{x}_{t+h} \mid \xi_{j t}=1, \Omega_{t-1}\right)-E\left(\mathbf{x}_{t+h} \mid \Omega_{t-1}\right) \\
& =\frac{\mathbf{R}_{h} \mathbf{G}_{0}^{-1} \mathbf{P} \mathbf{e}_{j}}{\sqrt{\mathbf{e}_{j}^{\prime} \mathbf{\Sigma} \mathbf{e}_{j}}}
\end{aligned}
$$

para $j=1,2, \ldots, k$, em que $\Omega_{t}=\left\{\mathbf{x}_{t}, \mathbf{x}_{t-1}, \ldots\right\}$ é o conjunto de informação contendo toda a informação disponível até o período $t$ e $\mathbf{e}_{j}$ é um vetor de seleção $k \times 1$ que seleciona a variável na posição $j$. Ademais, as matrizes $\mathbf{R}_{h}$ de ordens $k \times k$ são obtidas recursivamente a partir de

\footnotetext{
${ }^{22}$ Note que, na Equação (2.8), $\mathbf{u}_{t}=\mathbf{G}_{0}^{-1} \boldsymbol{\varepsilon}_{t}$ e que $\boldsymbol{\varepsilon}_{t}=\left(\boldsymbol{\varepsilon}_{0 t}^{\prime}, \boldsymbol{\varepsilon}_{1 t}^{\prime}, \ldots, \boldsymbol{\varepsilon}_{N t}^{\prime}\right)$.
} 
(2.25):

$$
\mathbf{R}_{h}=\sum_{\ell=1}^{p} \mathbf{F}_{\ell} \mathbf{R}_{h-\ell}, \operatorname{com} \mathbf{R}_{0}=\mathbf{I}_{k} \text { e } \mathbf{R}_{\ell}=\mathbf{0} \text { para } \ell<0
$$

É importante lembrar que a fatoração de Cholesky não é única e depende da ordenação das variáveis no vetor $\mathbf{x}_{t}$. Tal característica apresenta-se como uma dificuldade no contexto de um modelo global de alta dimensão, pois requer um número de restrições grande demais, que seria problemático para motivar (CHUDIK; PESARAN, 2016).

Outras soluções para identificação de choques na forma reduzida de VARs também são sugeridas pela literatura como restrições a priori sob a matriz de covariâncias contemporâneas dos choques; restrições no impacto de longo prazo dos choques; e restrições de sinal (CHUDIK; PESARAN, 2016). Os métodos tradicionais de estimação de funções de resposta ao impulso, além de seus problemas idiossincráticos, enfrentam dificuldades adicionais no caso modelo GVAR devido as interações entre os modelos VARX* e a alta dimensionalidade.

\subsubsection{A função de resposta ao impulso generalizada}

Em vista das dificuldades apresentadas na análise tradicional de resposta ao impulso, Pesaran, Schuermann e Weiner (2004) e a literatura que continuou a desenvolver e aplicar o modelo GVAR adotaram a abordagem da função de resposta ao impulso generalizada ( $g e$ neralized impulse response function, GIRF) de Koop, Pesaran e Potter (1996), desenvolvida posteriormente por Pesaran e Shin (1998). Tal escolha é justificada pelo fato de que a abordagem, ao contrário da análise de resposta ao impulso tradicional, não requer a ortogonalização dos choques e é invariante à ordenação das variáveis no sistema (PESARAN; SHIN, 1998).

A princípio, Koop, Pesaran e Potter (1996) tinham interesse em oferecer uma forma de análise dos efeitos de choques para modelos multivariados não-lineares, já que utilizar os métodos tradicionais produz respostas ao impulso dependentes do passado das variáveis e do choque. Em contrapartida, o passado não afeta a resposta do sistema a choques nos modelos lineares (propriedade de independência da história), demandando tal nova resposta para a análise vinda com a GIRF.

Como as vantagens desse novo tipo de análise de resposta ao impulso também facilitam a avaliação de modelos lineares, Pesaran e Shin (1998) dedicam-se a desenvolver formalmente a GIRF para o caso dos modelos VAR, considerando também o caso em que há cointegração. Além disso, mostra-se a relação que existe entre a OIR e a GIRF, apesar desta abordagem em si não buscar a identificação dos choques de acordo com um sistema canônico ou com a teoria econômica por trás do problema abordado (CHUDIK; PESARAN, 2016).

A GIRF realiza o exercício de lidar com o futuro ao utilizar o operador esperança condicional ao passo e ao choque, de maneira que os choques futuros, na média, não são 
considerados. De tal modo, a resposta ao choque construída é uma média do que poderá ocorrer dado presente e passado (KOOP; PESARAN; POTTER, 1996), ou seja, é um exercício contrafactual em que as correlações entre os choques são assumidas como dadas (CHUDIK; PESARAN, 2016).

Como descrito por Chudik e Pesaran (2016), no contexto do modelo GVAR representado por (2.8), o vetor $k \times 1$ de GIRFs é dado por:

$$
\begin{aligned}
\mathbf{g}_{\varepsilon j}(h) & =E\left(\mathbf{x}_{t+h} \mid \boldsymbol{\varepsilon}_{j t}=\sqrt{\sigma_{j j}}, \Omega_{t-1}\right)-E\left(\mathbf{x}_{t+h} \mid \Omega_{t-1}\right) \\
& =\frac{\mathbf{R}_{h} \mathbf{G}_{0}^{-1} \boldsymbol{\Sigma} \mathbf{e}_{j}}{\sqrt{\mathbf{e}_{j}^{\prime} \boldsymbol{\Sigma} \mathbf{e}_{j}}}
\end{aligned}
$$

para $j=1,2, \ldots, k, h=0,1,2, \ldots$, em que $\sqrt{\sigma_{j j}}=\sqrt{E\left(\varepsilon_{j t}^{2}\right)}$ é o tamanho do choque, que no caso é considerado um desvio padrão de $\boldsymbol{\varepsilon}_{j t}$. Note que a diferença entre a fórmula de estimação da função de resposta ao impulso ortogonalizada em relação à generalizada está no fato de que, como a GIRF é invariante à ordenação das variáveis, o choque de um desvio padrão é selecionado diretamente a partir da matriz de variância-covariância $\Sigma$. No caso tradicional, o choque é dado sob os erros ortogonalizados em que $E\left(\boldsymbol{\xi}_{t} \boldsymbol{\xi}_{t}^{\prime}\right)=\mathbf{P}^{-1} E\left(\boldsymbol{\varepsilon}_{t} \boldsymbol{\varepsilon}_{t}^{\prime}\right) \mathbf{P}^{\prime-1}=\mathbf{P}^{-1} \boldsymbol{\Sigma} \mathbf{P}^{\prime-1}=$ $\mathbf{I}_{k}$, daí o choque especificado ser $\xi_{j t}=1$, ao passo que na GIRF especifica-se o tamanho do choque é dado por $\boldsymbol{\varepsilon}_{j t}=\sqrt{\sigma_{j j}}$.

Por fim, segundo Chudik e Pesaran (2016), as GIRFs também podem ser obtidas para um choque "global", o qual é definido por $\boldsymbol{\varepsilon}_{m, t}^{g}=\mathbf{m}^{\prime} \boldsymbol{\varepsilon}_{t}$, em que o vetor de pesos, $\mathbf{m}$, está relacionado a um agregado global (ou seja, agregação das unidades que compõem o sistema). O vetor da GIRF, agora para um choque global, passa a ser

$$
\begin{aligned}
\mathbf{g}_{m}(h) & =E\left(\mathbf{x}_{t+h} \mid \boldsymbol{\varepsilon}_{m, t}^{g}=\sqrt{\mathbf{m}^{\prime} \Sigma \mathbf{m}}, \Omega_{t-1}\right)-E\left(\mathbf{x}_{t+h} \mid \Omega_{t-1}\right) \\
& =\frac{\mathbf{R}_{h} \mathbf{G}_{0}^{-1} \mathbf{\Sigma} \mathbf{m}}{\sqrt{\mathbf{m}^{\prime} \mathbf{\Sigma} \mathbf{m}}}
\end{aligned}
$$

\subsection{Aplicações do GVAR na literatura}

O GVAR tem sido aplicado diversas vezes na literatura desde a publicação de Pesaran, Schuermann e Weiner (2004), apresentando-se não apenas como uma importante ferramenta para estudos acadêmicos, mas também como método de análise e avaliação de políticas ${ }^{23}$. Em Chudik e Pesaran (2016) é possível encontrar diversas das contribuições de trabalhos que utilizaram o GVAR.

Destacam-se aplicações em diversas áreas de estudo com enfoque analisar a economia global como em previsão, finanças (focando principalmente nas interconexões de mercados e

\footnotetext{
${ }^{23}$ Entidades como o Fundo Monetário Internacional (FMI) e o Banco Central Europeu (BCE) estão entre as que utilizam tal método.
} 
riscos globais), macroeconomia (neste caso com diversos enfoques, como inflação, comércio internacional, efeitos de política monetária e fiscal, entre outros) e estudos setoriais, como o presente estudo. Com uma vasta gama de áreas de pesquisa com interesse no método, diversos trabalhados foram unidos em di Mauro e Pesaran (2013) a fim de além de apresentar o método, também fornecer diversas aplicações, para assim ajudar a difundir-lo e auxiliar pesquisadores.

A maioria dos estudos foca na estimação de modelos multi-países, assim como feito desde o primeiro artigo sobre o GVAR. Deste modo, ainda poucos são os trabalhos que se valem do método para aplicações setoriais, como se pretende realizar. Podem-se citar como exemplos de aplicações setoriais Holly e Petrella (2012), que aplicam o GVAR a um modelo altamente desagregado de setores manufatureiros do Reino Unido, e Hiebert e Vansteenkiste (2010), que analisam o mercado de trabalho do setor manufatureiro dos Estados Unidos.

A partir da literatura apresentada por Pesaran (2015) e di Mauro e Pesaran (2013), observou-se que inexiste até o presente momento um estudo que utilize o GVAR com aplicação setorial para estimar o grau de repasse cambial. Na literatura que aborda a elasticidade dos preços ao câmbio, Razafindrabe (2016) é o único trabalho encontrado que utiliza o GVAR, não para estimar o grau de repasse, mas usa a previsão de longo prazo obtida da forma reduzida do GVAR com cointegração como estado estacionário de variáveis observáveis dentro de um modelo DSGE multi-países. Razafindrabe (2016) adicionalmente descreve que existe vantagem adicional desta estimativa, pois leva em conta as relações diretas e indiretas entre países, além da possibilidade de existir relações de cointegração entre as variáveis internas e externas específicas.

De tal forma, o presente trabalho se apresenta na literatura do GVAR contribuindo em duas frentes. Primeiramente, utilizam-se setores e não países, o que pouco ainda tem sido feito até o momento. Em segundo lugar, o método será então aplicado a um problema para o qual nunca fora usado, ou seja, uma contribuição não apenas para a literatura do método, mas também do repasse cambial, que é tema de interesse não apenas teórico, mas bastante relevante também para policy-makers. 



\section{DADOS E ESTRUTURA DE ESTIMAÇÃO}

Segundo Chudik e Pesaran (2016), as interligações existentes na economia são consideradas de diversas formas na literatura, mas a possibilidade de restarem interdependências residuais devido a fatores não-observados e efeitos transbordamento são questões as quais o GVAR busca solucionar. Os autores citam o método como uma maneira efetiva de modelar tais interações em grandes sistemas, sendo que uma de suas contribuições metodológicas reside na tentativa de reduzir a dimensionalidade do modelo.

No caso do repasse de um choque cambial aos preços em uma economia, cujos setores são integrados não apenas nacional, mas internacionalmente, o efeito direto deste ou quaisquer outros choques terá ramificações sobre o resto do sistema. Neste espírito, a principal conclusão obtida por Holly e Petrella (2012) é que as ligações de demanda entre setores, representadas pela matriz de insumo-produto, podem ser importantes para a transmissão de choques, tanto setoriais como vindos de agregados da economia. Assim, o GVAR se apresenta como uma metodologia apropriada para a estimação do grau de repasse, pois considera as relações intra e inter-setoriais, além das interdependências com as variáveis globais e fatores comuns, que afetam todos os setores simultaneamente.

A decisão de um estudo setorial de repasse cambial baseia-se também na já documentada heterogeneidade do coeficiente de repasse entre setores. Nesta linha, podem ser citados trabalhos como os de Hooper e Mann (1989), Yang (1997) e Cao, Dong e Tomlin (2015), por exemplo. Adicionalmente, Hooper e Mann (1989) observam que, em alguns casos, a desagregação dos dados parece reduzir o grau de repasse e até mesmo a defasagem com que ele acontece. Em específico, os autores utilizam apenas os setores que compõem a indústria de transformação.

Esta seção terá como papel desenvolver a aplicação do GVAR ao problema de estimação do repasse cambial. Serão apresentados (1) a estratégia empírica para o problema baseada na combinação de estrutura analítica vinda da literatura de repasse cambial voltada para modelos de Organização Industrial e de elementos da literatura de NOEM, (2) as bases de dados necessárias para a estimação, (3) a estrutura de ponderação dos setores necessária para estimar o GVAR e (4) o método de cálculo das elasticidades dos preços ao câmbio.

\subsection{Estratégia empírica}

Primeiramente, desenha-se uma estrutura analítica de determinação de preços de importação e domésticos que está em linha com a formulação geral apresentada por Goldberg e Knetter (1997) e parte da estrutura analítica de Hooper e Mann (1989). Os autores seguem a literatura de repasse cambial que se baseia em modelos de Organização Industrial, 
considerando a existência de mercados imperfeitos, de modo que os preços são determinados por regras de markup.

Sendo o preço das importações free on board em moeda estrangeira $\left(P^{m}\right)$ composto pelo markup das importações ${ }^{24}\left(\mu^{m}\right)$ e pelo custo externo arcado pelas firmas estrangeiras em moeda internacional $\left(C^{e}\right)$, o preço de importação pode ser expresso por (3.1),

$$
P^{m}=\mu^{m} C^{e}
$$

Assim, o preço final das importações pode ser definido em moeda doméstica, Reais (R\$), por meio da multiplicação do custo estrangeiro pela taxa de câmbio, $E=R \$ / F \$$,

$$
P_{R \$}^{m}=\mu^{m} C^{e} E,
$$

em que $P_{R \$}^{m}$ é preço de importação em moeda local.

Levando em conta a argumentação teórica apresentada anteriormente, de que as firmas estrangeiras que exportam para o mercado local levam em conta as pressões competitivas sofridas, a decisão da magnitude do markup sobre os seus custos de produção será pautada pela noção de competitividade internacional. O markup será então definido como uma função dos preços domésticos ao atacado, $P^{a}$, e do custo de produção externo medido na moeda doméstica, $C^{e} E$, buscando representar uma espécie de rentabilidade do seu produto quando exportado, considerando o nível corrente de preços praticados no mercado de destino.

$$
\mu^{m}=\alpha\left(\frac{P^{a}}{C^{e} E}\right)^{\delta} .
$$

Substituindo (3.3) em (3.1) e tomando o logaritmo natural, obtém-se a seguinte representação log-linear a ser estimada:

$$
\ln P^{m}=\ln \alpha+\delta \ln P^{a}-\delta \ln E+(1-\delta) \ln C^{e}+\varepsilon^{m}
$$

sendo $(1-\delta)$ o grau de repasse cambial quando $P^{m}$ é medido na moeda local ${ }^{25}$, podendo-se obter uma interpretação direta deste a partir do parâmetro $\delta$ que representa a sensibilidade das firmas estrangeiras à competição local brasileira.

Por outro lado, considerando que a regra de markup também é utilizada pelas firmas domésticas, similar ao realizado para os preços de importação, tem-se que o preço ao atacado doméstico $\left(P^{a}\right)$ é dado por

$$
P^{a}=\mu^{a} C^{d}
$$

sendo $\mu^{a}$ e $C^{d}$ o markup no atacado e o custo doméstico, respectivamente.

\footnotetext{
${ }^{24}$ Seguindo a ideia de pricing-to-market de Krugman (1986), o markup da firma estrangeira não é específico a ela, mas sim ao país de destino. Assim, o markup é definido a partir do fato que o bem em questão está sendo importado pelo Brasil, por exemplo.

${ }^{25}$ Para verificar esta afirmação, basta substituir (3.3) em (3.2).
} 
Novamente, partindo da suposição de que as firmas levam em conta o ambiente competitivo para a formulação de preço, o markup da firma doméstica é função do ambiente de competição com as firmas exportadoras externas (ou seja, função do preço praticado pelo exportador estrangeiro no mercado doméstico), assim como dos próprios custos de produção das firmas, admitindo-se que $0 \leq \lambda \leq 1$, sendo $\lambda$ o parâmetro da pressão competitiva que os produtores domésticos sofrem dos bens importados. Então, $\mu^{a}$ é dado por:

$$
\mu^{a}=\sigma\left(\frac{P^{m} E}{C^{d}}\right)^{\lambda},
$$

a qual implica, em conjunto com (3.3), os preços dos bens importados e produzidos domésticos são definidos simultaneamente.

Substitui-se (3.6) em (3.5), e toma-se o logaritmo natural da equação de precificação, obtendo a representação log-linear também a ser estimada:

$$
\ln P^{a}=\ln \sigma+(1-\lambda) \ln C^{d}+\lambda \ln E+\lambda \ln P^{m}+\varepsilon^{a}
$$

Tal estrutura de precificação representada pelas Equações (3.4) e (3.7) é bastante comum em estimações de regressões de repasse, mas também podem ser aplicados a modelos multi-equacionais a fim de levar em conta a simultaneidade de determinação de $P^{m}$ e $P^{a}$. Assim, as relações a serem estimadas para cada um dos $K$ setores são dadas pela estrutura obtida em (3.4) e (3.7):

$$
\begin{aligned}
\ln P_{i t}^{m} & =\ln \alpha_{i}+\delta_{i} \ln P_{i t}^{a}-\delta_{i} \ln E_{t}+\left(1-\delta_{i}\right) \ln C_{i t}^{e}+\varepsilon_{i t}^{m} \\
\ln P_{i t}^{a} & =\ln \sigma_{i}+\left(1-\lambda_{i}\right) \ln C_{i t}^{d}+\lambda_{i} \ln E_{t}+\lambda_{i} \ln P_{i t}^{m}+\varepsilon_{i t}^{a} .
\end{aligned}
$$

no qual a relação de simultaneidade de determinação de $P_{i t}^{m}$ e $P_{i t}^{a}$ está explícita na formulação de $\mu_{i t}^{m}$ e $\mu_{i t}^{a}$, sendo que $\operatorname{cov}\left(\varepsilon_{i t}^{m}, \varepsilon_{i t}^{a}\right)=0$.

Agora, $\mathrm{C}=$ considere uma indústria composta por $J$ setores, sendo $i=1,2, \ldots, J$, similar ao proposto por Greene (2003, p. 339), em que a formação de preços de cada setor $i$ seja como definido pelas equações (3.8) e (3.9). Desse modo, o comportamento de precificação da indústria seria dado a partir da estimação de um sistema de $2 J$ equações, em que o vetor de preços $\mathbf{p}_{i t}=\left(\ln P_{i t}^{m}, \ln P_{i t}^{a}\right)=\left(p_{i t}^{m}, p_{i t}^{a}\right)^{\prime}$ é uma função dos custos, $\mathbf{c}_{i t}=\left(\ln C_{i t}^{e}, \ln C_{i t}^{d}\right)^{\prime}=$ $\left(c_{i t}^{e}, c_{i t}^{d}\right)^{\prime}$, o vetor $\mathbf{d}_{t}$ de componentes globais (no presente modelo, considerou-se por hora apenas o câmbio, sendo $\ln E_{t}=e_{t}$ ) e dos respectivos componentes idiossincráticos, $\boldsymbol{\varepsilon}_{i t}=$ $\left(\varepsilon_{i t}^{m}, \varepsilon_{i t}^{a}\right)^{\prime}$, para todo $i$.

Uma vez que a indústria é composta por diversos setores, é possível que, por meio da interdependência das relações de produção, estejam presentes fatores comuns de distúrbio aos setores nos componentes idiossincráticos de cada um deles, similar a um problema de Seemingly Unrelated Regressions (SUR) de Zellner (1962), que parte da suposição de que $\mathbf{c}_{i t} \mathrm{e}$ $e_{t}$ são variáveis exógenas,

$$
\mathbf{p}_{i t}=\boldsymbol{\alpha}_{i} \mathbf{d}_{t}+\boldsymbol{\beta}_{i} \mathbf{c}_{i t}+\boldsymbol{\varepsilon}_{i t}, \forall i,
$$


em que

$$
E\left(\boldsymbol{\varepsilon}_{i t} \boldsymbol{\varepsilon}_{j t}^{\prime}\right)=\left[\begin{array}{cc}
E\left(\varepsilon_{i t}^{m} \varepsilon_{j t}^{m}\right) & E\left(\varepsilon_{i t}^{m} \varepsilon_{j t}^{a}\right) \\
E\left(\varepsilon_{i t}^{a} \varepsilon_{j t}^{m}\right) & E\left(\varepsilon_{i t}^{a} \varepsilon_{j t}^{a}\right)
\end{array}\right] .
$$

Entretanto, os custos são funções de preços de todos setores, sendo estes referentes a bens produzidos interna ou externamente. Por isso, também estão sujeitos aos mesmos fatores comuns que $\mathbf{p}_{i t}$ (ou seja, $\mathbf{c}_{i t}=f\left(\mathbf{d}_{t}, \mathbf{f}_{t} \mid \boldsymbol{\theta}_{i}\right)$ ). Logo, $\mathbf{c}_{i t}$ não pode ser considerado classificadas como um setor de variáveis exógenas, como proposto para a estimação de SUR. Dessa forma, o problema de estimação apresenta-se como aquele proposto, por exemplo, por Pesaran (2006) cujos regressores são endógenos e determina-se uma estrutura multifatorial dos erros.

A decomposição multifatorial dos erros proposta para $\varepsilon_{i t}^{m}$ e $\varepsilon_{i t}^{a}, i=1,2, \ldots, J$, é similar àquela de Pesaran (2006). Considera-se que os erros podem ser divididos em três partes. A primeira é um componente idiossincrático relacionado apenas ao preço específico considerado na equação $\left(v_{i t}^{m}\right.$ e $\left.v_{i t}^{a}\right)$, o que não é correlacionado com os erros das demais unidades do corte transversal e nem entre si. O segundo, representado pelo vetor $q \times 1, \lambda_{i t}$, refere-se àqueles fatores setoriais que afetam tanto $p_{i t}^{m}$ como $p_{i t}^{a}$ simultaneamente no tempo, seja pela competição já citada entre os bens domésticos e importados, ou mesmo eventualmente por algum aspecto intrínseco ao setor. Por fim, o componente que representa os fatores comuns, denotado pelo vetor $r \times 1, \mathbf{f}_{t}$, que afetam todo o sistema, ou seja, todos os setores (e por isso esta parcela da decomposição não é indexada em $i$ ). Representa-se a decomposição multifatorial por:

$$
\begin{aligned}
\varepsilon_{i t}^{m} & =\boldsymbol{\kappa}_{i}^{m} \boldsymbol{\lambda}_{i t}+\boldsymbol{\gamma}_{i}^{m} \mathbf{f}_{t}+v_{i t}^{m} \\
\varepsilon_{i t}^{a} & =\boldsymbol{\kappa}_{i}^{a} \boldsymbol{\lambda}_{i t}+\boldsymbol{\gamma}_{i}^{a} \mathbf{f}_{t}+v_{i t}^{a},
\end{aligned}
$$

sendo $\boldsymbol{\kappa}_{i}^{m}, \boldsymbol{\kappa}_{i}^{a}, \boldsymbol{\gamma}_{i}^{m}$ e $\boldsymbol{\gamma}_{i}^{a}$ são matrizes factor loading com componentes fixos, de modo que cada setor é afetado de maneira diferenciada pelos fatores contidos nos erros.

Uma vez que os componentes setoriais $\boldsymbol{\lambda}_{i t}$ são considerados na estimação por métodos multiequacionais, como VAR ou VECM, a partir da consideração de determinação simultânea entre as variáveis do modelo em forma reduzida. Neste caso, os componentes comuns sistêmicos ainda continuam nos resíduos destas estimações, permanecendo o problema de endogeneidade das variáveis de custo. Pesaran (2006) sugere que então que se estimem as variáveis em um sistema como:

$$
\mathbf{x}_{i t}=\left[\begin{array}{c}
\mathbf{p}_{i t} \\
\mathbf{c}_{i t}
\end{array}\right]=\mathbf{A}_{i} \mathbf{d}_{t}+\mathbf{B}_{i} \mathbf{f}_{t}+\mathbf{u}_{i t} .
$$

Dées et al. (2007) também propõem que $\mathbf{x}_{i t}$ seja representado por um modelo de fatores globais observáveis, $\mathbf{d}_{t}$, e não observáveis, $\mathbf{f}_{t}$, como:

$$
\mathbf{x}_{i t}=\delta_{i 0}+\delta_{i 1} t+\boldsymbol{\Gamma}_{i d} \mathbf{d}_{t}+\boldsymbol{\Gamma}_{i f} \mathbf{f}_{t}+\xi_{i t}, \text { para } i=1,2, \ldots, N ; T=1,2, \ldots, T,
$$


de modo que é possível aproximá-lo a partir de um modelo $\operatorname{VAR}\left(p_{i}\right)$ :

$$
\boldsymbol{\Phi}_{i}\left(L, p_{i}\right)\left(\mathbf{x}_{i t}-\delta_{i 0}-\delta_{i 1} t-\boldsymbol{\Gamma}_{i d} \mathbf{d}_{t}-\boldsymbol{\Gamma}_{i f} \mathbf{f}_{t}\right) \approx \mathbf{v}_{i t}
$$

Dées et al. (2007) afirmam que a presença de fatores comuns não-observáveis torna a estimação do modelo complexa, principalmente na presença de alto $N$, sendo que com a abordagem de Pesaran (2006) obtém-se uma solução relativamente simples para o problema. Este afirma que uma proxy para $\mathbf{f}_{t}$ pode ser obtida em termos de uma média no corte transversal das variáveis internas específicas ao setor, $\mathbf{x}_{i t}$, e dos fatores globais observados, $\mathbf{d}_{t}$. Assim,

$$
\begin{gathered}
\sum_{j=1}^{N} w_{j} \mathbf{x}_{j t}=\sum_{j=1}^{N} w_{j} \delta_{j 0}+\left(\sum_{j=1}^{N} w_{j} \delta_{j 1}\right) t+\left(\sum_{j=1}^{N} w_{j} \boldsymbol{\Gamma}_{j d}\right) \mathbf{d}_{t}+\left(\sum_{j=1}^{N} w_{j} \boldsymbol{\Gamma}_{j f}\right) \mathbf{f}_{t}+\sum_{j=1}^{N} w_{j} \xi_{i t}, \text { ou seja } \\
\mathbf{x}_{t}^{*}=\delta_{0}^{*}+\delta_{1}^{*} t+\boldsymbol{\Gamma}_{d}^{*} \mathbf{d}_{t}+\boldsymbol{\Gamma}_{f}^{*} \mathbf{f}_{t}+\xi_{t}^{*}
\end{gathered}
$$

Sob certas condições que podem ser verificadas em Dées et al. (2007) e Chudik e Pesaran (2016), sendo uma delas que $\Delta \xi_{i t}, i=1, \ldots, N$, sejam covariância-estacionários e fracamente dependentes no corte transversal, é possível provar que

$$
\mathbf{f}_{t} \stackrel{q . m .}{\rightarrow}\left(\boldsymbol{\Gamma}_{f}^{*^{\prime}} \boldsymbol{\Gamma}_{f}^{*}\right)^{-1} \boldsymbol{\Gamma}_{f}^{*}\left(\mathbf{x}_{t}^{*}-\delta_{0}^{*}-\delta_{1}^{*} t-\boldsymbol{\Gamma}_{d}^{*} \mathbf{d}_{t}-\xi^{*}\right)
$$

o que justifica a utilização do vetor de variáveis observáveis $\left(1, t, \mathbf{d}_{t}, \mathbf{x}_{t}^{*}\right)$ como proxy para os fatores comuns não-observáveis. Assim, o modelo $\operatorname{VAR}\left(p_{i}\right)$ pode ser escrito como

$$
\boldsymbol{\Phi}_{i}\left(L, p_{i}\right)\left(\mathbf{x}_{i t}-\tilde{\delta}_{i 0}-\tilde{\delta}_{i 1} t-\tilde{\boldsymbol{\Gamma}}_{i d} \mathbf{d}_{t}-\tilde{\boldsymbol{\Gamma}}_{i f} \mathbf{x}_{t}^{*}\right) \approx \mathbf{v}_{i t}
$$

em que $\tilde{\delta}_{i 0}, \tilde{\delta}_{i 1}, \tilde{\boldsymbol{\Gamma}}_{i d}$ e $\tilde{\boldsymbol{\Gamma}}_{i f}$ são dados em termos de $\delta_{i 0}, \delta_{i 1}, \boldsymbol{\Gamma}_{i d}$ e $\boldsymbol{\Gamma}_{i f}, \delta_{0}^{*}+\xi^{*}, \delta_{1}^{*}, \boldsymbol{\Gamma}_{d}^{*}$ e $\boldsymbol{\Gamma}_{f}^{*}$.

Valendo-se da possibilidade de que os fatores globais de um sistema podem ser aproximados a partir da média ponderada de suas variáveis, aplica-se o GVAR, tal qual foi feito por Dées et al. (2007) para solucionar um problema multi-países, agora para uma estimação multi-setorial. As estimações dos modelos VARX* com cointegração do GVAR dão conta de considerar a simultaneidade na determinação das variáveis de um mesmo setor $\left(\boldsymbol{\lambda}_{i t}\right)$, enquanto $\mathbf{x}_{i t}^{*}=\left(p_{i t}^{m *}, p_{i t}^{a *}, c_{i t}^{e *}, c_{i t}^{d *}\right)^{\prime}$ e o vetor de variáveis globais $\mathbf{d}_{t}$ são uma aproximação de $\mathbf{f}_{t}$ na estimação.

Além de ser usada para obter os chamados fatores comuns para o setor $i$, a ponderação das variáveis dos demais setores dada pelas variáveis externas específicas de $i, \mathbf{x}_{i t}^{*}$, terão papel adicional aqui, o de servir como proxy para os custos domésticos do setor. Como os custos domésticos são, como mencionado anteriormente, ponderações dos preços de insumos e salários, uma vez que $\mathbf{x}_{i t}^{*}$ contém variáveis que são ponderações de preços de produtos das demais atividades da indústria, criadas a partir de pesos que ilustram a estrutura 
de dependência inter-setorial, então estas podem servir como proxy do custo das firmas domésticas. Note que, para a produção doméstica, são necessários insumos nacionais e importados, de maneira que os primeiros podem ser obtidos a partir de $p_{i t}^{a *}$, enquanto que para os segundos uma aproximação seria a partir de $p_{i t}^{m *}$ e $c_{i t}^{e *}$, já que ambos são variáveis que explicam o comportamento dos preços de insumos estrangeiros.

Assim, a dinâmica dos custos domésticos do setor $i$ será vinda de todas as demais unidades do corte transversal da amostra, e os vetores $\mathbf{x}_{i t}$ não conterão a variável $c_{i t}^{d}$. Uma vantagem adicional dessa estratégia é que esta reduz a dimensão do modelo estimado, dado que além de se estimar a dinâmica dos componentes do custo doméstico separadamente setor a setor, não será mais necessário estimar uma equação de $c_{i t}^{d}$ em cada modelo VARX*, para cada $i$. Assim, reduz-se o número de parâmetros a serem estimados, diminuindo a dimensão do modelo.

Por sua vez, como é evidenciado a partir da equação (3.14) e do desenvolvimento da proxy gerada para $\mathbf{f}_{t}$, é possível inserir variáveis globais no modelo (como já discutido na Seção 2.4), auxiliando na composição de tal proxy. Haja visto que o câmbio é invariante ao setor (como evidenciado nas equações (3.8) e (3.9)), pois não é definido exclusivamente a partir do comportamento de um só setor, este será considerado dentro do vetor de fatores globais observáveis, $\mathbf{d}_{t}$.

Como evidenciado pela literatura, flutuações cambiais são frequentemente consideradas exógenas aos preços quando se estimam as chamadas regressões de repasse cambial. Como crítica a esse tipo de abordagem de estimação, Forbes, Hjortsoe e Nenova (2018) afirmam que é preciso considerar que o câmbio também sofre pressões vindas da própria variável, bem como de outros fatores que também afetam os preços. Por exemplo, a partir da decomposição de Cholesky nos modelos VAR, como estimados por Faruqee (2006) e McCarthy (2007), choques cambiais têm efeito contemporâneo sobre os preços, enquanto choques nestes afetam o câmbio com, ao menos, um período de defasagem. Logo, considera-se a interdependência entre tais variáveis neste de tipo de estrutura.

Assim, a introdução do câmbio nominal como variável global, dentro da estrutura do GVAR, é feita no âmbito do que se chamou anteriormente de unidade dominante. A partir dessa configuração, o câmbio é variável explicativa para os preços ao atacado e de importação, e ao mesmo tempo faz parte de um VARX*, como descrito pela equação (2.20). Nesta estrutura, permite-se a existência de efeito de retroalimentação das variáveis de todo o sistema para as variáveis globais, sendo que tal efeito vem das defasagens das médias das variáveis setoriais, $\mathbf{x}_{i t}$, não considerando efeitos contemporâneos destas ${ }^{26}$. A partir de tal configuração, o câmbio

\footnotetext{
${ }^{26}$ Em suma, utiliza-se a hipótese de Choudhri, Faruqee e Hakura (2005), que baseia a ordenação das variáveis no VAR para o uso da decomposição de Cholesky, de que os preços são observados com, ao menos, um período de defasagem, fazendo com que choques cambiais não estejam contemporaneamente correlacionados com os preços. Apesar de mais convidativa para dados mensais, esta hipótese pode também ser válida, no caso de dados trimestrais, para a maioria dos preços.
} 
também é função dos fatores comuns, $\mathbf{f}_{t}$, de modo que sua dinâmica será também explicada por estes, ou seja, conjuntamente com o resto do sistema.

Para compor o vetor de fatores globais observáveis, insere-se uma outra fonte de choques que afeta todo o sistema: o preço do barril de petróleo $\left(P_{t}^{o}\right)$. A commodity tem papel importante nos processos produtivos em todo o globo, uma vez que é matéria prima de uma gama de produtos consumidos em todo o mundo. Todavia, o preço do barril é afetado por diversos fatores além da demanda das firmas e os preços dos seus produtos, como, por exemplo, conflitos geopolíticos, incertezas no cenário econômico internacional etc. Com isso, tem-se a hipótese de que a sua inserção como variável global se faz necessária, pois seu comportamento pode não ser captado pela proxy de fatores comuns obtidos por meio das variáveis externas específicas. Esta então também fará parte do vetor de logaritmos das variáveis globais, $\left(e_{t}, p_{t}^{o}\right)$, e da unidade dominante, ou seja, também poderá existir retroalimentação do sistema sobre a variável, além do fato dela e o câmbio serem modeladas conjuntamente dentro de um VARX*, permitindo a captura de relações existentes entre elas.

Diversos trabalhos na literatura corroboram a importância do preço do petróleo para a definição de preços e do grau de repasse cambial. Por exemplo, Razafindrabe (2016) utiliza tal variável na estimação do estado-estacionário das variáveis de seu modelo DSGE, mostrando que ela tem seu papel na determinação do comportamento não apenas do curto, mas como do longo prazo de diversas economias. Ademais, McCarthy (2007) e Ito e Sato (2008) incluem esta variável no seu modelo VAR como parte do sistema de determinação de preços, ao passo que Forbes, Hjortsoe e Nenova (2018) utilizam choques de longa duração dos preços do petróleo na identificação da parcela da variação cambial que se deve ao que chamam de "choques globais permanentes". Além do mais, dentro do próprio arcabouço do GVAR, esta variável se mostra bastante relevante na modelagem das interações entre países (que é a aplicação mais comum da metodologia), sendo usada como variável global mesmo nos trabalhos seminais que desenvolvem o GVAR, como em Pesaran, Schuermann e Weiner (2004) e Dées et al. (2007).

Dessa forma, apesar da estrutura analítica de Hooper e Mann (1989) trazer importantes considerações, como o fato dos preços internos dependerem dos externos e vice-versa, entre outros aspectos, ela deixa de fora as diversas formas como todas as atividades da economia estão interligadas. Tendo isto em vista, existe vantagem no uso de um arcabouço econométrico de equações simultâneas, sendo então necessário o ajuste da estrutura vinda de uma literatura voltada para modelos de Organização Industrial, combinando-a com características de modelos macroeconômicos, como se propõe no presente trabalho. 


\subsection{Base de dados}

Como foi sugerido pela estratégia empírica desenvolvida, seriam necessários dados de (1) preços de importação, (2) preços aos produtores, ou também denominado como ao atacado, (3) custo doméstico, (4) custo externo, (5) câmbio nominal, e (6) preço do petróleo. Esta estrutura de dados para modelos econométricos é bastante comum nos trabalhos de repasse cambial, uma vez que representa bem a dinâmica da cadeia de transmissão de choques, como foi buscado por trabalhos como Belaisch (2003) e McCarthy (2007), entre outros que também usam modelos VAR. A estimação se valerá do logaritmo das variáveis com periodicidade trimestral.

Seguindo a ordem de disposição denotada acima, serão descritos os dados utilizados para cada uma das variáveis elencadas. Começando pelos preços de importação em moeda estrangeira (neste caso, medidos em dólares estadunidenses), a base de dados utilizada é a do Índice Preços das Importações Brasileiras (IPI) calculado pela Fundação Centro de Estudos do Comércio Exterior (Funcex). Para os dados de preços ao produtor, também denominados como preços ao atacado, são utilizadas as aberturas setoriais do Índice de Preços ao Produtor Amplo (IPA) do Índice Geral de Preços - Disponibilidade Interna (IGP-DI) calculado pela Fundação Getúlio Vargas (FGV).

Os custos domésticos, como já definido anteriormente, terão como proxy as variáveis externas específicas do setor que são as médias ponderadas dos preços dos demais setores da indústria. Por sua vez, é utilizado como proxy dos custos das firmas estrangeiras o Índice de Preços das Importações dos Estados Unidos, calculado pelo Bureau of Labour Statistics (BLS). Tal suposição é justificada por meio da teoria que indica que os preços são composições do markup e do custo marginal, e uma vez que as importações dos Estados Unidos advém de diversos países, combinado ao fato de ser um mercado competitivo, o que leva a um markup baixo, os preços destas devem refletir os custos mundiais de tais setores.

Os dados da taxa de câmbio nominal foram obtidos por meio do Sistema Gerenciador de Séries Temporais (SGS) do Banco Central do Brasil (BCB). Mais precisamente, é útilizada a série do câmbio de venda para a média do período, sendo que a unidade da série está em reais por dólar. Já para representar o preço do petróleo, utilizou-se a série de Crude Oil Prices: Brent (dólar/barril) obtida pelo Federal Reserve Economic Data (FRED) do Federal Reserve Bank of St. Louis, uma vez que este é o dado considerado como referência para tal commodity pela Agência Nacional do Petróleo, Gás Natural e Biocombustíveis (ANP).

Uma questão enfrentada aqui foi a da compatibilização das classificações dos setores, uma vez que o índice de preços de importação dos Estados Unidos difere do sistema adotado no Brasil, que é a Classificação Nacional de Atividades Econômicas (CNAE). A pesquisa do BLS era anteriormente divulgada seguindo o Standard International Trade Classification 
(SITC) que bastante se assemelha à CNAE. Todavia, o BLS deixou de utilizar este sistema de classficação, passando a divulgar seus pesquisas usando o North American Industry Classification System (NAICS), que também é similar à CNAE, mas os dados do índice de preço das importações nesta classificação só existem a partir do final de 2005. Tal restrição resultaria em um corte significativo das séries históricas utilizadas no exercício.

A fim de evitar a redução da base de dados, valeu-se das demais classificações nas quais o índice de preços é divulgado pelo BLS: a Harmonized System (HS) e a End of Use (EoU), para as quais existem séries mais longas. Para isso, primeiramente, foram selecionados os produtos disponíveis pelas classificações HS e EoU, para unir os preços das aberturas que compõem cada setor. Em seguida, utilizando os dados de valor das importações disponibilizados pela Funcex, que têm início em 2005, calculou-se o peso de cada setor no total das importações brasileiras a partir da média dos pesos entre 2005 e 2017, para assim ponderar os itens das classificações EoU e HS.

A tentativa era criar um índice dos custos internacionais, dando pesos para os setores de acordo com a sua importância sobre os preços de importados brasileiros. O resultado obtido foi que as séries ponderadas tinham o mesmo comportamento que aquelas calculadas pelo BLS a partir do NAICS. Assim, o exercício foi capaz de recompor, de maneira muito satisfatória, as séries originais. Logo, concluiu-se que a proxy continuaria a servir para os propósitos deste trabalho, não pois apenas seria capaz de representar os custos mundiais, mas também por recriar os dados originais indisponíveis. Assim, os índices ponderados obtidos foram utilizados para estimar as séries do BLS para o período de 1999 a 2005, que são os dados faltantes da classificação NAICS.

Por fim, é necessário ressaltar que a CNAE divide a indústria de transformação em 24 setores, porém a FGV ao calcular o IPA não inclui o setor de código 18 (Impressão e Reprodução de Gravações) no índice, o que impossibilita seu uso nas estimações. Além disso, o GVAR necessita de uma matriz de ponderação dos setores, sendo que para isso é utilizada a matriz de insumo-produto estimada usando dados do Sistema de Contas Nacionais (SCN) ${ }^{27}$. A questão é que o SCN, apesar de usar a CNAE, coloca os setores de Produtos Diversos e Móveis como apenas um. Desse modo, para o IPI dos Estados Unidos e o brasileiro foi utilizado o peso médio entre 2005 e 2017 do valor das importações brasileiras para cada um destes; já o IPA da FGV foi reponderado utilizando os pesos do próprio indicador, que são disponibilizados juntamente com os índices de preço. Outro setor da indústria de transformação que não é incorporado é o de Manutenção, Reparação e Instalação de Máquinas e Equipamentos, mas este não faz parte nem da pesquisa da Funcex, e nem da FGV.

\footnotetext{
${ }^{27} \mathrm{~A}$ discussão da estimação dessa matriz pode ser encontrada na Seção 3.3.
} 


\begin{tabular}{cl}
\hline Código CNAE & \multicolumn{1}{c}{ Setores } \\
\hline \hline 10 & Fabricação de Produtos Alimentícios \\
11 & Fabricação de Bebidas \\
12 & Fabricação de Produtos do Fumo \\
13 & Fabricação de Produtos Têxteis \\
14 & Fabricação de Produtos do Vestuário e Acessórios \\
15 & Fabricação de Produtos de Couro \\
16 & Fabricação de Produtos de Madeira \\
17 & Fabricação de Celulose, Papel e Produtos de Papel \\
19 & Fabricação de Coque, de Derivados de Petróleo e Biocombustíveis \\
20 & Fabricação de Produtos Químicos \\
21 & Fabricação de Produtos Farmoquímicos e Farmacêuticos \\
22 & Fabricação de Produtos de Borracha e Material de Plástico \\
23 & Fabricação de Produtos de Minerais Não-Metálicos \\
24 & Metalurgia \\
25 & Fabricação de Produtos de Metal, Exceto Máquinas e Equipamentos \\
26 & Fabricação de Equipamentos de Informática, Eletrônicos e Ópticos \\
27 & Fabricação de Máquinas, Aparelhos e Materiais Elétricos \\
28 & Fabricação de Máquinas e Equipamentos \\
29 & Fabricação de Veículos Automotores, Reboques e Carrocerias \\
30 & Fabricação de Outros Equipamentos de Transporte \\
$31 \& 32$ & Fabricação de Móveis e de Produtos Diversos \\
\hline
\end{tabular}

Tabela 3.1 - Setores da indústria de transformação

\subsection{A ponderação dos setores}

Como discutido, para a construção das variáveis externas específicas de cada setor, é preciso uma matriz de ponderação $\mathbf{W}_{i}$ representando a importância de todos os demais setores na dinâmica do setor $i$. A ferramenta econômica para melhor explicar as interdependências entre os setores é a matriz insumo-produto, que representa as trocas intermediárias entre as atividades para produção dos seus respectivos bens finais.

Para a obtenção da matriz de pesos foi então utilizada a matriz coeficientes técnicos ${ }^{28}$ calculada a partir das matriz insumo-produto brasileira de 68 setores, a qual é construída utilizando os dados do Sistema de Contas Nacionais (SCN) a partir da metodologia desenvolvida por Guilhoto e Sesso Filho (2005) e Guilhoto e Sesso Filho $(2010)^{29}$. Os pesos foram obtidos,

\footnotetext{
${ }^{28} \mathrm{O}$ coeficiente técnico representa o valor de consumo intermediário que um setor precisa para a produção de uma unidade monetária de produto final, ou seja, a razão entre o consumo intermediário de determinado setor, vindo dele mesmo ou de outro, e seu produto final (MILLER; BLAIR, 2009, p. 16). Logo, a soma de todos os coeficientes do setor é o valor de consumo intermediário de qualquer setor necessário para a produção de uma unidade de produto, sendo a partir desta ideia que surgem os pesos aqui utilizados.

${ }^{29}$ As matrizes de insumo-produto estimadas por tal metodologia podem ser obtidas na página do Núcleo de Estudos Regionais e Urbanos da Universidade de São Paulo (NEREUS-USP) <http://www.usp.br/nereus/ ?fontes=dados-matrizes $>$.
} 
primeiramente, selecionando apenas os setores que compõem a indústria de transformação e que constam na Tabela 3.1, e então dividindo o coeficiente técnico, por exemplo, do consumo intermediário do setor $i$ vindo do setor $j$ pela soma de todos os coeficientes de $i$.

Uma vez que $w_{i i}=0$, ou seja, as informações referentes ao setor $i$ não são incluídas em $\mathbf{x}_{i t}^{*}$, a diagonal principal da matriz de pesos é substituída por zeros e as colunas são reponderadas a fim de que suas entradas somem um. Deste modo, a matriz de coeficientes técnicos passa a ser uma matriz cujas colunas representam o setor de referência dos pesos contidos nela, e nas linhas está o peso que um setor tem para aquele referenciado na coluna. Assim, as matrizes $\mathbf{W}_{i}$ para cada setor serão obtidas pelas colunas da matriz de pesos construída.

Devido a mudanças na CNAE por parte do Instituto Brasileiro de Geografia e Estatística (IBGE), os dados do SCN com a nova classificação não estão disponíveis desde 1999, que será considerado o período inicial desta análise. Em virtude disso, havendo apenas a possibilidade de estimar as matrizes de insumo-produto na classificação desejada entre 2010 e 2013, foi utilizada uma média dos pesos obtidos a partir destas ${ }^{30}$.

Em suma, a ponderação construída terá o papel de representar aqui a importância que o restante da indústria de transformação tem sobre cada um dos setores que fazem parte dela. Desse modo, nos modelos específicos de cada setor, a determinação de um preço terá como variável dependente a variação, presente e passada, dos demais setores da indústria, representando variações nos preços dos seus insumos, e uma proxy dos fatores comuns que afetam o processo de precificação de toda a indústria.

Por fim, é importante salientar que além dos pesos utilizados pelo GVAR para o cálculo das variáveis externas específicas, o uso de variáveis globais como unidade dominante também demanda uma estrutura de ponderação. Neste caso, como discutido, a unidade dominante sofre efeito feedback das variáveis do sistema vindo das defasagens de $\mathbf{x}_{\omega t}=\mathbf{W}_{\omega} \mathbf{x}_{t}$, havendo então a necessidade de inserir uma matriz $\mathbf{W}_{\omega}$ na estimação. Para isso são utilizados os pesos calculados pelo IBGE para construção do índice de produção da indústria brasileira da Pesquisa Industrial Mensal - Produção Física (PIM-PF).

\subsection{Estimação do repasse cambial}

O repasse cambial, como já dito anteriormente, é a elasticidade dos preços de um país ao câmbio nominal $\left(e_{P, E}\right)$, ou seja, o quanto uma variação de um ponto percentual no câmbio afeta o preço. Para estimar tal elasticidade, a literatura valeu-se de diferentes métodos, sendo que um dos mais usados é aquele que ficou conhecido como "regressão de repasse" (“pass-through regression”). Bache e Naug (2007) argumentam que esse tipo de estimação não

\footnotetext{
${ }^{30}$ A hipótese de que a matriz de pesos é invariante no tempo para uma análise usando dados trimestrais não é uma hipótese tão restritiva de acordo com Pesaran, Schuermann e Weiner (2004)
} 
leva em conta o mecanismo das expectativas, sendo que se espera que os agentes precifiquem olhando para o futuro.

$$
e_{P, E}=\frac{\Delta \% P}{\Delta \% E}
$$

De tal modo, os coeficientes da regressão de repasse dependeriam dos parâmetros de regras de precificação e de expectativas, o que por sua vez faz com que o mecanismo das expectativas dependa da política monetária, ficando a estimação sujeita a Críticas de Lucas (1976) (BACHE; NAUG, 2007). Na literatura, a ligação do grau de repasse cambial aos preços com a política monetária já foi explorado diversas vezes, como por Taylor (2000) que afirma que o tamanho do repasse depende do ambiente inflacionário, o que está diretamente ligado à política monetária.

Por sua vez, como demonstrado por Dées et al. (2007), o GVAR pode ser representado por uma aproximação de um modelo de fatores comuns que, dentre outros aspectos, contêm também os efeitos do ambiente inflacionário. Ademais, Garratt et al. (2006) exploram o importante papel da abordagem do VAR com cointegração (denotado pelos autores como CVAR) como alterativa aos modelos DSGE. Garratt et al. (2006) destacam então o GVAR como uma das alternativas trazidas pela literatura de CVAR aos DSGE.

Segundo Chudik e Pesaran (2016), os modelos VARX* do GVAR se assimilam com os small open economy macroeconomic models, em que as variáveis internas específicas da unidade do corte transversal são modeladas condicionais ao resto do sistema de "equilíbrio geral". O shrinkage dos dados, realizado quando se define o vetor $\mathbf{x}^{*}$, resolve o problema de dimensionalidade deste tipo de modelo.

Assim, tendo em vista tais características do GVAR, a estimação por este método passa a ser uma alternativa viável para contornar a Crítica de Lucas (1976). Então, tendo em mãos tal método e suas ferramentas de análise, segue-se Belaisch (2003) que utiliza funções de resposta ao impulso para calcular os graus de repasse cambial aos preços brasileiros. Este modo de calcular a elasticidade dos preços ao câmbio também foi utilizado em outros trabalhos da literatura de repasse como, por exemplo, por Ito e Sato (2008) e Faruqee (2006).

Belaisch (2003) descreve que os coeficientes de repasse acumulado podem ser derivados a partir das funções de resposta ao impulso de um modelo VAR, representando assim a trajetória do repasse do choque no período zero de $1 \%$ no câmbio pelo número de períodos desejados. O coeficiente de repasse acumulado é dado por

$$
P T_{t, t+j}=\frac{\sum_{j=1}^{T} \Delta P_{t, t+j}}{\sum_{j=1}^{T} \Delta E_{t, t+j}}
$$

sendo que $\Delta P_{t, t+j}$ é a resposta ao impulso da variação do preço a um choque no câmbio nominal depois de $j$ meses, enquanto que $\Delta E_{t, t+j}$ denota a resposta ao impulso da variação 
do câmbio ${ }^{31}$. Destaca-se aqui que, uma vez que o modelo utiliza o nível de preços e não a variação dos preços (ou mesmo do câmbio), a resposta ao impulso obtida não é aquela referente à variação do preço, mas sim a do próprio preço. Além disso, é possível distinguir que, mesmo quando se estimam os VARX* dos setores considerando a presença de cointegração e da unidade dominante (que contém as variáveis globais exógenas, ou seja, os modelos são estimados usando as primeiras diferenças das variáveis), para a solução do modelo global, o vetor de variáveis de interesse é $\mathbf{x}_{t}$ (ou $\mathbf{y}_{t}=\left(\boldsymbol{\omega}_{t}^{\prime}, \mathbf{x}_{t}\right)$, mais especificamente), e é sobre ele que é aplicado o choque considerado na GIRF.

Logo, como o acumulado da taxa de variação do preço representado por $\sum_{j=1}^{T} \Delta P_{t, t+j}$ representa a variação do nível de preço entre $t$ e $t+j$, e o modelo global tem suas variáveis consideradas em nível, tal acumulado já é obtido a partir da resposta ao impulso estimada por tal modelo global. Deste modo, no presente caso, não é preciso acumular as respostas as estimativas da GIRF. Assim, para o cálculo do grau de repasse de um choque no câmbio nominal, basta dividir a GIRF referente à resposta do preço de interesse por aquela que representa o comportamento do câmbio resultante do choque ocorrido nele mesmo.

Ao se referir ao que Belaisch (2003) denomina como coeficiente de repasse acumulado, Ito e Sato (2008) por sua vez o chamam de "dynamic exchange rate pass-through elasticity". Este coeficiente mostra que o grau de repasse cambial não é, simplesmente, o efeito de um choque do câmbio sobre os preços, isso porque uma variação cambial afeta as realizações posteriores da própria variável. Assim, como o câmbio continua a se movimentar, os preços continuam a ser influenciados por seus movimentos, de maneira que a resposta os preços precisa ser corrigida. Por esta razão, este coeficiente de repasse é denominado por Ito e Sato (2008) como "dinâmico".

Assim, o grau de repasse a ser estimado neste trabalho, a partir de um modelo GVAR, oferece a possibilidade de verificar o efeito de um choque cambial ao longo de qualquer horizonte desejado. Ademais, esta fórmula não oferece apenas a possibilidade de calcular a elasticidade das variáveis ao câmbio, mas também a qualquer outra. Deste modo, assim como para o câmbio nominal, os preços das commodities (no caso, o preço do petróleo) também são fatores extremamente importantes para a determinação dos preços internos e externos dos produtos consumidos pelas economias de todo globo.

\footnotetext{
${ }^{31}$ Note que, uma vez que os preços de importação estão medidos em dólar estadunidense, para obter o repasse de um choque do câmbio a estes, quando medidos em real, é preciso somar um à medida definida em (3.20).
} 



\section{RESULTADOS}

Nesta seção serão apresentados primeiramente os resultados das estimações do modelo GVAR obtidas utilizando o GVAR Toolbox de Smith e Galesi (2014), como por exemplo, o número de relações de cointegração encontradas, os testes de exogeneidade fraca e funções de resposta ao impulso generalizadas. De tal forma, busca-se caracterizar o sistema estimado pelo método do GVAR e verificar a validade de hipóteses necessárias para validar o modelo escolhido.

Em seguida, direcionando para o exercício proposto aqui serão explicitados os resultados do repasse cambial (tanto de curto como de longo prazo) estimado de acordo com o método utilizado por Belaisch (2003) e Ito e Sato (2008). Na literatura brasileira, a estimação de tais coeficientes de maneira desagregada ainda é pouco explorada e as estimativas de Kannebley Júnior, Reis e Toneto Júnior (2016) não são comparáveis com as obtidas aqui, pois estas vêm dos coeficientes do vetor de cointegração, além de não ser capaz de produzir os coeficientes de todos os setores observados na indústria.

Por fim, vale-se das vantagens trazidas por um modelo global, em que se insere como variável global não apenas a taxa de câmbio nominal, mas também os preços do barril de petróleo. Tal preço representa, dentre outros fatores, o estado do mercado de commodities e o preço de um importante insumo para diversas atividades produtivas, ou seja, representa um "choque de oferta".

\subsection{Estimação do GVAR}

Como já discutido, a estimação do modelo GVAR é um procedimento em duas etapas. A primeira é a estimação dos modelos VARX* que representam o comportamento dos setores da indústria de transformação brasileira. Logo, inicia-se com a especificação e estimação destes.

Primeiramente, para a estimação de tais modelos, é preciso definir o número de defasagens desejado para as variáveis internas específicas (denotadas por $p_{i}$ ) e das externas específicas (denotadas por $q_{i}$ ) para todos os setores $i$. Deste modo, foi utilizado o critério de informação Akaike (AIC) para a escolha das ordens dos VARX* permitindo que, no máximo, entrassem no modelo duas defasagens de $\mathbf{x}_{i t}$, e uma de $\mathbf{x}_{i t}^{* 32}$. Os resultados estão dispostos na Tabela 4.1.

\footnotetext{
${ }^{32}$ Tal decisão é tomada em prol da obtenção de um modelo mais parcimonioso, haja vista o número de parâmetros a serem estimados e a pequena amostra para o caso brasileiro. Ademais, também devido à limitação dos dados, outros modelos estimados utilizando o GVAR também utilizaram o mesmo número de defasagens máximas como Dées et al. (2007).
} 


\begin{tabular}{lll}
\hline \multirow{2}{*}{\multicolumn{1}{c}{ Setores }} & \multicolumn{2}{c}{ Ordem do VARX* } \\
\cline { 2 - 3 } & $p_{i}$ & $q_{i}$ \\
\hline \hline Alimentos & 1 & 1 \\
Bebidas & 1 & 1 \\
Fumo & 1 & 1 \\
Têxtil & 1 & 1 \\
Vestuário & 2 & 1 \\
Couro & 1 & 1 \\
Madeira & 1 & 1 \\
Papel e Celulose & 2 & 1 \\
Derivados de petróleo & 1 & 1 \\
Químicos & 1 & 1 \\
Farmoquímicos & 2 & 1 \\
Borracha e Plástico & 2 & 1 \\
Minerais não metálicos & 2 & 1 \\
Metalurgia & 2 & 1 \\
Produtos de metal & 1 & 1 \\
Informática & 1 & 1 \\
Máquinas elétricas & 1 & 1 \\
Máquinas e equipamentos & 2 & 1 \\
Veículos & 1 & 1 \\
Outros eq. transporte & 1 & 1 \\
Móveis e Prod. diversos & 2 & 1 \\
\hline
\end{tabular}

Tabela 4.1 - Ordem dos modelos VARX* setoriais

Outra importante característica dos modelos setoriais é a possibilidade de existência de relações de cointegração entre as variáveis que eles contêm. Para tanto, é preciso primeiro definir qual o tratamento dos termos determinísticos dentro dos modelos, sendo que foi escolhido para todos os setores o que ficou convencionado como "Caso IV" (o intercepto é irrestrito, enquanto a tendência é restrita para ficar dentro do espaço de cointegração) ${ }^{33}$.

Definido o caso determinístico, são calculadas as estatísticas do traço e do máximo autovalor de Johansen (1991) como definidas por Pesaran, Shin e Smith (2000) para modelos que contêm variáveis fracamente exógenas que são I(1). É utilizado por padrão um nível de significância de $5 \%$, sendo que os valores críticos para modelos contendo variáveis fracamente exógenas são obtidos por MacKinnon, Haug e Michelis (1999). Uma vez que são diversos setores, dispõe-se na Tabela 4.2 o número de relações de cointegração identificadas pelo teste do $\operatorname{traço}^{34}$.

\footnotetext{
${ }^{33}$ Este caso foi escolhido pois nas estimações realizadas setor a setor, verificou-se que a tendência determinística se mostrava estatisticamente significante. Ademais, é possível verificar que o comportamento das variáveis de níveis de preços, tanto internas quando externas específicas ao setor, apresentam muitas vezes comportamento que se assemelha à tendência linear, e o vetor cointegração incorpora ambos tipos de variáveis, não apenas as variáveis contidas em cada $\mathbf{x}_{i t}$, o que também pode ser uma justificativa para o uso do Caso IV.

${ }^{34}$ As estimativas completas dos vetores de cointegração podem ser encontradas no Apêndice B.
} 


\begin{tabular}{lc}
\hline \multicolumn{1}{c}{ Setores } & $\begin{array}{c}\text { No de } \\
\text { relações de } \\
\text { cointegração }\end{array}$ \\
\hline \hline Alimentos & 0 \\
Bebidas & 2 \\
Fumo & 1 \\
Têxtil & 1 \\
Vestuário & 2 \\
Couro & $3^{\dagger}$ \\
Madeira & 2 \\
Papel e Celulose & 2 \\
Derivados de petróleo & 2 \\
Químicos & 2 \\
Farmoquímicos & 2 \\
Borracha e Plástico & 1 \\
Minerais não metálicos & 1 \\
Metalurgia & 1 \\
Produtos de metal & 2 \\
Informática & $3^{\dagger}$ \\
Máquinas elétricas & 2 \\
Máquinas e equipamentos & 2 \\
Veículos & 2 \\
Outros eq. transporte & $3^{\dagger}$ \\
Móveis e Prod. diversos & 1 \\
\hline
\end{tabular}

†: "Posto completo"

Tabela 4.2 - Número de relações de cointegração por setor

Um fato a ser ressaltado aqui é a indicação feita na Tabela 4.2 de que três setores apresentam "posto completo" 35 . Para o teste de Johansen (1991), a conclusão de que existe posto completo na matriz de coeficientes usualmente denotada por $\boldsymbol{\Pi}_{i}=-\boldsymbol{\alpha}_{i} \boldsymbol{\beta}_{i}^{\prime}$, indica que as variáveis dentro do vetor de endógenas são estacionárias.

Todavia, no caso aqui apresentado, a matriz $\Pi_{i}$ não contém os coeficientes do vetor $\mathbf{x}_{i t}$, como em um VECM, mas sim do vetor $\boldsymbol{\zeta}_{i, t-1}=\left(\mathbf{z}_{i, t-1}^{\prime}, \mathbf{d}_{t-1}^{\prime}\right)$, como definido na Equação (2.16). Logo, a existência de três relações de cointegração para um VARX* que possui três variáveis endógenas não indica estacionariedade, mas sim a existência de relações de longo prazo entre as demais variáveis inseridas no modelo, como as variáveis externas específicas $\left(\mathbf{x}_{i t}^{*}\right)$ e globais $\left(\mathbf{d}_{t}\right)$.

Como já discutido anteriormente, a estimação do GVAR se baseia na hipótese de que as variáveis externas específicas e globais podem ser consideradas como fracamente exógenas.

\footnotetext{
${ }^{35}$ Testou-se a retirada do termo de tendência determinística do vetor de cointegração para tais setores, a fim de verificar se este não era responsável pelo resultado de um posto completo. Todavia, tal mudança não resultou em redução do número de relações de cointegração para tais setores.
} 
O resultado do teste para tal hipótese pode ser verificado na Tabela 4.3, sendo que a hipótese não é testada para o setor de Alimentos, pois não se encontraram relações de cointegração para este. Observa-se que para apenas uma variável é rejeitada a hipótese nula, que é o caso da proxy de custo externo para o setor de Couro.

\begin{tabular}{lccccccc}
\hline \multicolumn{1}{c}{ Setores } & Teste F & Crít. (5\%) & $p^{m *}$ & $p^{a *}$ & $c^{e *}$ & $e$ & $p^{o}$ \\
\hline \hline Alimentos & $\mathrm{F}(0,55)$ & - & - & - & - & - & - \\
Bebidas & $\mathrm{F}(2,58)$ & 3.156 & 2.729 & 1.752 & 0.854 & 1.623 & 0.131 \\
Fumo & $\mathrm{F}(1,63)$ & 3.993 & 1.124 & 0.069 & 0.016 & 0.249 & 0.031 \\
Têxtil & $\mathrm{F}(1,63)$ & 3.993 & 0.278 & 0.888 & 0.013 & 1.231 & 0.000 \\
Vestuário & $\mathrm{F}(2,62)$ & 3.145 & 1.598 & 0.362 & 1.537 & 1.355 & 1.104 \\
Couro & $\mathrm{F}(3,61)$ & 2.755 & 1.891 & 2.251 & $5.413^{\dagger}$ & 1.018 & 1.258 \\
Madeira & $\mathrm{F}(2,62)$ & 3.145 & 0.013 & 0.703 & 0.229 & 0.360 & 1.108 \\
Papel e Celulose & $\mathrm{F}(2,62)$ & 3.145 & 0.353 & 1.914 & 1.089 & 0.682 & 0.346 \\
Derivados de petróleo & $\mathrm{F}(2,62)$ & 3.145 & 0.815 & 0.027 & 0.199 & 0.763 & 0.006 \\
Químicos & $\mathrm{F}(2,62)$ & 3.145 & 2.901 & 1.915 & 2.121 & 1.821 & 2.060 \\
Farmoquímicos & $\mathrm{F}(2,62)$ & 3.145 & 0.861 & 0.519 & 1.383 & 2.213 & 1.001 \\
Borracha e Plástico & $\mathrm{F}(1,63)$ & 3.993 & 0.591 & 0.135 & 1.301 & 2.725 & 1.132 \\
Minerais não metálicos & $\mathrm{F}(1,54)$ & 4.020 & 0.035 & 0.197 & 0.210 & 0.112 & 0.004 \\
Metalurgia & $\mathrm{F}(1,63)$ & 3.993 & 1.194 & 1.784 & 0.192 & 0.754 & 0.154 \\
Produtos de metal & $\mathrm{F}(2,62)$ & 3.145 & 0.330 & 1.804 & 1.466 & 1.241 & 0.943 \\
Informática & $\mathrm{F}(3,61)$ & 2.755 & 0.351 & 0.122 & 1.333 & 1.210 & 1.092 \\
Máquinas elétricas & $\mathrm{F}(2,62)$ & 3.145 & 1.625 & 2.958 & 1.537 & 0.107 & 1.176 \\
Máquinas e equipamentos & $\mathrm{F}(2,62)$ & 3.145 & 0.031 & 0.617 & 0.297 & 0.596 & 0.995 \\
Veículos & $\mathrm{F}(2,62)$ & 3.145 & 0.905 & 0.556 & 2.557 & 2.665 & 1.742 \\
Outros eq. transporte & $\mathrm{F}(3,61)$ & 2.755 & 0.321 & 1.698 & 2.401 & 1.313 & 1.788 \\
Móveis e Prod. diversos & $\mathrm{F}(1,63)$ & 3.993 & 0.080 & 0.042 & 1.664 & 0.189 & 2.647 \\
\hline
\end{tabular}

$\dagger$ : Rejeita hipótese nula de exogeneidade fraca a $5 \%$.

Tabela 4.3 - Teste de exogeneidade fraca

Haja vista a importância da hipótese para a validade da estimação do modelo, a rejeição da hipótese de exogeneidade para uma variável externa específica poderia ser uma fonte de preocupação a respeito da validade do exercício realizado. Todavia, Dées et al. (2007) encontram problema similar para uma das variáveis externas específicas do Reino Unido ${ }^{36}$, apontando que tal rejeição seria um problema para a estimação caso fosse uma unidade do corte transversal como o bloco de países da Zona do Euro ou os Estados Unidos, que são países com alto peso na economia mundial. Assim, no caso deste trabalho, o risco de invalidação do exercício surge a depender do setor que estiver envolvido, ao passo que o setor de Couro não possui grande peso dentro da indústria de transformação, de acordo com os pesos da PIM-PF.

Outro exemplo encontrado na literatura do GVAR para casos em que há rejeição da

\footnotetext{
${ }^{36}$ Veja Tabela IV de Dées et al. (2007).
} 
nula para o teste de exogeneidade fraca foi encontrado em Hebous e Zimmermann (2013). Enquanto Dées et al. (2007) não fornecerem extensa justificativa de por que não haveria problema com o resultado do teste, Hebous e Zimmermann (2013) observam que, ao rejeitar a hipótese nula, em alguns poucos casos para o modelo global em tal teste, não se gera maiores complicações. Isso pois os autores destacam que existe rejeição, mas ao final afirmam que o resultado geral do teste corrobora a especificação utilizada. No presente caso, o resultado geral é bastante positivo dado que apenas uma variável externa específica, de um setor com baixo peso dentro do agregado, rejeita a hipótese de exogeneidade fraca, em vista da dimensão do modelo multi-setores.

Este trabalho baseia-se nos setores da indústria de transformação do Brasil, ou seja, vale-se de um número relativamente grande de unidades no corte transversal do GVAR. Dessa forma, uma vez que o setor de Couro tem um baixo peso no agregado da indústria de transformação, cerca de 1,8\% de acordo com os dados da PIM-PF, como em outros casos documentados da estimação do GVAR (por exemplo, a justicativa de Dées et al. (2007)), considera-se o ajuste geral do modelo, desprezando este caso pontual.

\subsection{Estimação da função de resposta ao impulso generalizada}

Conforme discutido anteriormente, na literatura do GVAR, a função de resposta ao impulso generalizada foi adotada em vista de suas várias vantagens para modelos de alta dimensão quando comparada com o modo de tradicional de análise, que se baseia na ortogonalização dos resíduos. Primeiramente, foi observado o impacto de um choque de um desvio padrão no câmbio sob as variáveis de preços de importação e ao atacado, que são os principais focos neste trabalho. Em seguida, também são apresentadas as respostas ao choque de um desvio padrão sobre o preço do petróleo. Os resultados apresentados para as GIRFs são para as suas medianas estimadas usando bootstrap (considerando 1000 replicações), com bandas de confiança de $90 \%$.

\subsubsection{Respostas ao choque cambial}

Nesta seção, dispõem-se as estimativas das GIRFs para um choque de um desvio padrão do câmbio nominal. Primeiro, são apresentadas na Figura 4.1 as respostas do próprio câmbio, uma vez que, como discutido anteriormente o comportamento da variável após o choque é de extrema importância para o cálculo das elasticidades. Os gráficos apresentados para as GIRFs mostram as bandas superior e inferior (em linhas tracejadas) bem como a mediana (linha contínua), estas calculadas por bootstrap.

Verifica-se que um choque positivo de um desvio padrão no câmbio resulta em uma 


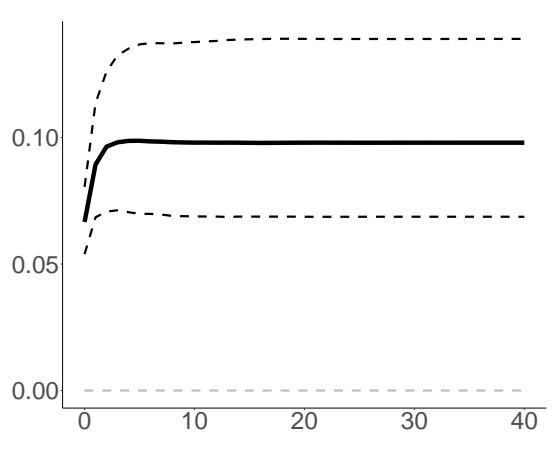

(a) Câmbio

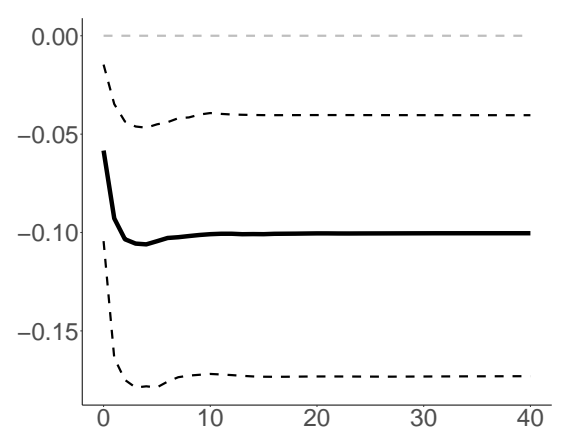

(b) Preço do petróleo

Figura 4.1 - Função de resposta ao impulso a choque cambial

desvalorização de 6-10\% no valor da moeda brasileira em relação ao dólar ${ }^{37}$. Como a estimação da GIRF supõe apenas este choque e sendo a variável não-estacionária, o choque se conserva ao longo dos períodos seguintes. Por sua vez, o efeito sobre o preço do barril de petróleo, medido em dólar, é negativo sendo quase da mesma magnitude do efeito observado no câmbio.

No caso do petróleo, observa-se que uma desvalorização do real, o que também pode significar uma valorização do dólar, leva a uma redução dos seus preços de 5-10\%, sendo que a resposta desta variável também é persistente (o que é de se esperar, dado que o câmbio permanece em patamar diferente do inicial). Uma possível explicação para tal efeito é que uma valorização do dólar leva à redução dos preços comercializados internacionalmente, uma vez que os extratores do petróleo teriam maiores preços em sua moeda nacional, o que lhes permitiria reduzir seus preços internacionais e ainda assim manter ou até aumentar seus lucros.

O efeito do choque de um desvio padrão no câmbio sobre os preços de importação, para a maioria dos setores, é negativo, indicando que as firmas estrangeiras abrem mão de parte do seu markup, para que os preços não subam na mesma proporção que o câmbio. Alguns setores se destacam com uma suas respostas negativas, como Derivados de petróleo (-3,3\% chegando a $-7,9 \%$ após 40 trimestres), Farmoquímicos (-2,5\% indo para $-4,2 \%)$ e Alimentos (-1,9\% a -3,7\%). As exceções encontradas para este caso, mesmo após passados 40 trimestres do choque, são Bebidas (0\%), Produtos de metal (1,8\%), Máquinas elétricas $(0,6 \%)$ e Outros equipamentos de transporte $(1,8 \%)$.

Por sua vez, os preços ao atacado indicam que todos os setores da indústria tendem a elevar seus preços frente a um choque cambial. As respostas obtidas diferem entre os setores em magnitude, mas todas apontam para a mesma direção. Destacam-se neste caso trajetórias como as de Alimentos (cuja resposta inicial é de 1,3\%, chegando a 3\%), Químicos (1,8\%-4,4\%) e Papel e celulose (1,6\%-4,0\%).

\footnotetext{
${ }^{37}$ Como em Dées et al. (2007), evidenciam-se as medianas das estimativas da GIRF por bootstrap como as respostas das variáveis frente a um choque. Os valores apresentados ao longo desta seção são referentes a elas.
} 

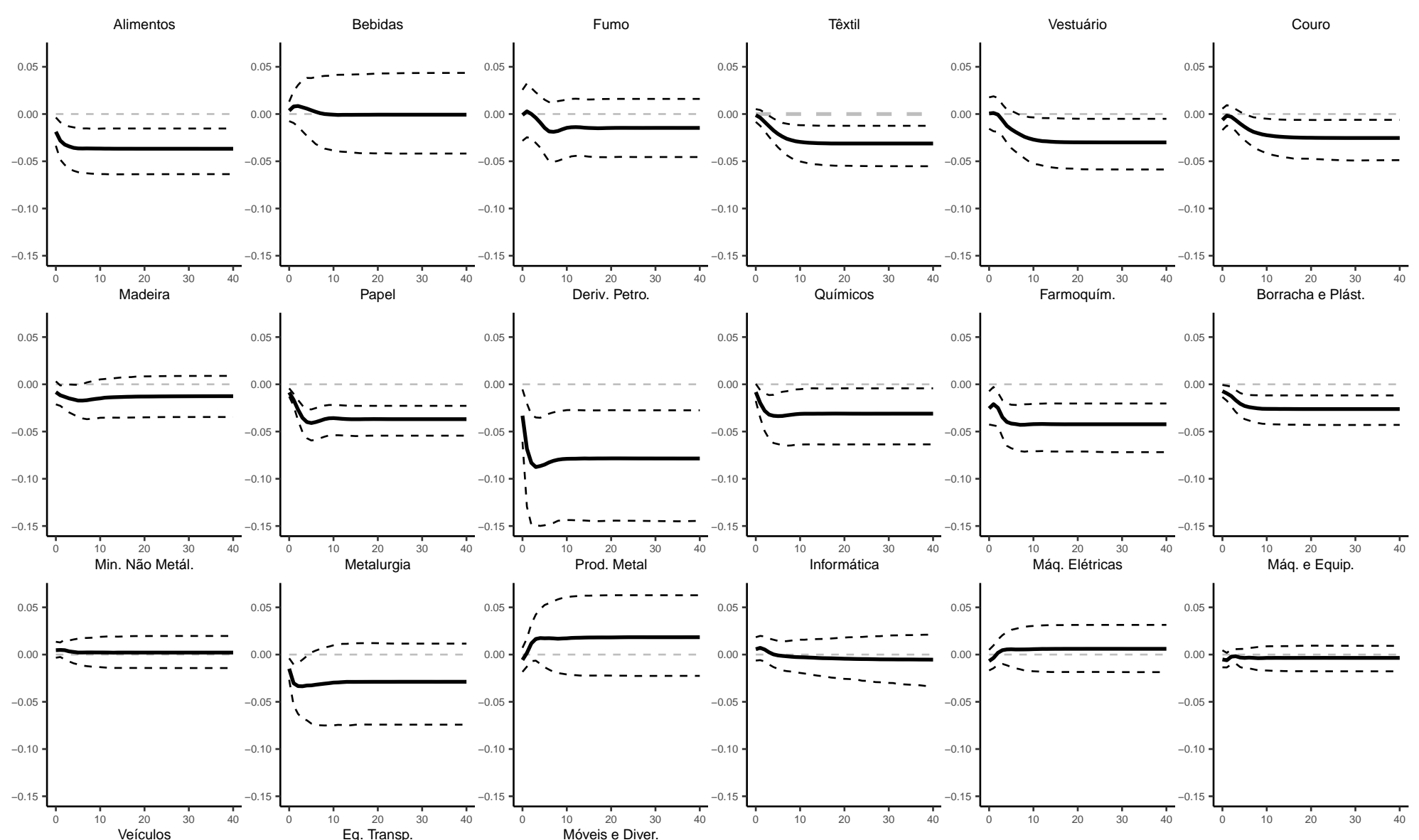

${ }^{10}$ Máq. e Equip.

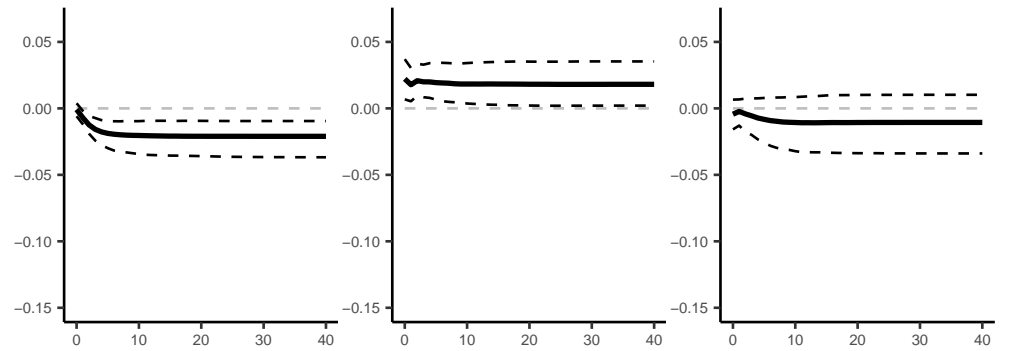

Figura 4.2 - Função de resposta ao impulso generalizada dos preços de importação a choque positivo no câmbio 

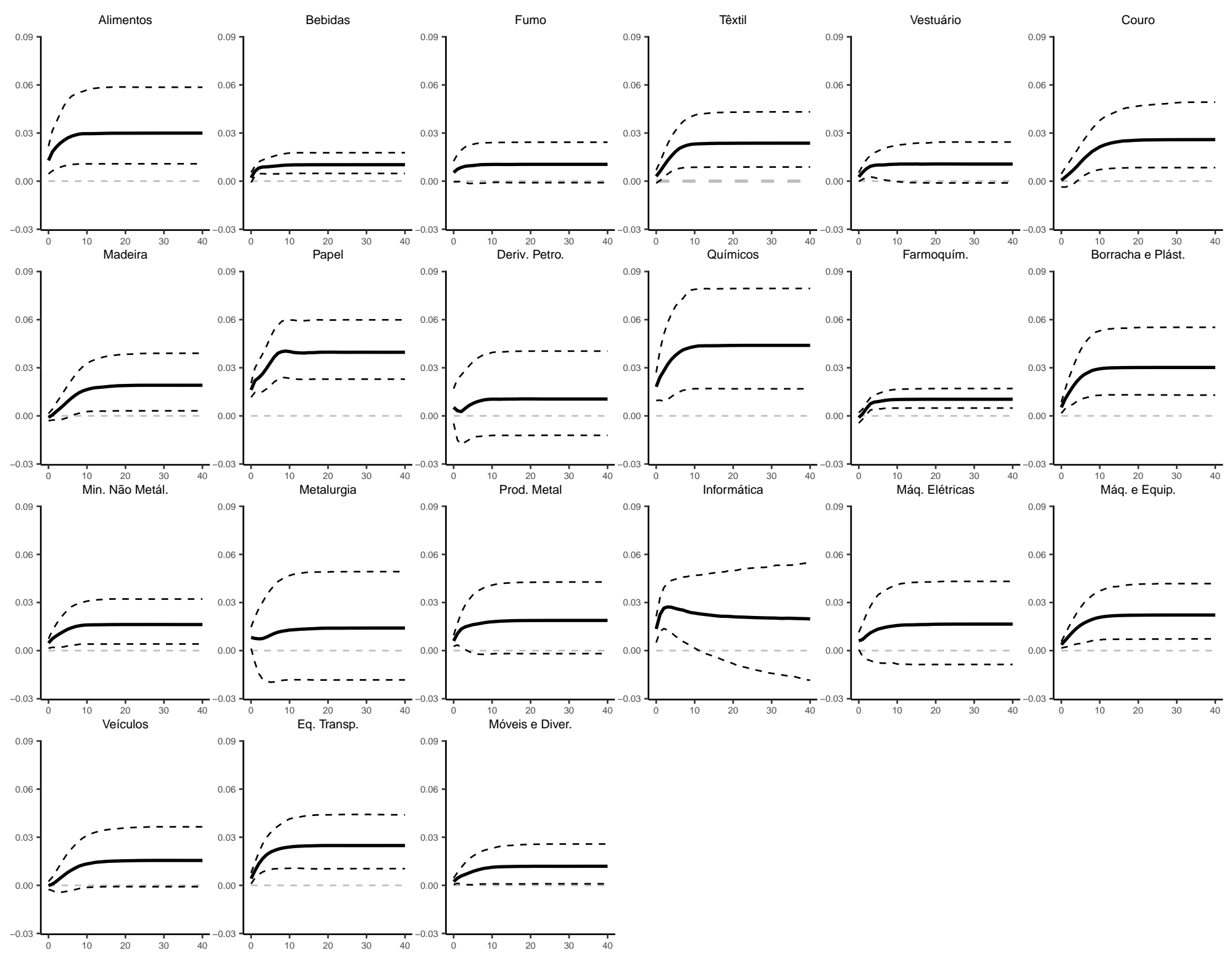

Figura 4.3 - Função de resposta ao impulso generalizada dos preços ao atacado a choque positivo no câmbio 
Pela Figura 4.2 é possível verificar que dos 21 setores, sete têm resposta significativa (ambas as bandas estão indicando intervalo que cujos valores têm mesmo sinal) durante os 40 períodos para os quais a GIRF é estimada, como pode ser visto por meio das bandas superior e inferior estimadas ${ }^{38}$. Na Figura 4.3, é possível observar que oito setores não incluem o zero dentro das bandas estimadas para a GIRF.

\subsubsection{Respostas ao choque no preço do petróleo}

A partir daqui são descritos os efeitos sobre as variáveis da indústria de transformação após um choque positivo de um desvio padrão do preço do barril de petróleo. Assim, como ocorre com o câmbio nominal, dada a natureza não-estacionária da variável, o choque sobre o preço do petróleo não dissipa, apenas se estabiliza após alguns trimestres. Esta resposta, bem como a do câmbio, ao choque pode ser observada na Figura 4.4.

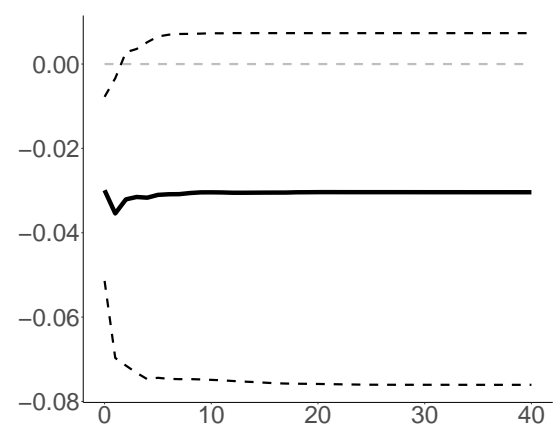

(a) Câmbio

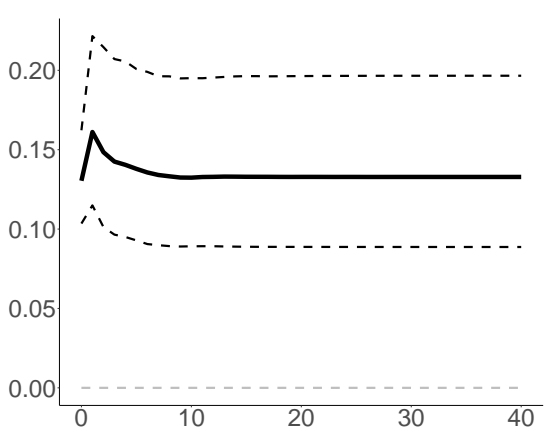

(b) Preço do petróleo

Figura 4.4 - Função de resposta ao impulso ao choque no preço do petróleo

É possível observar que o choque positivo de um desvio padrão no preço do petróleo faz com que este preço se eleve, inicialmente, em $13 \%$ sendo que no período seguinte o efeito é de $16 \%$. Parte do choque se dissipa gradualmente, retornando a patamar de $13 \%$, o que se mantém depois pelo horizonte avaliado. $\mathrm{O}$ impacto no câmbio nominal por sua vez, inicialmente, é de redução de 3\%, seguido de efeito de 3,5\% no período seguinte ao choque. Todavia, a mediana das respostas ao choque voltam a indicar que há uma redução de $3 \%$ do câmbio nominal.

A partir da observação de tais resultados, é possível inferir que este choque, ao contrário do cambial, não apresenta uma "potencialização" dos efeitos. No presente caso, o choque aparentemente se mantém em magnitude muito próxima ao impacto inicial, apesar de não

\footnotetext{
${ }^{38} \mathrm{Na}$ literatura econométrica, o termo "significância"é também utilizado para a função de resposta ao impulso, como feito por Dées et al. (2007) para analisar as GIRFs, tendo propósito de informar se pode ser inferido um sinal, positivo ou negativo, para a resposta de uma variável ao choque em outra ou nela mesma. Quando a banda superior está em campo positivo e a inferior em negativo, cria-se a possibilidade de que choques de interesse afetem a variável de maneira positiva ou negativa, deixando dúvidas acerca da possível resposta, o que é frequentemente denotado como uma resposta "não significativa".
} 

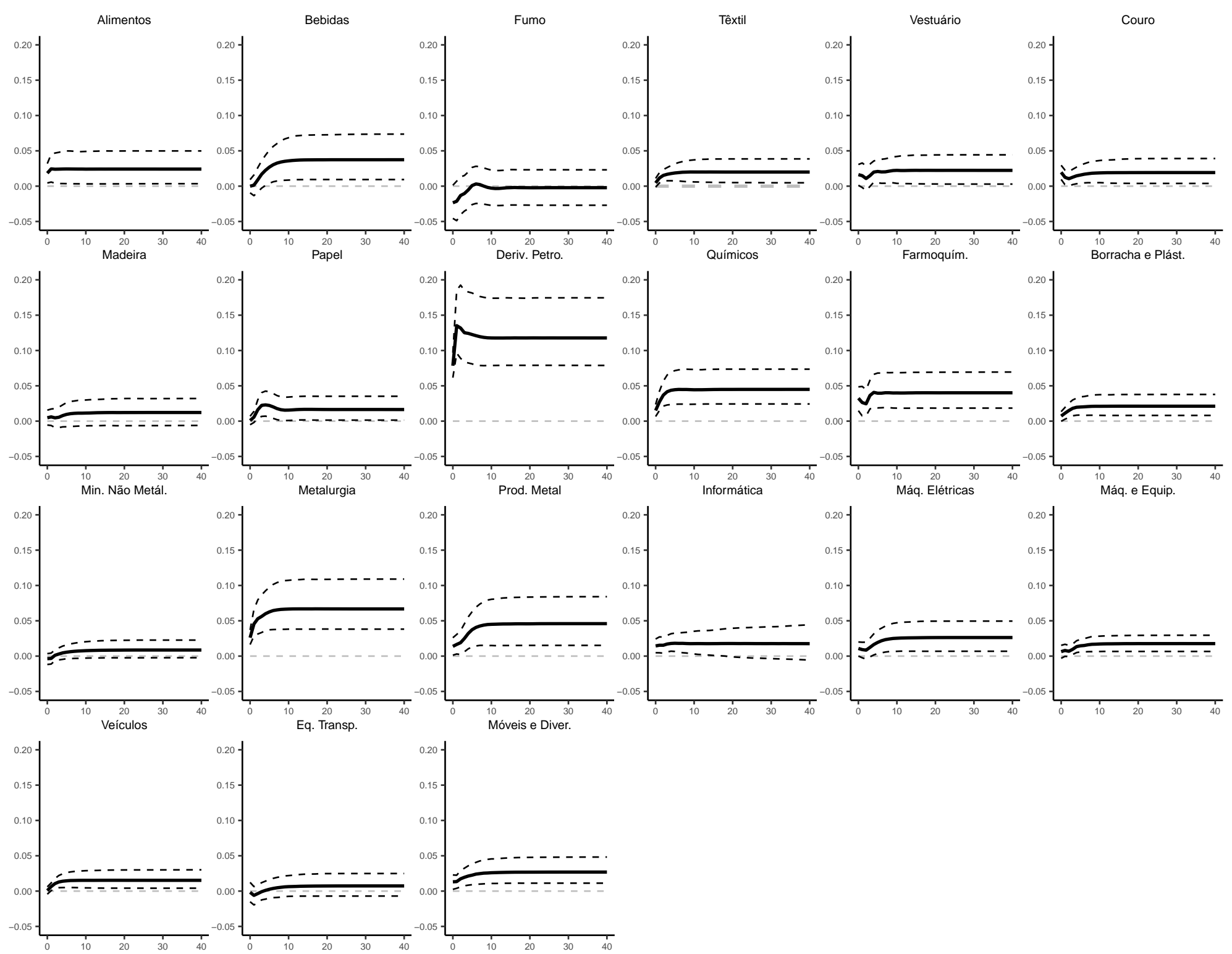

Figura 4.5 - Função de resposta ao impulso generalizada dos preços de importação a choque positivo no preço do petróleo 


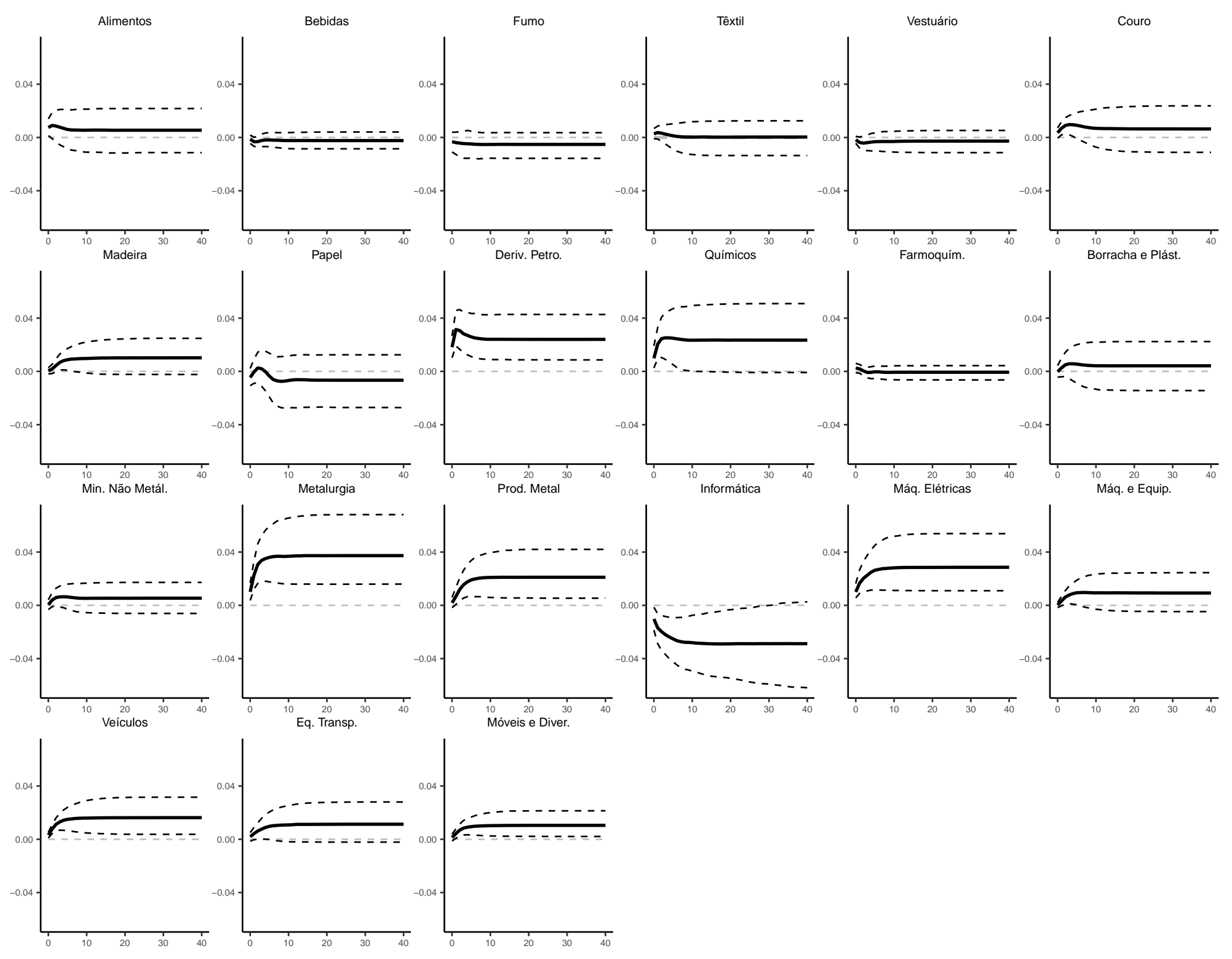

Figura 4.6 - Função de resposta ao impulso generalizada dos preços ao atacado a choque positivo no preço do petróleo 
se dissipar devido à não-estacionariedade da variável. Por sua vez, a relação negativa entre o câmbio e o preço do petróleo volta a aparecer, mas com base neste exercício percebe-se que os efeitos não são simétricos para os dois choques (flutuações cambiais parece ter mais efeito sobre o preço do barril do petróleo, do que o contrário).

Os efeitos obtidos para os preços de importação mostram que, de maneira homogênea, a sua resposta é positiva a este choque de custo. Destacam-se aqui as respostas positivas dos setores de Derivados do petróleo (7,8\%-11,8\%), Farmoquímicos (3,2\%-4\%) e Metalurgia (2,6\%-6,7\%). O único a mostrar redução em seus preços foi o setor de Fumo (resposta inicial de $-2,3 \%$ a qual se dissipa ao longo do tempo, convergindo para $-0,2 \%$ ).

Já os preços domésticos ao atacado apresentam reações ao choque sob a commodity um pouco mais heterogêneas. Existem setores como Bebidas, Fumo e Têxtil cujas respostas dos preços são praticamente nulas ao longo de todo o horizonte, ao passo que outros têm respostas positivas consideráveis (e.g. Máquinas elétricas (1\%-2,8\%) e Derivados do petróleo $(1,9 \%-2,4 \%))$. Ademais, verifica-se também que um setor indica a redução de seus preços de maneira significativa, que é o de Informática, o qual tem resposta inicial de -1\% ao choque, chegando a $-2,9 \%$ após 40 trimestres.

\subsection{Estimativa de repasse}

Nesta seção serão dispostas as estimativas, primeiramente, do repasse cambial ao preços domésticos aos produtores e de importação do Brasil, sendo possível avaliar não apenas o grau de repasse do choque como também seu comportamento ao longo do horizonte de estimação. Para tanto, serão dispostos gráficos e tabelas para mostrar o comportamento do repasse deste choque para os setores da indústria de transformação. Em seguida, da mesma forma, o impacto sobre os preços domésticos e de importação brasileiros de outro choque, o do preço do barril do petróleo, será disposto ${ }^{39}$.

\subsubsection{Estimativas de repasse cambial}

Na literatura, como observado por Burstein e Gopinath (2014), estimativas apontam que os choques do câmbio sob os preços são maiores para os preços de importação, ficando bastante próximo do repasse completo, enquanto que os preços domésticos apresentam menor grau de repasse. Levando isso em consideração, e o fato de grande parte dos trabalhos utilizar índices de preços agregados, para uma primeira verificação do repasse cambial foram ponderados os coeficientes setoriais, utilizando os pesos da PIM-PF já mencionados para

\footnotetext{
${ }^{39}$ Os gráficos com o comportamento dos coeficientes setoriais de repasse ao longo do horizonte de estimação podem ser encontrados no Apêndice C.
} 
obter o repasse "agregado“. O comportamento do repasse para o IPA e para o IPI de um choque cambial é disposto na Figura 4.7 abaixo.

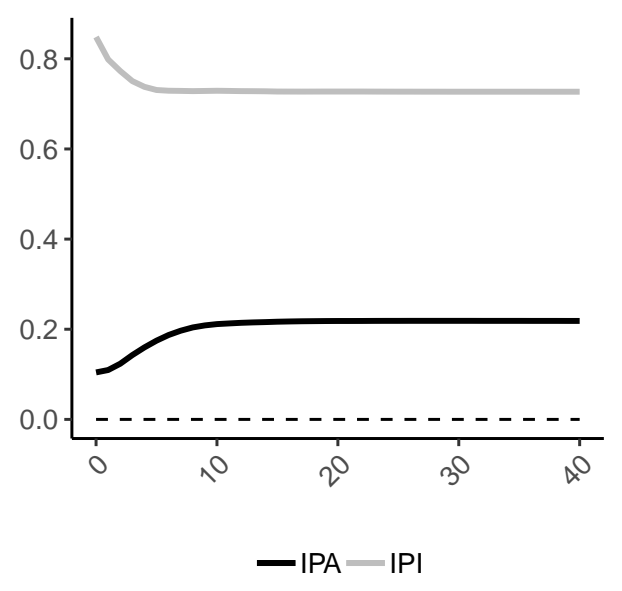

Figura 4.7 - Repasse cambial agregado aos preços de importação e ao atacado doméstico

Apesar de a magnitude do repasse do câmbio estar de acordo com a literatura, a dinâmica da elasticidade dos preços apresentada na Figura 4.7 deve ser analisada com mais cautela. Uma depreciação do real frente ao dólar mostrou levar a um repasse de $80 \%$ para os preços de importação e de $20 \%$ ao atacado, aproximadamente. Como mencionado anteriormente, os preços de importação costumam mostrar um repasse próximo ao completo, enquanto que os preços ao atacado costumam apresentar menor repasse comparado, assim como aqueles coeficientes aqui obtidos.

Com relação à dinâmica do repasse, o coeficiente para os preços ao atacado mostra uma dinâmica de elevação suave ao longo do tempo, assim como foi obtido por Faruqee (2006) para a Zona do Euro ${ }^{40}$. Entretanto, para a Zona do Euro, Faruqee (2006) indica que comportamento similar deveria ser apresentado pelos preços de importação, sendo que na Figura 4.7 é possível observar que o contrário ocorre, com o coeficiente reduzindo com o passar dos trimestres, indicando que as firmas absorvem mais do choque cambial conforme o tempo passa.

Esta característica da dinâmica de transmissão do choque cambial para os preços de importação é devida ao fato de tais preços, em dólar, não se alterarem em grande magnitude logo em sequência ao choque, como observado na Figura 4.2. Para certos setores, são necessários alguns trimestres para se observar uma redução de seus preços, de modo a absorver uma parcela do choque, enquanto outros prontamente reagem à mudança. Uma possibilidade para tal comportamento devem ser as pressões competitivas, fazendo com que as firmas

\footnotetext{
${ }^{40}$ Belaisch (2003) também se ocupa da estimação do grau de repasse cambial para os preços brasileiros ao atacado, sendo que, com uma dinâmica de crescimento do coeficiente, a autora mostra uma transferência de $165 \%$ no longo prazo. Apesar de diferente do que foi encontrado no presente trabalho, tanto no comportamento como na magnitude, a amostra utilizada por Belaisch (2003) é reduzida, contando com apenas dois anos, além do período ser próximo ao fim da atuação do Banco Central no mercado cambial.
} 
estrangeiras busquem manter sua parcela do mercado brasileiro, buscando reduzir o impacto sobre os preços em moeda local, ou mesmo por uma possível adaptação das expectativas dada a dinâmica do câmbio após o choque.

Além disso, como visto na seção anterior, cada setor possui sua resposta a um choque do câmbio e, portanto, um grau de transmissão deste choque. Além disso, como observado por Ito e Sato (2008), existe uma dinâmica temporal no repasse cambial, a qual é uma nova característica que pode vir a diferenciar ainda mais o repasse cambial entre os setores de indústria. Estes pontos podem ser observados para os preços de importação na Tabela 4.4, e para aqueles ao atacado na Tabela $4.6^{41}$.

\begin{tabular}{lccccc}
\hline \multirow{2}{*}{\multicolumn{1}{c}{ Setores }} & \multicolumn{4}{c}{ Número de trimestres após o choque } \\
\cline { 2 - 6 } & $\mathbf{0}$ & $\mathbf{1}$ & $\mathbf{4}$ & $\mathbf{8}$ & $\mathbf{2 0}$ \\
\hline \hline Alimentos & 0.719 & 0.685 & 0.637 & 0.629 & 0.625 \\
Bebidas & 1.053 & 1.090 & 1.058 & 1.000 & 0.993 \\
Fumo & 0.985 & 1.032 & 0.909 & 0.817 & 0.850 \\
Têxtil & 0.983 & 0.957 & 0.824 & 0.718 & 0.682 \\
Vestuário & 1.009 & 1.012 & 0.873 & 0.754 & 0.695 \\
Couro & 0.906 & 0.981 & 0.897 & 0.793 & 0.744 \\
Madeira & 0.875 & 0.870 & 0.838 & 0.836 & 0.868 \\
Papel e Celulose & 0.871 & 0.816 & 0.595 & 0.624 & 0.624 \\
Derivados de petróleo & 0.501 & 0.236 & 0.123 & 0.186 & 0.199 \\
Químicos & 0.876 & 0.778 & 0.662 & 0.671 & 0.683 \\
Farmoquímicos & 0.617 & 0.765 & 0.596 & 0.564 & 0.568 \\
Borracha & 0.891 & 0.893 & 0.792 & 0.740 & 0.733 \\
Minerais não metálicos & 1.070 & 1.055 & 1.028 & 1.023 & 1.022 \\
Metalurgia & 0.775 & 0.660 & 0.668 & 0.686 & 0.706 \\
Produtos de metal & 0.915 & 1.019 & 1.177 & 1.171 & 1.185 \\
Informática & 1.085 & 1.080 & 1.002 & 0.977 & 0.955 \\
Máquinas elétricas & 0.897 & 0.960 & 1.055 & 1.056 & 1.062 \\
Máquinas e equipamentos & 0.923 & 0.933 & 0.968 & 0.961 & 0.964 \\
Veículos & 0.987 & 0.922 & 0.821 & 0.795 & 0.786 \\
Outros eq. transporte & 1.333 & 1.199 & 1.202 & 1.188 & 1.185 \\
Móveis e prod. diversos & 0.934 & 0.974 & 0.927 & 0.896 & 0.892 \\
\hline Média & 0.848 & 0.799 & 0.738 & 0.728 & 0.727 \\
Desvio Padrão & 0.180 & 0.248 & 0.281 & 0.257 & 0.254 \\
\hline
\end{tabular}

Tabela 4.4 - Repasse cambial aos preços de importação para os setores da indústria

Primeiro, referente aos preços de importação, é possível observar que, no período de ocorrência do choque, os setores que mostram maior transmissão aos seus preços são Bebidas, Vestuário, Minerais não metálicos, Informática e Outros equipamentos de transporte. Apesar de todos mostrarem praticamente repasse completo, estes aumentam seus preços

\footnotetext{
${ }^{41}$ As informações também estão dispostas nas Figuras C.1 e C.2 no Apêndice C.
} 
acima do efeito do próprio câmbio. Em contrapartida, os setores de Derivados de petróleo e Farmoquímicos são aqueles que têm menor repasse inicial.

Como mencionado anteriormente, a possibilidade de diferentes dinâmicas do repasse cambial se confirma na Tabela 4.4. Exemplos com certo destaque são, por exemplo, os setores mencionados que inicialmente reajustam seus preços acima da variação cambial, porém fica evidente que enquanto setores, como o de Bebidas, permanecem com repasse em alto patamar, outros como o de Vestuário, reduzem de maneira significativa o seu grau de repasse. Ademais, é possível verificar que o setor de Derivados de petróleo, além de ter um baixo repasse inicial, reduz ainda mais o impacto do choque cambial aos seus preços, sendo aquele com menor coeficiente de repasse no longo prazo, enquanto que os de maior coeficiente são os de Produtos de metal e de Outros equipamentos de transporte.

Como teorizado acerca do repasse cambial, um dos fatores que determina o quanto dos choques cambiais são transmitidos aos preços das importações é a parcela do mercado que é atendida por exportadores estrangeiros. Investigou-se então a relação do repasse de longo prazo estimado com o Coeficiente de Penetração das Importações (CPI) da Confederação Nacional da Indústria (CNI). Utilizando o coeficiente de correlação de posto de Spearman, tomando para o exercício a média do CPI da amostra disponível (dados anuais de 2003 a 2017) e o grau de repasse para os preços de importação após 40 períodos passados do choque (os resultados podem ser verificados na Tabela 4.5). Verifica-se a existência de uma correlação positiva $(0,01)$, apesar de pequena e não estatisticamente significante a $10 \%$.

\begin{tabular}{c|cc} 
& ERPT IPI & ERPT IPA \\
\hline OPPT IPI & -0.30 & -0.22 \\
& $(-1.38)$ & $(-0.99)$ \\
OPPT IPA & 0.16 & 0.04 \\
& $(0.72)$ & $(0.15)$ \\
CPI & 0.01 & 0.08 \\
& $(0.04)$ & $(0.36)$ \\
CE & 0.13 & 0.28 \\
& $(0.55)$ & $(1.27)$ \\
CII & -0.28 & -0.12 \\
& $(-1.28)$ & $(-0.55)$ \\
TPE & 0.05 & 0.00 \\
& $(0.22)$ & $(0.02)$ \\
\hline
\end{tabular}

Estatística t em parênteses ${ }^{*} \mathrm{p}<0.1,{ }^{* *} \mathrm{p}<0.05,{ }^{* * *} \mathrm{p}<0,01$ $\mathrm{ERPT}=$ exchange rate passthrough, OPPT = oil price pass-through.

Tabela 4.5 - Coeficiente de correlação de posto de Spearman

Por sua vez, Castilho e Miranda (2017) ao estudarem a estrutura tarifária sobre as importações brasileiras, tanto nominal como efetiva trazem também outro olhar para os 
resultados apresentados acima. Os autores afirmam que as tarifas de importação sobre um bem têm duplo efeito, de incentivar sua produção ao ampliar o valor agregado do bem e, ao mesmo tempo, reduzir o valor agregado dos demais setores que utilizam o bem como insumo. Deste modo, toma-se como base a Tarifa de Proteção Efetiva (TPE), que considera o fenômeno descrito em sua formulação, calculada por Castilho e Miranda (2017), para verificar a existência de alguma relação com os grau de repasse aos preços de importação estimados. O coeficiente de correlação de posto de Spearman também foi calculado neste caso, e o resultado foi de uma correlação positiva $(0,05)$, mas não estatisticamente significante a $10 \%$.

Apesar das relações do repasse cambial para os preços de importação com o CPI e a TPE não se mostrarem estatisticamente significantes, pode-se tentar unir as três informações para buscar entender algo sobre a dinâmica dos preços. Por exemplo, Castilho e Miranda (2017) destacam a diferença entre as TPEs dos setores de Químicos e Farmoquímicos, em que a do segundo é quase três vezes menor que a do primeiro. Além disso, o CPI do setor de Farmoquímicos é maior ( $31 \%$ contra $24 \%$ ), de modo que seria de se esperar que produtos farmacêuticos importados tivessem maior repasse, tanto por menores tarifas como por terem uma maior fatia do mercado brasileiro do que os produtos químicos têm. Todavia, o contrário é observado: o repasse de longo prazo dos Químicos é maior do que o de Farmoquímicos (0,683 contra 0,568). Segundo Castilho e Miranda (2017), a menor proteção tarifária sob o setor de Farmoquímicos se dá pela política existente de buscar a redução dos preços destes bens, de modo que se pode inferir que o repasse apresentado pelo setor pode corresponder a uma estratégia dos exportadores estrangeiros de manter menores reajustes de modo a incentivar a continuidade da política, e assim se beneficiarem dela, seja por conseguirem maior margem devido às menores tarifas ou pelo interesse em aumentarem suas vendas para o Brasil. Enquanto isso, as firmas do setor de Químicos, não possuindo incentivos, apesar de sua participação semelhante no consumo interno daquela dos Farmoquímicos, apresentam repasse maior de modo que, devido às maiores tarifas, as firmas incorporam parte da variação cambial a fim de não elevarem seus preços na moeda brasileira. Ademais, é provável que, apesar de ambos os setores terem repasse incompleto, o setor sob maiores tarifas deve ter que absorver uma maior parcela dos ajustes no câmbio nominal.

Outro setor de destaque na política tarifária brasileira é o de Veículos, em vista do papel de exportadora que esta indústria tem. Castilho e Miranda (2017) destacam os acordos firmados com os demais países do Mercado Comum do Sul (Mercosul) para facilitar a exportação dos produtos do setor entre os países membros, bem como dificultar a entrada de produtos de outras origens (elevação de tarifas de importação e outras medidas). Assim, observa-se que, neste caso, o baixo CPI e alta TPE conjuntamente geram um repasse incompleto de longo prazo, o que é previsto pela teoria já que as firmas estrangeiras desse setor têm menor market share no mercado interno, além de terem que pagar altos impostos, o que reduz a capacidade delas de repassar seus choques de custo. 
Contudo, setores com repasse de longo prazo similar e maior market share em relação às empresas domésticas, apresentam proteção tarifária significativamente menor. Duas hipóteses podem ser levantadas: a primeira, que o repasse de praticamente $80 \%$ no setor do choque cambial no longo prazo seja fruto da importação de peças e acessórios (que são os produtos do setor que sofrem menor tarifação) ou; segundo, devido à importação de veículos automotivos e caminhões ser, basicamente, de produtos de alto valor, de modo que seus preços já sendo bastante elevados pouco se modifiquem com o câmbio. Deste modo, pode-se verificar que, apesar de relações estatísticas pouco significantes, pode-se averiguar complexas conexões entre diversos fatores que determinam os preços das importações e a dinâmica da transmissão de choques cambiais.

Por sua vez, é possível verificar que a maneira com que as firmas estrangeiras transmitem depreciações da moeda brasileira para os preços dos bens importados é bastante diferente do modo como as firmas brasileiras o fazem para os preços ao atacado. Nota-se que não apenas mudam as magnitudes, como a heterogeneidade dos coeficientes, o que pode ser percebido pelo fato do desvio padrão para os graus de repasse dos bens importados ser praticamente o dobro em relação aos bens domésticos no atacado, como ser visto na Tabela 4.6 .

No caso do atacado brasileiro, têm-se preços de setores como os de Madeira, Farmoquímicos e Veículos que sofrem impacto inicial negativo (apesar de praticamente nulo) sobre seus preços. Enquanto isso, outros como de Alimentos, Papel e Celulose, Químicos e Informática têm repasse de $20 \%$ do choque cambial, o que apesar de estar longe de ser completo, são os mais significativos dentre os ramos da indústria de transformação. Adicionalmente, nota-se que o setor de Outros equipamentos de transporte, apesar de elevar seus preços acima do efeito do choque cambial no caso dos preços de importação, apresenta agora coeficiente relativamente baixo no que diz respeito aos preços ao atacado doméstico.

No longo prazo, percebe-se que os coeficientes permanecem relativamente diferentes entre si, cada qual com a sua dinâmica própria. É possível enxergar casos em que, apesar de repasse inicial quase nulo, os preços se elevam de forma significativa após diversos períodos do choque, como o setor de Couro e Borracha e Plástico. Enquanto isso, outros setores evidenciam que a elasticidade dos seus preços ao atacado variam pouco com o passar do tempo, como é o caso de Fumo, Metalurgia e Informática, por exemplo. Outro fator a ser notado é que, assim como no caso do repasse cambial para os preços de importação, o setor de Derivados de petróleo é um dos que se destacam por ter um dos menores reajustes também para os preços aos produtores domésticos.

Para o repasse aos preços ao atacado foi verificada existência de correlação com outros indicadores de abertura comercial calculados pela CNI. Desta vez, foi utilizado o Coeficiente de Exportações (CE), que mede o quanto da produção industrial brasileira é exportada, e o Coeficiente de Insumo Industriais Importados (CII), que verifica a proporção de insumos 


\begin{tabular}{lccccc}
\hline \multirow{2}{*}{ Setores } & \multicolumn{4}{c}{ Número de trimestres } & após o choque \\
\cline { 2 - 6 } & $\mathbf{0}$ & $\mathbf{1}$ & $\mathbf{4}$ & $\mathbf{8}$ & $\mathbf{2 0}$ \\
\hline \hline Alimentos & 0.194 & 0.204 & 0.258 & 0.299 & 0.305 \\
Bebidas & 0.032 & 0.069 & 0.090 & 0.100 & 0.105 \\
Fumo & 0.081 & 0.084 & 0.097 & 0.105 & 0.107 \\
Têxtil & 0.045 & 0.068 & 0.160 & 0.228 & 0.241 \\
Vestuário & 0.040 & 0.061 & 0.100 & 0.106 & 0.109 \\
Couro & 0.008 & 0.028 & 0.092 & 0.188 & 0.261 \\
Madeira & -0.015 & 0.006 & 0.069 & 0.148 & 0.193 \\
Papel e Celulose & 0.243 & 0.246 & 0.300 & 0.408 & 0.405 \\
Derivados de petróleo & 0.080 & 0.035 & 0.065 & 0.102 & 0.108 \\
Químicos & 0.272 & 0.271 & 0.358 & 0.428 & 0.448 \\
Farmoquímicos & -0.016 & 0.015 & 0.087 & 0.102 & 0.106 \\
Borracha & 0.079 & 0.118 & 0.217 & 0.288 & 0.308 \\
Minerais não metálicos & 0.071 & 0.083 & 0.122 & 0.158 & 0.166 \\
Metalurgia & 0.124 & 0.085 & 0.085 & 0.123 & 0.143 \\
Produtos de metal & 0.091 & 0.119 & 0.157 & 0.178 & 0.192 \\
Informática & 0.203 & 0.252 & 0.274 & 0.249 & 0.216 \\
Máquinas elétricas & 0.091 & 0.078 & 0.125 & 0.153 & 0.168 \\
Máquinas e equipamentos & 0.055 & 0.071 & 0.142 & 0.198 & 0.226 \\
Veículos & -0.002 & 0.008 & 0.063 & 0.123 & 0.156 \\
Outros eq. transporte & 0.063 & 0.102 & 0.193 & 0.236 & 0.253 \\
Móveis e prod. diversos & 0.035 & 0.050 & 0.078 & 0.108 & 0.121 \\
\hline Média & 0.104 & 0.110 & 0.160 & 0.204 & 0.218 \\
Desvio Padrão & 0.085 & 0.086 & 0.096 & 0.105 & 0.104 \\
\hline
\end{tabular}

Tabela 4.6 - Repasse cambial aos preços ao atacado para os setores da indústria

utilizados em cada setor que é importada. Para o CE, o coeficiente de correlação de posto de Spearman indica relação positiva com os coeficientes de repasse cambial para os preços domésticos $(0,28)$, enquanto que com o CII, a relação se mostra negativa $(-0,12)$, em direção contrária ao esperado. Todavia, para ambos, o coeficiente não é estatisticamente significante a $10 \%$, como disposto na Tabela 4.5 .

Como discutido, escassos são os trabalhos na literatura de repasse cambial cujo foco é estimar o grau de repasse setorial para os preços brasileiros, tanto de importação como ao atacado. Um dos poucos a fazê-lo foi Kannebley Júnior, Reis e Toneto Júnior (2016) que utilizaram os coeficientes das relações de cointegração como elasticidades de longo prazo dos preços ao câmbio. Apesar de não serem diretamente comparáveis tais estimações com aquelas obtidas nas Tabelas 4.4 e 4.6, podem servir como um modo de verificar os resultados aqui apresentados, bem como observar como diferem.

Observa-se que os coeficientes médios de repasse obtidos neste trabalho são similares àqueles apresentados pelos autores. Utilizando a média ponderada dos resultados de Kanne- 
bley Júnior, Reis e Toneto Júnior $(2016)^{42}$, os preços de importação apresentam repasse de longo prazo de $70 \%$, e aqueles ao atacado de $21 \%$, ao passo que utilizando o GVAR obtiveramse coeficientes médios de $73 \%$ e $22 \%$, respectivamente. Assim, pode-se concluir que, em média, o presente trabalho está em linha com os achados pré-existentes para o Brasil.

Apesar das estimativas estarem em linha na média dos parâmetros, pode-se verificar que os desvios-padrão diferem daqueles obtidos por Kannebley Júnior, Reis e Toneto Júnior (2016), principalmente no que diz respeito ao repasse aos preços ao atacado ${ }^{43}$ (sendo que, nos primeiros trimestres após o choque, o desvio-padrão dos coeficientes é ainda menor). Para os preços de importação, o desvio-padrão é maior do que do trabalho anterior, mas nota-se que os coeficientes de repasse de longo prazo, em sua maioria, estão acima da média, o que justifica um maior desvio-padrão, mesmo diversos setores mostrando graus de repasse similar.

Além disso, em média, as diferenças dos coeficientes setoriais mostram que o repasse obtido nas Tabelas 4.4 e 4.6 são maiores do que os de Kannebley Júnior, Reis e Toneto Júnior (2016). Esta evidência, além da baixa correlação dos graus de repasse cambial com variáveis acerca da abertura comercial brasileira (contrário ao que foi verificado por Kannebley Júnior, Reis e Toneto Júnior (2016)), e menor dispersão dos coeficientes aqui obtidos, podem ser indicativos dos efeitos captados pelo método utilizado, que não o foram no trabalho anterior. Aqui foi possível captar os efeitos do fatores comuns existentes entre as unidades do sistema, bem como efeitos transbordamento da resposta de cada unidade para as demais.

Assim, mesmo os coeficientes não sendo comparáveis, uma vez que os métodos para obtenção dos graus de repasse setorial são diferentes entre os trabalhos, indícios apontam para a existência da captura dos efeitos desejados. Além disso, a partir das GIRFs, foi possível obter a dinâmica temporal dos coeficientes setoriais de transmissão do choque cambial, e não apenas identificar os coeficientes de longo prazo.

\subsubsection{Estimativas de repasse de choques no preço do petróleo}

O cálculo do repasse realizado aqui, para verificar a transmissão de choques vindos dos preços do barril de petróleo, é o mesmo feito para aferir a elasticidade dos preços a variações cambiais, usando a equação (3.20). Na Figura 4.8, pode-se observar os graus de repasse, no agregado, tanto para os preços de importação como os domésticos ao atacado. $\mathrm{O}$ choque inicial é de baixa magnitude e os efeitos vão sendo repassados aos preços ao longo do

\footnotetext{
${ }^{42}$ Em Kannebley Júnior, Reis e Toneto Júnior (2016), reportaram-se as médias aritméticas dos graus de repasse cambial, enquanto que nas Tabelas 4.4 e 4.6, as médias exibidas são ponderadas pelos pesos setoriais vindos da PIM-PF. Os resultados de Kannebley Júnior, Reis e Toneto Júnior (2016) reportados na presente análise, por sua vez, para fins de uma mais próxima comparação, também foram ponderados a partir da mesma estrutura de pesos.

${ }^{43}$ Em que o desvio padrão é o dobro do que foi obtido para o longo prazo utilizando o GVAR.
} 
tempo, sendo que é transmitida uma maior proporção do choque aos preços de importação do que aos domésticos. Os resultados setoriais constam nas Tabelas 4.7 e $4.8^{44}$.

Castro e Jiménez-Rodríguez (2017) não apresentam uma estimativa média do repasse dos choques no preço da commodity, mas é possível verificar que, os preços ao produtor, em média, apresentam uma baixa transmissão do choque e que, gradualmente, esta se eleva (na maioria dos casos, também abaixo de 10\%). Logo, o comportamento dinâmico do IPA na Figura 4.8 mostra-se similar ao obtido pelos autores para os países da Zona do Euro.

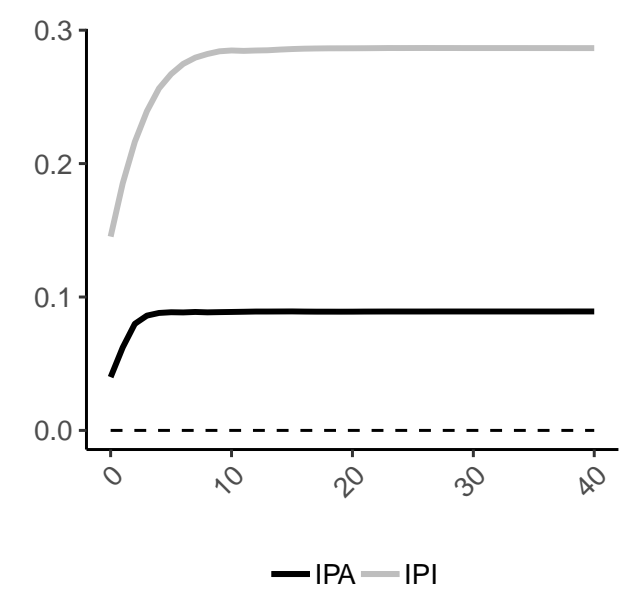

Figura 4.8 - Repasse agregado de choque positivo sobre o preço do petróleo sobre os preços de importação e ao atacado

Analisando setorialmente, em primeiro lugar, para os preços de importação, os impactos no período de choque são baixos, praticamente nulos, para a maioria dos setores. As exceções observadas são ligadas principalmente àquelas atividades que dependem do petróleo como insumo em maior escala, como Derivados de petróleo e Metalurgia, que estão acima do repasse médio no período. Outros setores que podem possuem um coeficiente de destaque no período do choque são os setores de Farmoquímicos e de Fumo, sendo que no caso deste último há indicação que as firmas estrangeiras reduziriam seus preços frente ao choque.

Nos períodos posteriores ao choque é possível observar que as firmas estrangeiras dos setores de Derivados de petróleo e Metalurgia elevam o repasse do choque de custos para os preços, sendo que o setor de Derivados do petróleo tem repasse quase completo. No longo prazo, preços de importação de outros setores passam apresentar um coeficiente mais considerável, como Bebidas, Químicos e Produtos de metal, mas ainda assim longe de um repasse completo. Este efeito pode ser resultante do fato observado na Figura 4.4, que indica a permanência do choque sobre o preço ao longo dos períodos, de modo que, possivelmente, haja um processo de adaptação das expectativas, as quais passam a considerar que tal choque é permanente e, neste caso, as firmas decidem repassar o choque.

\footnotetext{
${ }^{44}$ A trajetória temporal dos coeficientes podem ser vistas também no Apêndice C, nas Figuras C.3 e C.4.
} 


\begin{tabular}{lccccc}
\hline \multirow{2}{*}{\multicolumn{1}{c}{ Setores }} & \multicolumn{4}{c}{ Número de trimestres após o choque } \\
\cline { 2 - 6 } & $\mathbf{0}$ & $\mathbf{1}$ & $\mathbf{4}$ & $\mathbf{8}$ & $\mathbf{2 0}$ \\
\hline \hline Alimentos & 0.141 & 0.152 & 0.173 & 0.182 & 0.182 \\
Bebidas & -0.001 & 0.009 & 0.160 & 0.256 & 0.281 \\
Fumo & -0.180 & -0.133 & -0.038 & 0.001 & -0.017 \\
Têxtil & 0.035 & 0.072 & 0.127 & 0.149 & 0.150 \\
Vestuário & 0.125 & 0.092 & 0.142 & 0.159 & 0.168 \\
Couro & 0.150 & 0.078 & 0.104 & 0.137 & 0.145 \\
Madeira & 0.037 & 0.037 & 0.056 & 0.085 & 0.092 \\
Papel e Celulose & 0.007 & 0.035 & 0.164 & 0.121 & 0.124 \\
Derivados de petróleo & 0.601 & 0.839 & 0.885 & 0.890 & 0.887 \\
Químicos & 0.115 & 0.170 & 0.311 & 0.336 & 0.338 \\
Farmoquímicos & 0.249 & 0.163 & 0.290 & 0.301 & 0.302 \\
Borracha e Plástico & 0.055 & 0.070 & 0.140 & 0.157 & 0.159 \\
Minerais não metálicos & -0.028 & -0.021 & 0.033 & 0.054 & 0.064 \\
Metalurgia & 0.200 & 0.282 & 0.427 & 0.496 & 0.503 \\
Produtos de metal & 0.106 & 0.103 & 0.229 & 0.329 & 0.344 \\
Informática & 0.111 & 0.096 & 0.127 & 0.134 & 0.134 \\
Máquinas elétricas & 0.083 & 0.057 & 0.117 & 0.182 & 0.198 \\
Máquinas e equipamentos & 0.049 & 0.050 & 0.096 & 0.126 & 0.133 \\
Veículos & 0.006 & 0.040 & 0.100 & 0.114 & 0.115 \\
Outros eq. transporte & -0.013 & -0.038 & 0.008 & 0.040 & 0.054 \\
Móveis e Prod. diversos & 0.101 & 0.083 & 0.152 & 0.191 & 0.202 \\
\hline Média & 0.145 & 0.185 & 0.256 & 0.282 & 0.286 \\
Desvio Padrão & 0.182 & 0.252 & 0.250 & 0.248 & 0.246 \\
\hline
\end{tabular}

Tabela 4.7 - Repasse de choque do preço do petróleo aos preços de importação dos setores da indústria brasileira

Assim, em linhas gerais, é possível observar que os choques do preço do petróleo tendem a ser repassados em menor escala para os preços das importações brasileiras no momento de sua ocorrência, mas a transmissão se eleva após alguns trimestres. Mostrando então que as firmas estrangeiras que vendem para o Brasil, além de não transferirem todo o choque de custos, tendem a suavizar este processo por alguns períodos.

Os preços ao atacado do Brasil, por sua vez, apresentam comportamento bastante diferenciado daquele mostrado pelos preços de importação frente ao choque. Primeiro, a média dos coeficientes setoriais, bem como seu desvio padrão, é inequivocamente menor, mesmo diversos períodos após o choque. Em segundo lugar, no trimestre de ocorrência do choque, o impacto é praticamente zero para a maioria do setores, com exceção apenas de Derivados de petróleo. Apesar deste setor apresentar um repasse maior do que os demais já no período do choque, a transmissão do aumento de custos para os preços é bastante reduzida quando comparada aos de importação do mesmo (indicando que o fenômeno do repasse deste choque tem comportamento semelhante ao do câmbio aos preços, sendo maior para 
os preços de importação e menor aos domésticos).

\begin{tabular}{lccccc}
\hline \multirow{2}{*}{\multicolumn{1}{c}{ Setores }} & \multicolumn{4}{c}{ Número de trimestres após o choque } \\
\cline { 2 - 6 } & $\mathbf{0}$ & $\mathbf{1}$ & $\mathbf{4}$ & $\mathbf{8}$ & $\mathbf{2 0}$ \\
\hline \hline Alimentos & 0.058 & 0.056 & 0.049 & 0.041 & 0.041 \\
Bebidas & -0.010 & -0.020 & -0.014 & -0.017 & -0.018 \\
Fumo & -0.024 & -0.024 & -0.034 & -0.040 & -0.039 \\
Têxtil & 0.021 & 0.023 & 0.013 & 0.003 & 0.002 \\
Vestuário & -0.014 & -0.023 & -0.025 & -0.023 & -0.021 \\
Couro & 0.027 & 0.043 & 0.068 & 0.056 & 0.048 \\
Madeira & 0.003 & 0.011 & 0.058 & 0.072 & 0.076 \\
Papel e Celulose & -0.035 & -0.002 & -0.002 & -0.056 & -0.050 \\
Derivados de petróleo & 0.140 & 0.195 & 0.193 & 0.183 & 0.181 \\
Químicos & 0.075 & 0.127 & 0.179 & 0.178 & 0.177 \\
Farmoquímicos & 0.020 & 0.012 & -0.005 & -0.006 & -0.005 \\
Borracha e Plástico & -0.002 & 0.016 & 0.040 & 0.034 & 0.032 \\
Minerais não metálicos & 0.003 & 0.025 & 0.046 & 0.040 & 0.040 \\
Metalurgia & 0.078 & 0.142 & 0.250 & 0.276 & 0.281 \\
Produtos de metal & 0.014 & 0.041 & 0.125 & 0.155 & 0.159 \\
Informática & -0.078 & -0.105 & -0.169 & -0.208 & -0.218 \\
Máquinas elétricas & 0.077 & 0.103 & 0.177 & 0.208 & 0.214 \\
Máquinas e equipamentos & 0.002 & 0.020 & 0.063 & 0.072 & 0.070 \\
Veículos & 0.024 & 0.048 & 0.102 & 0.118 & 0.122 \\
Outros eq. transporte & 0.015 & 0.027 & 0.063 & 0.080 & 0.085 \\
Móveis e Prod. diversos & 0.010 & 0.026 & 0.065 & 0.075 & 0.078 \\
\hline Média & 0.040 & 0.062 & 0.088 & 0.089 & 0.089 \\
Desvio Padrão & 0.051 & 0.069 & 0.088 & 0.099 & 0.100 \\
\hline
\end{tabular}

Tabela 4.8 - Repasse de choque do preço do petróleo aos preços ao atacado dos setores da indústria brasileira

Outros que mostram repasse inicial mais proeminente são os setores de Químicos, Metalurgia e Máquinas elétricas, enquanto que o setor de Informática tem coeficiente alto em magnitude, mas negativo como reação aos preços de petróleo ${ }^{45}$. Tais ramos da indústria, ao contrário de Derivados de petróleo, que mantém o grau de repasse praticamente constante ao longo do tempo, elevam o percentual do aumento dos seus custos que é repassado aos preços ao longo do tempo (por exemplo, firmas de Metalurgia mais do que dobram tal percentual passado um ano do choque, mas não transferem muito mais do que $25 \%$ do choque).

Nota-se que, com relação ao repasse de longo prazo de um aumento do preço do petróleo que, apesar dos preços de importações de Derivados de petróleo, que são definidos

\footnotetext{
${ }^{45}$ Castro e Jiménez-Rodríguez (2017) também encontram uma redução de preços deste tipo de bens frente a um aumento do preço do barril de petróleo, sendo o único setor a apresentar tal comportamento para os países da Zona do Euro. Aqui, apesar de outros setores indicarem uma redução de seus preços, o impacto é relativamente baixo, enquanto que os produtos do setor de Informática tem um coeficiente negativo considerável, quando comparado com os demais setores, no longo prazo.
} 
por firmas estrangeiras, ser o maior dentre os setores da indústria, para os preços ao atacado isto não é válido. No curto prazo, o setor é aquele com maior transferência do choque, porém, no longo prazo, observa-se que os setores de Metalurgia e Máquinas elétricas apresentam maiores coeficientes de repasse ${ }^{46}$.

Castro e Jiménez-Rodríguez (2017) buscaram preencher a lacuna existente na literatura sobre dos efeitos de choques nos preços mundiais do petróleo, e como esses são transmitidos na cadeia produtiva, afetando os preços dos produtos de cada setor da economia. Todavia, é possível verificar dois problemas em tais estimações: primeiro, o método do cálculo do repasse realizado pelos autores nada mais é do que o acumulado do efeito do choque sobre a taxa de inflação, desconsiderando o desenvolvimento posterior ao choque do próprio preço do petróleo, como é recomendado na literatura (e.g. Belaisch (2003), Faruqee (2006) e Ito e Sato (2008)); segundo, os autores ignoram em sua estimação os efeitos dos bens importados sobre a definição de preços internos, dado que apenas estimam um modelo VAR utilizando as variações de preços do petróleo, aos produtores e aos consumidores.

No presente trabalho, apesar de não se contemplar os efeitos sobre os preços ao consumidor, consideram-se os dois fatores elencados, que têm seu papel nesse tipo de modelagem. Além disso, considera-se o mesmo choque não apenas em um arcabouço de equilíbrio parcial para cada setor, como em Castro e Jiménez-Rodríguez (2017), mas sim de um sistema de setores.

Apesar das estimativas de Castro e Jiménez-Rodríguez (2017) para as respostas dos preços setoriais a um choque no preço do petróleo ser referente à Zona do Euro, além das críticas sobre o método de cálculo de coeficiente de repasse, em média, as estimativas utilizando o GVAR para os dados brasileiros estão em linha com os achados para a UE. Mais especificamente, com relação às respostas dos preços ao atacado. Desta forma, pode-se dizer que o repasse de choques no preço do petróleo para os preços domésticos brasileiros está de acordo com a literatura, além de trazer também as estimativas para os preços de importação.

Um outro fator a ser também ressaltado a respeito do repasse do choque de custos vindo do preço do petróleo, é a diferença que este têm em relação ao observado para o câmbio. Primeiramente observa-se redução do repasse do câmbio aos preços de importação, enquanto que este se eleva quando o choque é referente aos preços do petróleo. Em contrapartida, o grau de repasse do câmbio é, em média, maior do que para o preço do petróleo. Isso pois o aumento do câmbio afeta diretamente o preço dos bens importados de todos os setores via conversão monetária, enquanto que os preços da commodity devem afetar o valor dos bens via cadeia produtiva, afetando mais uns setores do que outros.

Ademais, não apenas para os preços de importação, mas também ao produtor, o coeficiente de repasse cambial é maior do que aquele para os preços de petróleo. Isto indica

\footnotetext{
${ }^{46}$ Em módulo, o setor de Informática também supera o de Derivados de petróleo na reação ao choque, porém em direção oposta, já que reduz seus preços.
} 
que o câmbio tem um papel mais determinante no processo de precificação, uma vez que tem efeitos maiores sobre os preços. Ambas são variáveis que afetam a economia como um todo e representam choques de custo, porém o câmbio se mostra como um choque que é mais difícil de absorver pelos setores como um todo, enquanto o preço do petróleo tem efeitos significativos apenas para alguns deles, de modo que uma parte do efeito do choque deve perder-se ao longo das cadeias produtivas. 


\section{CONCLUSÃO}

A estimação de um sistema de equações simultâneas é, por vezes, computacionalmente custosa, além de demandar diversas restrições de identificação, sendo que em alguns casos o número necessário não é factível. Todavia, sem a necessidade de definir restrições e aproveitando-se das relações estatísticas existentes no modelo global, o GVAR apresentou-se como uma alternativa factível para a finalidade proposta, considerando a simultaneidade de determinação entre preços de um mesmo setor, como entre os preços de diferentes setores, para assim estimar os graus de repasse cambial. Além disso, permitiu-se considerar que variáveis determinantes para o equilíbrio da economia, como o câmbio e o preço do petróleo, afetassem todas as variáveis setoriais conjuntamente, sendo que também são afetadas pelo restante das variáveis do sistema, pelo efeito de retroalimentação da unidade dominante.

Inicialmente, o problema foi definido a partir de uma estrutura analítica padrão para abordagem da questão, baseada na literatura inicial de repasse cambial voltada para modelos de equilíbrio parcial de Organização Industrial. Uniram-se então as características desta estrutura, aspectos importantes vindos da literatura de NOEM, definindo que além da existência da dinâmica de cada setor, há fatores comuns que afetam as decisões de todas as firmas e, consequentemente, o modo como choques são transmitidos, tanto no curto como no longo prazo. Tais modificações na definição da estrutura que modela as relações econômica, tornando-a mais completa e complexa, puderam ser feitas devido às características do GVAR.

As estimativas foram obtidas a partir das funções de resposta ao impulso generalizadas, tornando possível obter os graus de repasse cambial de curto e longo prazo. Os coeficientes médios de repasse estimados estão, de certa maneira, em linha com os achados da literatura internacional. Isto pois os preços de importação possuem um repasse cambial relativamente próximo de ser completo, enquanto que o repasse aos preços ao produtor são reduzidos, mesmo no longo prazo.

O que difere os resultados apresentados aqui com a literatura é que, apesar do repasse cambial os preços ao produtor se elevarem ao longo do tempo, passando de $10,4 \%$ para $21,8 \%$ após 20 trimestres, como visto na literatura, para os preços de importação a dinâmica mostra uma queda do grau de transmissão, $84,8 \%$ para $72,7 \%$. Outros trabalhos indicaram que os preços de importação teriam uma dinâmica crescente do grau de repasse, mas ao mesmo tempo, os resultados apresentados estão em linha com a teoria que assume que as firmas apenas modificam seus preços em vista de mudança de expectativa de que o choque seja permanente. Além do que, os efeitos transbordamento de um setor para o outro deve possuir defasagens, bem como as pressões competitivas para o ajuste dos preços.

Por sua vez, as estimativas dos coeficientes setoriais têm pouca base de comparação para os preços brasileiros, cuja referência existente é Kannebley Júnior, Reis e Toneto Júnior 
(2016). Estes utilizam os vetores de cointegração dos VECMs estimados setor a setor para identificar a elasticidades de longo prazo dos preços ao câmbio, de modo que os coeficientes não são comparáveis entre si. Ainda assim, foi possível avaliar, em certo grau, o repasse de longo prazo, mas não a dinâmica do coeficiente ao longo do tempo. O repasse médio, tanto para preços de importação como ao atacado, se mostrou em linha com o trabalho anterior.

Ademais, foi possível verificar que os coeficientes, obtidos pelo uso do GVAR, têm menor variabilidade do que aqueles de Kannebley Júnior, Reis e Toneto Júnior (2016). Esta característica pode ser um indicativo da capacidade do GVAR de captar efeitos dos fatores comuns sistêmicos e de transbordamento entre setores, além de explicar o motivo por detrás da correlação não estatisticamente significante dos coeficientes de repasse cambial com os indicadores de abertura comercial (contrária à evidência coletada por Kannebley Júnior, Reis e Toneto Júnior (2016)). O grau de repasse pode vir a ser pouco correlacionado com tais variáveis, pois as relações intersetoriais têm um papel também determinante na definição da transmissão do choque. Deste modo, a resposta com apenas efeitos diretos pode ser mais dependente da abertura comercial, mas considerar também efeitos indiretos dependeria de outros tantos fatores para determinar o grau de repasse que precisariam ser controlados.

Com respeito especificamente aos setores, pôde-se verificar que o setor Derivados de petróleo tem um baixo repasse do câmbio para preços de importação e ao produtor (no primeiro, uma queda significativa no tamanho do repasse nos trimestres logo seguidos ao choque, enquanto o segundo é reduzido em todo horizonte). Outro que apresenta baixo coeficiente para ambos preços é o de Farmoquímicos. Por outro lado, outros apresentam altos coeficientes, como Produtos de metal, Informática, Máquinas e equipamentos, Outros equipamentos de transporte.

Por sua vez, devido à característica do GVAR de permitir a inclusão de outras variáveis globais que afetem os preços de todos os setores do sistema, foi considerado o preço do barril de petróleo. Este é tido como um insumo que, além de essencial para diversos processos produtivos, traz consigo informações acerca de outras características da economia mundial. Dada sua importância, calculou-se também o repasse de seu choque aos preços brasileiros.

Tanto para o preço de importação como ao atacado, o grau de transmissão do choque é, inicialmente, bastante reduzido, em média, com uma trajetória de crescimento suave (maior para os preços de importação, que 14,5\% para 28,6\%, após cinco anos do choque, enquanto que os preços ao produto vão de $4 \%$ a 8,9\%), em linha com a evidência apresentada por Castro e Jiménez-Rodríguez (2017). É notável que a transmissão de surpresas cambiais levam a maiores ajustes dos preços, em média, do que as do preço do petróleo.

Analisando setorialmente, a atividade que mais é afetada pelo choque é a de Derivados de petróleo, que é uma das que menos repassa variações cambiais, devido a sua demanda pela commodity para processos manufatureiros. Outros setores de destaque com maiores graus de 
repasse são Químicos, Metalurgia e Produtos de metal. Como destaque de baixa transmissão do choque do preço do petróleo está Outros equipamentos de transporte, enquanto o setor de Fumo mostra recuo de seus preços frente à variação da precificação da commodity.

A estimação sistêmica para os setores da indústria de transformação, introduzida a partir do uso do GVAR de Pesaran, Schuermann e Weiner (2004), teve como intuito a solução do problema de estimação de um sistema de equações simultâneas com regressores endógenos, uma vez que estes são afetados por efeitos comuns que também fazem parte das variáveis endógenas do problema, os preços. A solução trazida pelo GVAR, como proposto por Dées et al. (2007), é capaz de aproximar os fatores comuns, além de permitir a captação de efeitos transbordamento entre os setores a que se referem às equações do modelo. Tais características trouxeram novas evidências acerca do repasse, como coeficientes setoriais, em média, maiores do que estimados por outras metodologias e com menor dispersão (além de permitir observar a dinâmica temporal do coeficiente após um choque cambial). Além disso, permitiu-se também estimar a transmissão de outro choque, o de preços de petróleo, questão ainda pouco explorada dentro da sua literatura específica, mas encontra interesse comum para o estudo do repasse cambial, o entendimento da dinâmica dos preços. 



\section{REFERÊNCIAS}

ATKESON, A.; BURSTEIN, A. Pricing-to-market, trade costs, and international relative prices. American Economic Review, v. 98, n. 5, p. 1998-2031, 2008.

AUER, R. A.; SCHOENLE, R. S. Market structure and exchange rate pass-through. Journal of International Economics, v. 98, p. 60-77, 2016.

BACHE, I. W. Econometrics of exchange rate pass-through. Tese (Doutorado) - Universidade de Oslo, Oslo, Setembro 2006.

BACHE, I. W.; NAUG, B. E. Estimating New Keynesian import price models. Oslo, 2007. (Working Paper Research Department, 15). Disponível em: <https://brage.bibsys.no/xmlui/ handle/11250/2498257>.

BELAISCH, A. A. Exchange rate pass-through in Brazil. [S.l.], 2003. (IMF Working Papers, 03/141). Disponível em: <https://www.imf.org/en/Publications/WP/Issues/2016/12/30/ Exchange-Rate-Pass-Through-in-Brazil-16622>.

BERGIN, P. R.; FEENSTRA, R. C. Pricing-to-market, staggered contracts, and real exchange rate persistence. Journal of International Economics, v. 54, p. 333-359, 2001.

BETTS, C.; DEVEREUX, M. B. The exchange rate in a model of pricing-to-market. European Economic Review, v. 40, n. 3-5, p. 1007-1021, 1996.

. Exchange rate dynamics in a model of pricing-to-market. Journal of International Economics, v. 50, n. 1, p. 215-244, 2000.

BHATTACHARYA, P. S.; KARAYALCIN, C. A.; THOMAKOS, D. D. Exchange rate pass-through and relative prices: An industry-level empirical investigation. Journal of International Money and Finance, v. 27, n. 7, p. 1135-1160, 2008.

BURSTEIN, A.; GOPINATH, G. International prices and exchange rates. In: GOPINATH, G.; HELPMAN, E.; ROGOFF, K. (Ed.). Handbook of International Economics. 1. ed. Oxford: Elsevier, 2014. v. 4, Capítulo 7, p. 391-451.

CALVO, G. A. Staggered prices in a utility-maximizing framework. Journal of Monetary Economics, v. 12, n. 3, p. 383-398, 1983.

CAMPA, J. M.; GOLDBERG, L. S. Exchange rate pass-through into import prices. Review of Economics and Statistics, v. 87, n. 4, p. 679-690, 2005.

CAO, S.; DONG, W.; TOMLIN, B. Pricing-to-market, currency invoicing and exchange rate pass-through to producer prices. Journal of International Money and Finance, v. 58, p. 128-149, 2015.

CASAS, C.; DÍEZ, F. J.; GOPINATH, G.; GOURINCHAS, P. O. Dominant currency paradigm: A new model for small open economies. [S.1.], 2017. (IMF Working Paper Series, 17/264). Disponível em: <https://www.imf.org/en/Publications/WP/Issues/2017/11/22/ Dominant-Currency-Paradigm-A-New-Model-for-Small-Open-Economies-45431>. 
CASTILHO, M.; MIRANDA, P. Tarifa aduaneira como instrumento de política industrial: A evolução da estrutura de proteção tarifária no brasil no período 2004-2014. In: MESSA, A.; OLIVEIRA, I. T. M. (Ed.). A política comercial brasileira em análise. 1. ed. Brasília: Instituto de Pesquisa Econômica Aplicada, 2017. Capítulo 1, p. 13-73.

CASTRO, C.; JIMÉNEZ-RODRÍGUEZ, R. Oil price pass-through along the price chain in the Euro Area. Energy Economics, v. 64, p. 24-30, 2017.

CHEN, S. S. Oil price pass-through into inflation. Energy Economics, v. 31, n. 1, p. 126-133, 2009.

CHOUDHRI, E. U.; FARUQEE, H.; HAKURA, D. S. Explaining the exchange rate pass-through in different prices. Journal of International Economics, v. 65, n. 2, p. 349-374, 2005.

CHOUDHRI, E. U.; HAKURA, D. S. Exchange rate pass-through to domestic prices: does the inflationary environment matter? Journal of International Money and Finance, v. 25, n. 4, p. 614-639, 2006.

CHUDIK, A.; PESARAN, M. H. Econometric analysis of high dimensional VARs featuring a dominant unit. Econometric Reviews, v. 32, n. 5-6, p. 592-649, 2013.

. Theory and Practice of GVAR Modelling. Journal of Economic Surveys, v. 30, n. 1, p. 165-197, 2016.

CORSETTI, G.; DEDOLA, L. A macroeconomic model of international price discrimination. Journal of International Economics, v. 67, n. 1, p. 129-155, 2005.

DÉES, S.; DI MAURO, F.; PESARAN, M. H.; SMITH, L. V. Exploring the international linkages of the Euro Area: a Global VAR analysis. Journal of Applied Econometrics, v. 22, n. 1, p. 1-38, 2007.

DI MAURO, F.; PESARAN, M. H. The GVAR Handbook: Structure and applications of a macro model of the global economy for policy analysis. 1. ed. Oxford: Oxford University Press, 2013.

DORNBUSCH, R. Exchange rates and prices. American Economic Review, v. 77, n. 1, p. 93-106, 1987.

FARUQEE, H. Exchange rate pass-through in the Euro Area. IMF Staff Papers, v. 53, n. 1, p. 63-88, 2006.

FISHER, E. A model of exchange rate pass-through. Journal of International Economics, v. 26, n. 1, p. 119-137, 1989.

FORBES, K.; HJORTSOE, I.; NENOVA, T. The shocks matter: improving our estimates of exchange rate pass-through. Journal of International Economics, v. 114, p. 255-275, 2018.

FROOT, K.; KLEMPERER, P. Exchange rate pass-through when market share matters. American Economic Review, v. 79, n. 4, p. 637-654, 1989.

GAGNON, J. E.; IHRIG, J. Monetary policy and exchange rate pass-through. International Journal of Finance \& Economics, v. 9, n. 4, p. 315-338, 2004.

GALÍ, J.; MONACELLI, T. Monetary policy and exchange rate volatility in a small open economy. The Review of Economic Studies, v. 72, n. 3, p. 707-734, 2005. 
GARRATT, A.; LEE, K.; PESARAN, M. H.; SHIN, Y. Global and national macroeconometric modelling: a long-run structural approach. Oxford: Oxford University Press, 2006.

GOLDBERG, P. K.; HELLERSTEIN, R. A structural approach to explaining incomplete exchange-rate pass-through and pricing-to-market. American Economic Review, v. 98, n. 2, p. 423-429, 2008.

GOLDBERG, P. K.; KNETTER, M. M. Goods prices and exchange rates: What have we learned? Journal of Economic Literature, v. 35, n. 3, p. 1243-1272, 1997.

GOPINATH, G.; ITSKHOKI, O.; RIGOBON, R. Currency choice and exchange rate pass-through. American Economic Review, v. 100, n. 1, p. 304-336, 2010.

GREENE, W. H. Econometric Analysis. 5. ed. Nova Jérsei: Prentice Hall, 2003.

GUILHOTO, J. J. M.; SESSO FILHO, U. A. Estimação da matriz insumo-produto a partir de dados preliminares das Contas Nacionais. Economia Aplicada, v. 9, n. 2, p. 277-299, 2005.

. Estimação da matriz insumo-produto utilizando dados preliminares das Contas Nacionais: Aplicação e análise de indicadores econômicos para o Brasil em 2005. Economia \& Tecnologia, v. 23, n. 6, 2010.

HARBO, I.; JOHANSEN, S.; NIELSEN, B.; RAHBEK, A. Asymptotic inference on cointegrating rank in partial systems. Journal of Business \& Economic Statistics, v. 16, n. 4, p. 388-399, 1998.

HEBOUS, S.; ZIMMERMANN, T. Estimating the effects of coordinated fiscal actions in the Euro Area. European Economic Review, v. 58, p. 110-121, 2013.

HIEBERT, P.; VANSTEENKISTE, I. International trade, technological shocks and spillovers in the labour market: a GVAR analysis of the US manufacturing sector. Applied Economics, v. 42, n. 24, p. 3045-3066, 2010.

HOLLY, S.; PETRELLA, I. Factor demand linkages, technology shocks, and the business cycle. Review of Economics and Statistics, v. 94, n. 4, p. 948-963, 2012.

HOOKER, M. A. Are oil shocks inflationary? asymmetric and nonlinear specifications versus changes in regime. Journal of Money, Credit and Banking, p. 540-561, 2002.

HOOPER, P.; MANN, C. L. Exchange rate pass-through in the 1980s: the case of US imports of manufactures. Brookings Papers on Economic Activity, v. 1989, n. 1, p. 297-337, 1989.

ITO, T.; SATO, K. Exchange rate changes and inflation in post-crisis Asian Economies: Vector autoregression analysis of the exchange rate pass-through. Journal of Money, Credit and Banking, v. 40, n. 7, p. 1407-1438, 2008.

JOHANSEN, S. Estimation and hypothesis testing of cointegration vectors in Gaussian vector autoregressive models. Econometrica, v. 59, n. 6, p. 1551-1580, 1991.

. Cointegration in partial systems and the efficiency of single-equation analysis. Journal of Econometrics, v. 52, n. 3, p. 389-402, 1992.

KANNEBLEY JÚNIOR, S.; REIS, G. H. A.; TONETO JÚNIOR, R. Repasse cambial na indústria de transformação brasileira: uma análise para os preços de importação e ao atacado - 1999 a 2012. Economia e Sociedade, v. 25, n. 56, p. 25-50, 2016. 
KOOP, G.; PESARAN, M. H.; POTTER, S. M. Impulse responde analysis in nonlinear multivariate models. Journal of Econometrics, v. 74, n. 1, p. 119-147, 1996.

KRUGMAN, P. R. Pricing to market when the exchange rate changes. Cambridge, Massachusetts, 1986. (NBER Working Paper Series, 1926). Disponível em: <http: //www.nber.org/papers/w1926>.

LUCAS, R. E. Econometric policy evaluation: A Critique. In: BRUNNER, K.; MELTZER, A. (Ed.). The Phillips Curve and Labor Markets. New York: North Holland, 1976. (Carnegie Rochester Conference Series), p. 19-46.

MACKINNON, J. G.; HAUG, A. A.; MICHELIS, L. Numerical distribution functions of likelihood ratio tests for cointegration. Journal of Applied Econometrics, v. 14, n. 5, p. 563-577, 1999.

MCCARTHY, J. Pass-through of exchange rates and import prices to domestic inflation in some industrialized economies. Eastern Economic Journal, v. 33, n. 4, p. 511-537, 2007.

MENON, J. Exchange rate pass-through. Journal of Economic Surveys, v. 9, n. 2, p. 197-231, 1995.

MILLER, R. E.; BLAIR, P. D. Input-Output Analysis: Foundations and Extensions. 2. ed. New York: Cambridge University Press, 2009.

NAKAMURA, E.; ZEROM, D. Accounting for incomplete pass-through. Review of Economic Studies, v. 77, n. 3, p. 1192-1230, 2010.

OBSTFELD, M.; ROGOFF, K. Exchange rate dynamics redux. Journal of Political Economy, v. 103, n. 3, p. 624-660, 1995.

PENNINGS, S. Pass-through of competitors' exchange rates to US import and producer prices. Journal of International Economics, v. 105, p. 41-56, 2017.

PESARAN, M. H. Estimation and inference in large heterogeneous panels with a multifactor error structure. Econometrica, v. 74, n. 4, p. 967-1012, 2006.

. Time Series and Panel Data Econometrics. 1. ed. Oxford: Oxford University Press, 2015.

PESARAN, M. H.; SCHUERMANN, T.; WEINER, S. M. Modeling regional interdependencies using a global error-correcting macroeconometric model. Journal of Business \& Economic Statistics, v. 22, n. 2, p. 129-162, 2004.

PESARAN, M. H.; SHIN, Y. Generalized impulse response analysis in linear multivariate models. Economics Letters, v. 58, n. 1, p. 17-29, 1998.

PESARAN, M. H.; SHIN, Y.; SMITH, R. J. Structural analysis of vector error correction models with exogenous I(1) variables. Journal of Econometrics, v. 97, n. 2, p. 293-343, 2000.

RAZAFINDRABE, T. M. A multi-country DSGE model with incomplete exchange rate pass-through: An application for the Euro-area. Economic Modelling, v. 52, p. 78-100, 2016.

SIMS, C. A. Macroeconomics and reality. Econometrica, p. 1-48, 1980.

SMITH, L. V.; GALESI, A. GVAR Toolbox 2.0. 2014. <https://sites.google.com/site/ gvarmodelling/gvar-toolbox>. 
TAYLOR, J. B. Aggregate dynamics and staggered contracts. Journal of Political Economy, v. 88, n. 1, p. 1-23, 1980.

. Low inflation, pass-through, and the pricing power of firms. European Economic Review, v. 44, n. 7, p. 1389-1408, 2000.

YANG, J. Exchange rate pass-through in US manufacturing industries. Review of Economics and Statistics, v. 79, n. 1, p. 95-104, 1997.

ZELLNER, A. An efficient method of estimating seemingly unrelated regressions and tests for aggregation bias. Journal of the American Statistical Association, v. 57, n. 298, p. 348-368, 1962. 

APÊNDICES 



\section{APÊNDICE A - RECONSTRUÇÃO DAS SÉRIES DE ÍNDICE DE PREÇOS DE IMPORTAÇÃO DOS ESTADOS UNIDOS}

Como mencionado na Seção 3.2, os dados do Índice de Preços de Importação dos Estados Unidos produzidos pelo BLS, que servem na estrutura utilizada como proxy do custo de produção das firmas estrangeiras, tiveram mudanças em suas estruturas de classificação. A pesquisa que anteriormente era divulgada usando a Standard International Trade Classification (SITC), passou a ter dados classificados pelo North American Industry Classification System (NAICS), sendo que as séries não foram retroagidas desde seu início para a nova classificação. Assim, as aberturas setoriais do índice usando o NAICS possuem informação a partir de 2005, o que deixaria o presente trabalho com uma amostra bastante reduzida.

Adicionalmente, o BLS também divulga os dados o índice de preços para outras duas classificações, o Harmonized System (HS) e o índice por End of Use (EoU), sendo que ambos têm séries cujos períodos iniciais datam da década de 1990. Nenhum dos dois sistemas, entretanto, possui padrão similar à CNAE, que é uma vantagem no uso do NAICS. Ademais, apesar de dispor-se de três sistemas de classificação para um mesmo indicador, o BLS não fornece a divulgação dos itens da pesquisa, em nenhuma delas, de maneira granulada o suficiente para que seja feita a "tradução" de uma classificação internacional para a brasileira.

Dadas as tais dificuldades na compatibilização das bases de dados internacional e brasileira, decidiu-se por tentar recriar os índices correspondentes aos setores como classificados pelo NAICS, com base na disponibilidade de dados dos sistemas HS e EoU. A partir dessas duas pesquisas, pode-se observar que, mesmo as informações em nível mais detalhado, em alguns casos, não eram suficientes para selecionar as atividades contidas dentro de alguns setores definidos pelo NAICS (seja por inexistência de informações ou mesmo pela aglutinação de atividades em itens que, de acordo com NAICS, pertenceriam a setores distintos). Dispondo-se dos sistemas HS e EoU, apesar de tais dificuldades, foi possível criar um índice ponderado, a partir de ao menos uma das classificações, para cada setor da amostra utilizada neste trabalho ${ }^{47}$ (para alguns setores foi possível criar um índice para cada uma das classificações).

Tendo selecionado, a partir da HS e da EoU, os itens que compõem cada um dos setores, foi preciso ponderá-los para assim obter um índice agregado. Em virtude do uso dos dados como uma proxy dos custos externos das firmas que comercializam com o Brasil,

\footnotetext{
${ }^{47}$ É importante destacar aqui a obtenção de índices para todos os setores, sendo que, utilizando apenas o NAICS, não seria possível contemplar na estimação o setor de Fumo, uma vez que este não fazia parte das categorias disponibilizadas pelo BLS em tal classificação. Todavia, a EoU continha uma categoria cuja série possui tais informações.
} 

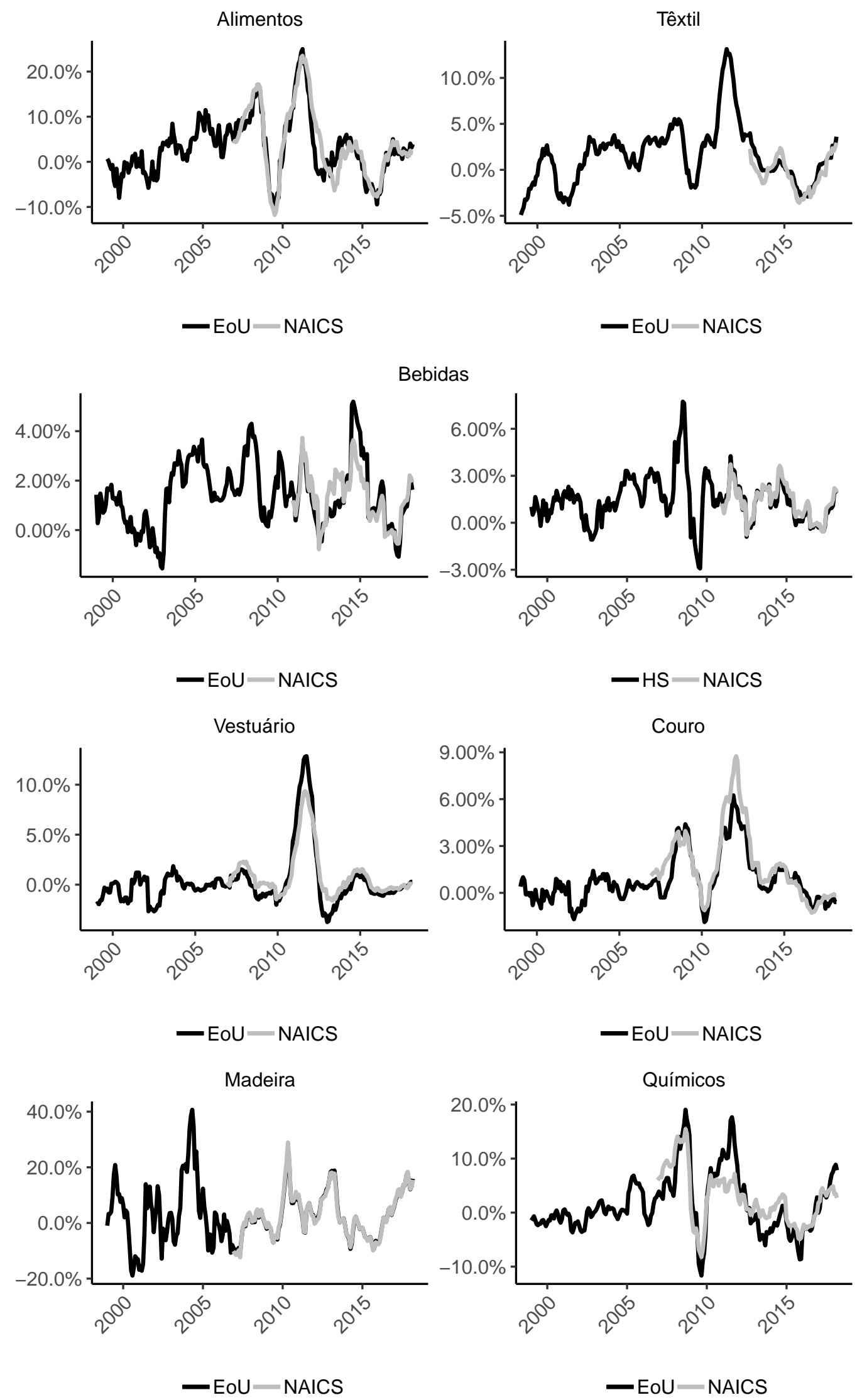

Figura A.1 - Variações YoY \% dos índices ponderados dos preços das importações dos Estados Unidos 


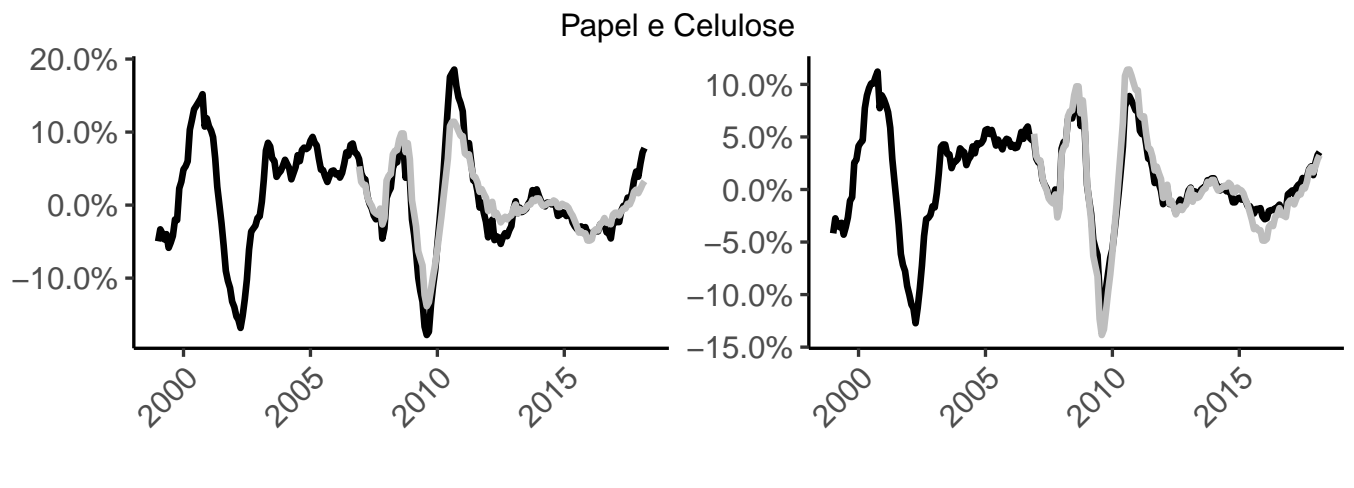

- EoU - NAICS

- HS - NAICS

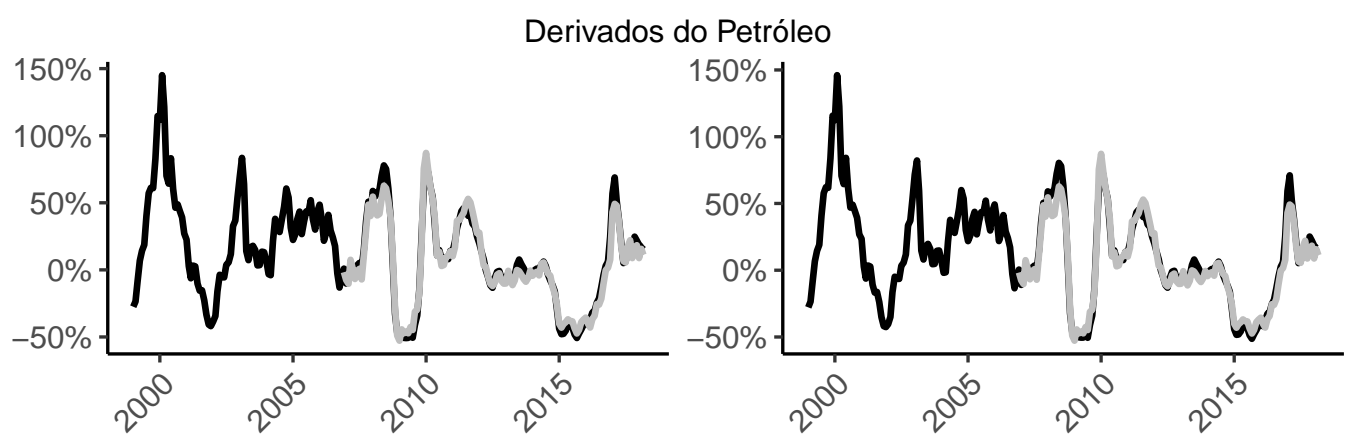

- EoU - NAICS

- HS - NAICS

Farmoquímicos
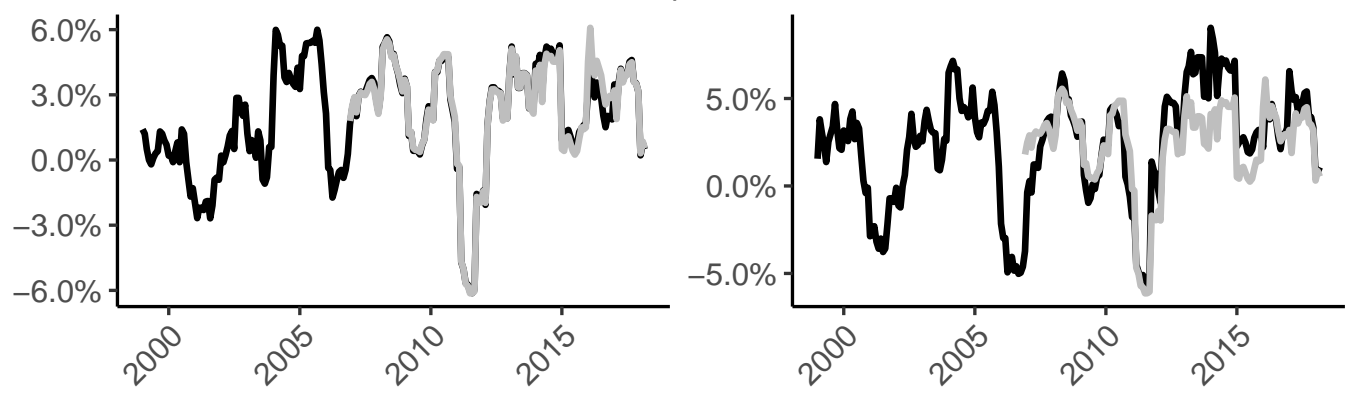

- EoU - NAICS

- HS - NAICS

Borracha e Plástico
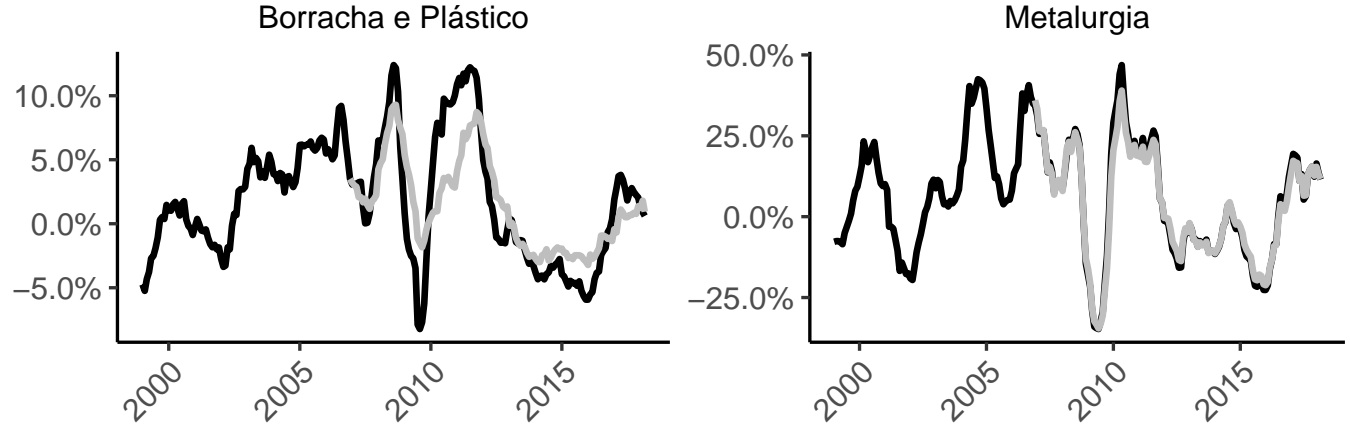

- HS - NAICS

- EoU - NAICS

Figura A.1 (cont.) - Variações YoY \% dos índices ponderados dos preços das importações dos Estados Unidos 

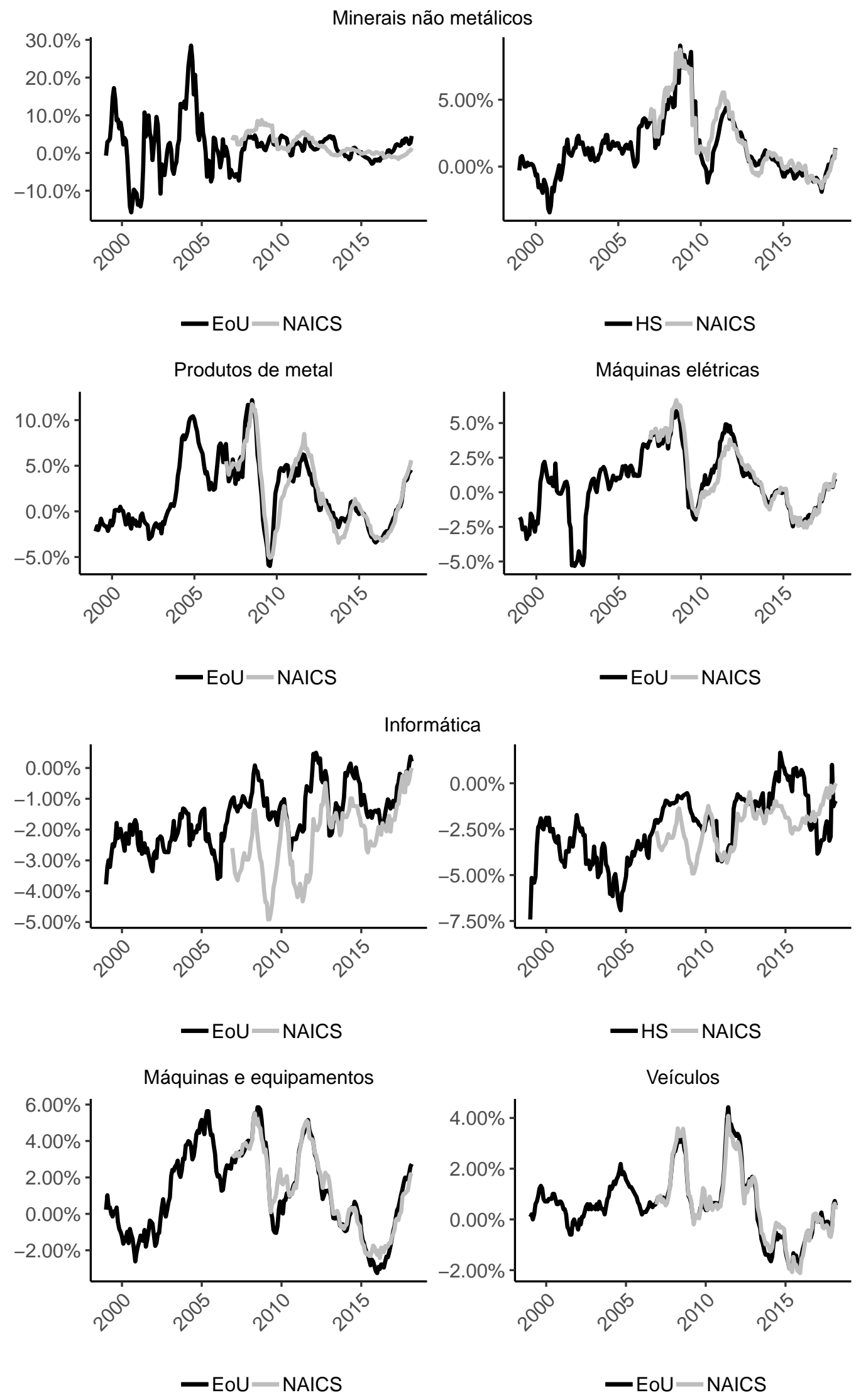

Figura A.1 (cont.) - Variações YoY \% dos índices ponderados dos preços das importações dos Estados Unidos 

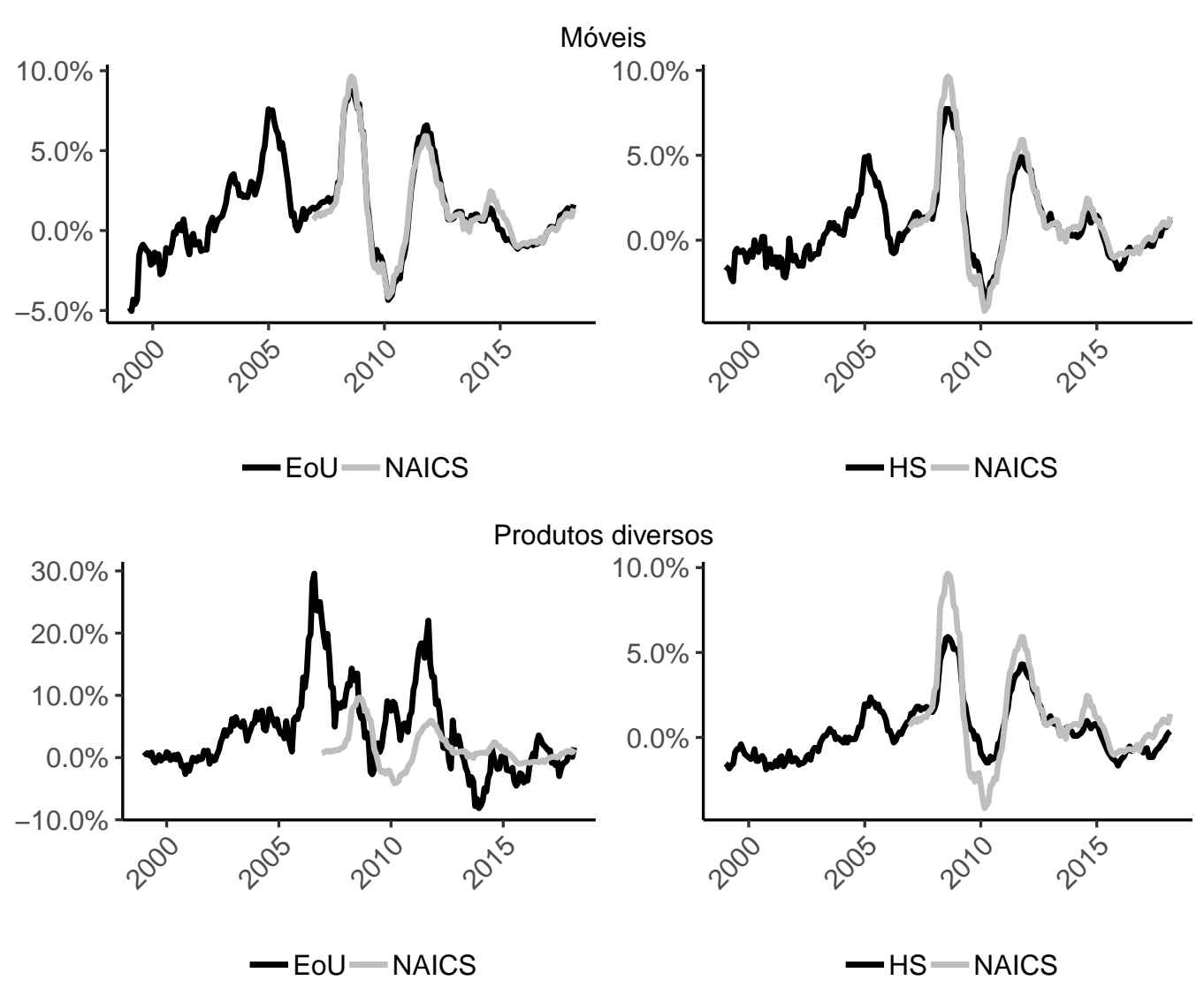

Figura A.1 (cont.) - Variações YoY \% dos índices ponderados dos preços das importações dos Estados Unidos

utilizaram-se os dados do valor das importações disponíveis no sistema de séries históricas da Funcex, que datam de 2005. Foram calculados os pesos mensais a partir da classificação CNAE a três dígitos e, usando a média histórica de 2005 a 2017 de tais pesos, os índices foram reponderados dentro de um indicador agregado para cada setor.

Na Figura A.1 estão dispostos os resultados obtidos a partir deste exercício. As séries em cor cinza são referentes aos dados disponibilizados pelo BLS de acordo com o NAICS (como constam nas legendas dos gráficos). Aquelas em cor preta, denominadas "EoU" ou "HS", são as séries obtidas a partir da ponderação realizada a partir dos dados da aberturas do índice usando o sistema de classificação especificado na legenda.

Para a apresentação dos resultados do exercício escolheu-se dispor a variação percentual ano-contra-ano (year over year, YoY \%), que nada mais é do que a variação do índice em um mês quando comparado com o mesmo mês do ano anterior. A partir dessa base de comparação, pode-se observar que, apesar do uso de uma ponderação diferente daquela utilizada pelo BLS, os dados aqui construídos acabam por imitar o comportamento da pesquisa que considera o NAICS.

Uma vez que os dados construídos a partir das informações dos índices de preços de importação, classificados pelos sistemas HS ou EoU, foram capazes de se comparar aos dados 
setoriais originais categorizados pelo NAICS, decidiu-se projetar os períodos faltantes desta última categorização utilizando as séries construídas. A projeção dos dados usando o NAICS foi feita utilizando MQO, sendo que as séries reponderadas foram usadas como variáveis explicativas de tais regressões. Uma vez que as séries são não estacionárias, foram utilizadas as primeiras diferenças destas nas estimações.

É importante notar que, como para alguns setores foi possível obter uma série a partir do índice utilizando o HS e outra daquele que usa o EoU, ambas foram utilizadas como regressores para estimar os dados dos setores como classificados pelo NAICS. Dessa maneira, informações disponíveis não foram desperdiçadas no processo, e o seguinte modelo seria estimado, sempre que possível:

$$
\text { naics }_{i t}=\beta_{0}+\beta_{1} e^{e o u_{i t}}+\beta_{2} h s_{i t}+e_{i t}
$$

em que $n a i c s_{i t}$ é a série obtida do BLS e $e o u_{i t}$ e $h s_{i t}$ são as séries construídas, cada qual nomeada a partir do sistema do qual advêm as aberturas utilizadas, todas elas referentes ao setor $i$. No caso em que, para o setor $i$, só tenha sido obtida uma série do exercício inicial, haveria apenas um regressor.

No processo de estimação do modelo, foi utilizada a metodologia Box-Jenkins para definição da ordem dos modelos ARIMA de cada um dos setores, como é usual em análise de séries temporais. Em alguns casos, apenas o modelo como está acima foi suficiente, enquanto em outros casos utilizou-se das defasagens das séries ponderadas corrigir os resíduos do modelo. Após esse passo, foi obtido o valor ajustado pelo modelo para a sua variável dependente.

O resultado deste exercício pode ser visto na Figura A.2. As séries em cor cinza continuam sendo as variações ano-contra-ano do índice vindo do BLS, enquanto que agora as séries em cor preta são as variações dos valores ajustados por cada um dos modelos. Por fim, para a obtenção das séries desde de 1999, foram utilizadas as variações ano-contra-ano sob as séries originais do BLS sob o NAICS de cada setor, para assim concatená-las e completar as séries com os períodos faltantes.

Por fim, um último detalhe é preciso ser discutido. Quando foram construídas as séries a partir da reponderação das aberturas dos índices calculados pelo BLS, de fato foram obtidos indicadores para todos os setores da amostra. Entretanto, para o setor de Outros equipamentos de transporte, apesar da existência de informações de seus preços no índice calculado usando a classificação EoU, estes dados existiam apenas a partir de dezembro de 2001 (enquanto para os demais, foram obtidas séries de janeiro de 1999).

Para a estimação dos dados de Outros equipamentos de transporte adotou-se outra estratégia. Primeiramente, observou-se que os preços dos bens importados para os setores de Produtos de metal e Máquinas e equipamentos possuíam comportamento bastante similar ao da série que ainda precisava ser estimada. A fim de comprovar a existência de uma relação 

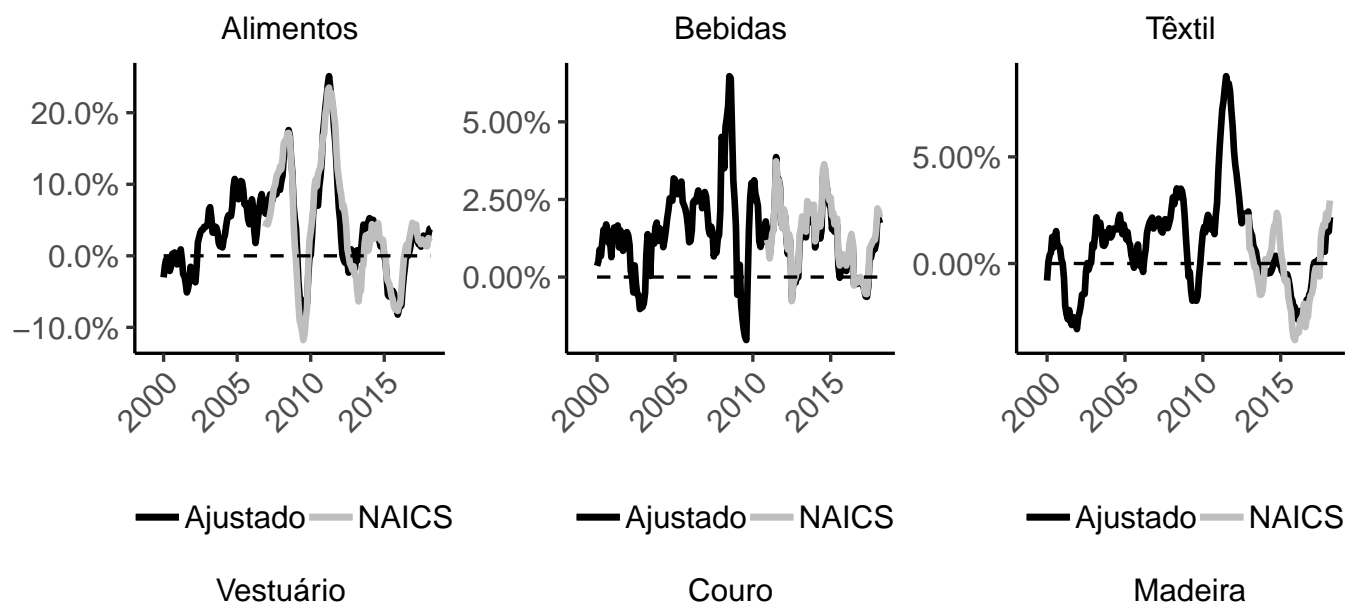

- Ajustado - NAICS

- Ajustado - NAICS

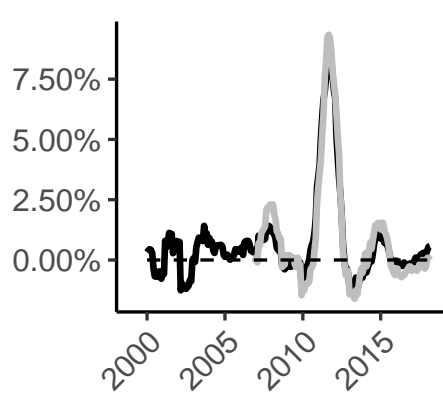

Couro

Madeira
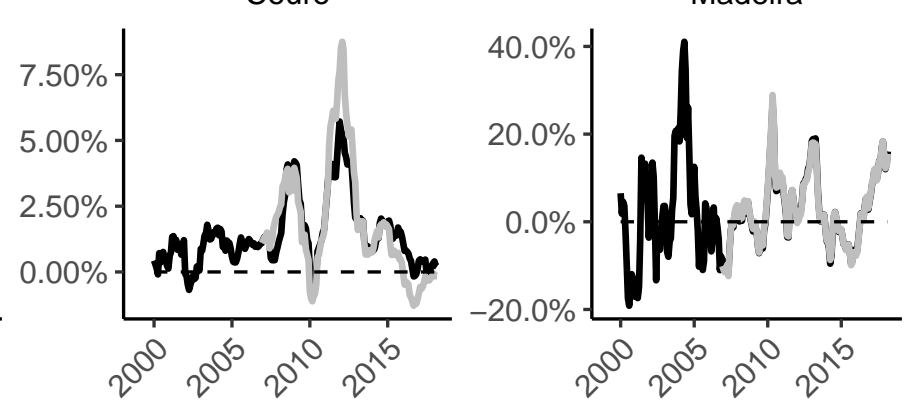

- Ajustado - NAICS

- Ajustado - NAICS

- Ajustado - NAICS

Celulose e Papel

Derivados do petróleo

Químicos
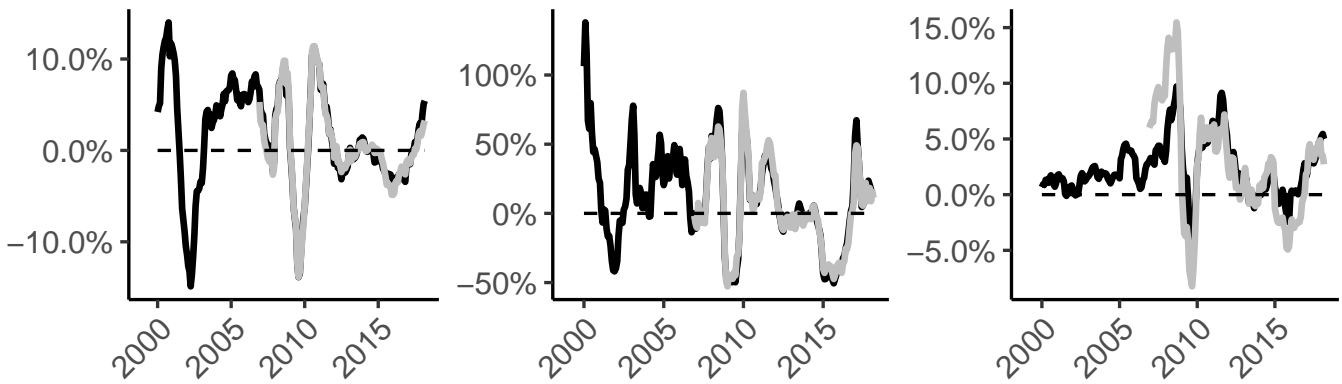

- Ajustado - NAICS

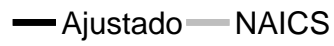

- Ajustado - NAICS

Farmoquímicos

Borracha e Plástico
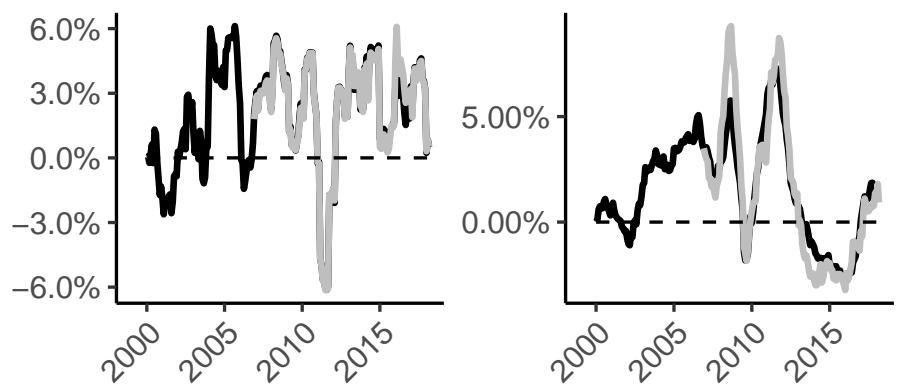

Minerais não metálicos

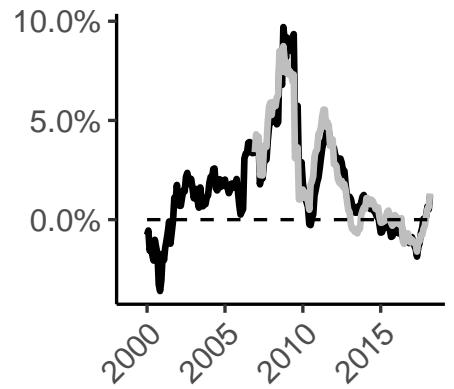

- Ajustado - NAICS

- Ajustado - NAICS

- Ajustado - NAICS

Figura A.2 - Variações YoY \% das projeções para os índices de preços das importações dos Estados Unidos 

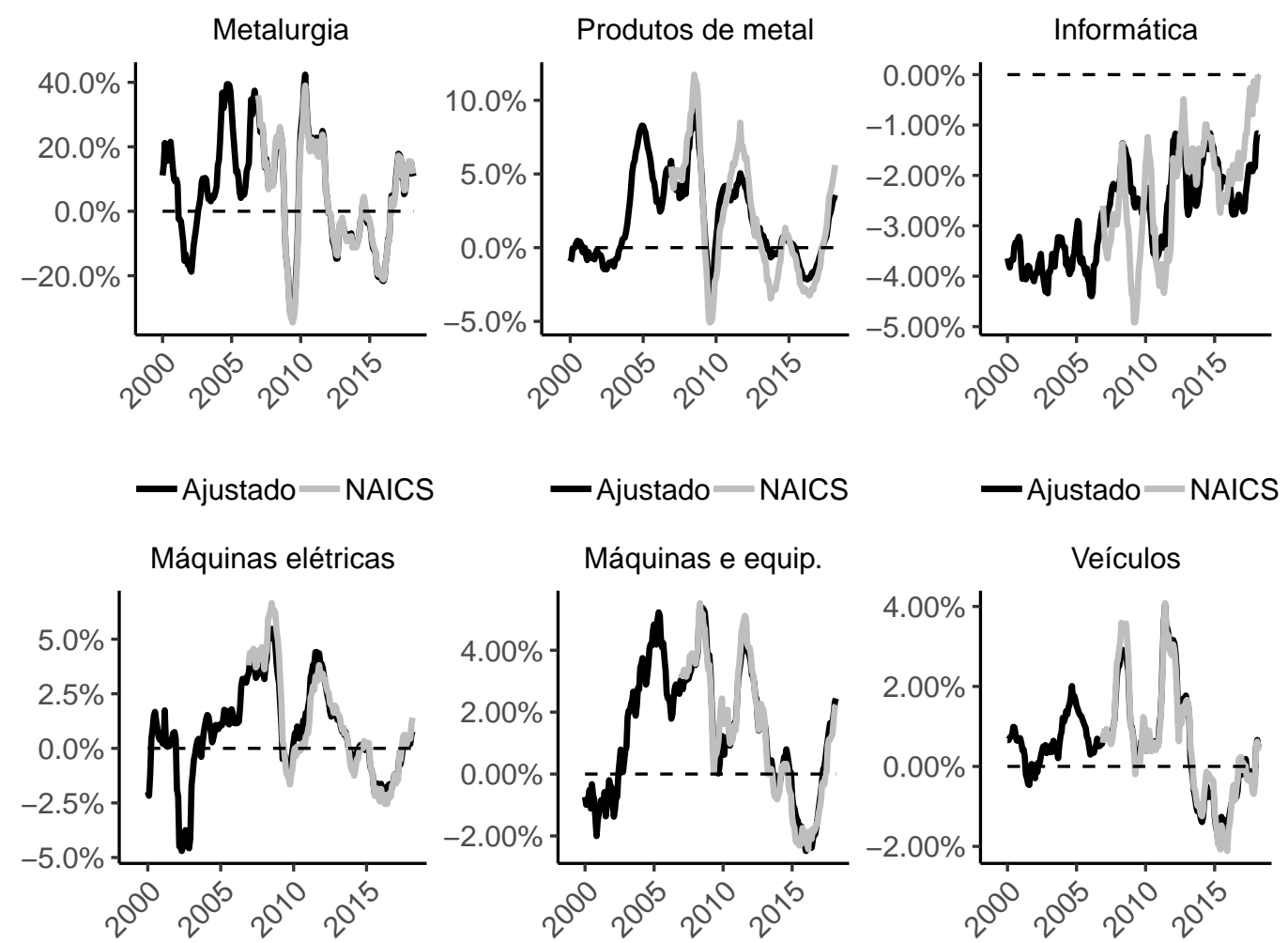

- Ajustado - NAICS

- Ajustado - NAICS

- Ajustado - NAICS

Outros eq. transp.

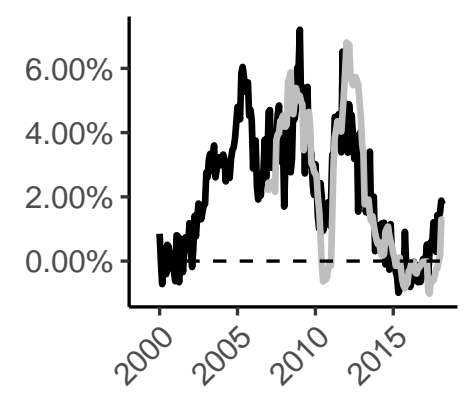

Móveis

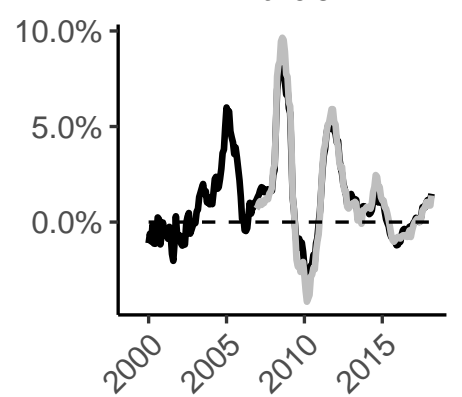

Produtos diversos

- Ajustado - NAICS

- Ajustado - NAICS

- Ajustado - NAICS

Figura A.2 (cont.) - Variações YoY \% das projeções para os índices de preços das importações dos Estados Unidos 
entre estas séries, testou-se a hipótese de cointegração entre elas ${ }^{48}$ a partir dos testes do traço e de máximo autovalor de Johansen (1991). Tais testes indicaram a presença de cointegração entre as séries mencionadas.

A partir da conclusão da existência de cointegração entre os preços dos três setores, decidiu-se realizar a projeção do índice de preços de Outros equipamentos de transporte utilizando como regressores os índices concatenados para os setores de Produtos de metal e Máquinas e equipamentos. A estimação do modelo é feita utilizando a metodologia de Fully-modified Ordinary Least Squares (FMOLS) dada a existência de cointegração entre as séries, considerando também a presença de tendência linear na especificação, uma vez que esta é significativa dentro do vetor de cointegração (o que foi observado quando se realizou o teste de Johansen (1991)). Em posse da projeção realizada a partir do modelo descrito, concatena-se a série do índice classificado pelo NAICS como realizado para os demais setores, obtendo-se a última série necessária para a realização do exercício proposto neste trabalho.

\footnotetext{
${ }^{48}$ Para a realização do teste, foram utilizadas as séries concatenadas dos setores de Produtos de metal e Máquinas e equipamentos, juntamente com a série original de Outros equipamentos de transporte de acordo com o NAICS.
} 



\section{APÊNDICE B - RESULTADOS DA ESTIMAÇÃO DOS VETORES DE COINTEGRAÇÃO SETORIAIS}

\begin{tabular}{|c|c|c|c|c|c|c|c|c|c|c|c|c|c|c|}
\hline Setores & $\alpha$ & $p^{i}$ & $p^{a}$ & $c^{e}$ & $\beta$ & Tendência & $p^{i}$ & $p^{a}$ & $c^{e}$ & $p^{i *}$ & $p^{a *}$ & $c^{e *}$ & $e$ & $p^{o}$ \\
\hline Alimentos & - & - & - & - & - & - & - & - & - & - & - & - & - & - \\
\hline \multirow[b]{2}{*}{ Bebidas } & $\alpha_{1}$ & $-0,47$ & $-0,02$ & $-0,02$ & Vetor 1 & $-0,03$ & 1,00 & 0,00 & 5,78 & $-2,91$ & 0,94 & 0,60 & $-0,50$ & $-0,05$ \\
\hline & $\alpha_{2}$ & $-1,01$ & $-0,60$ & 0,03 & Vetor 2 & $-0,01$ & 0,00 & 1,00 & $-0,32$ & 0,36 & $-0,23$ & $-0,96$ & $-0,10$ & 0,08 \\
\hline Fumo & $\alpha_{1}$ & $-0,69$ & $-0,04$ & 0,00 & Vetor 1 & $-0,04$ & 1,00 & 0,91 & $-0,10$ & 0,69 & 0,79 & $-1,07$ & $-0,21$ & 0,02 \\
\hline Têxtil & $\alpha_{1}$ & $-0,12$ & 0,03 & $-0,03$ & Vetor 1 & 0,01 & 1,00 & $-2,98$ & 5,32 & $-0,88$ & 3,63 & $-4,80$ & $-1,24$ & $-0,42$ \\
\hline \multirow[b]{2}{*}{ Vestuário } & $\alpha_{1}$ & $-0,74$ & $-0,01$ & $-0,01$ & Vetor 1 & $-0,02$ & 1,00 & 0,00 & $-7,79$ & $-0,01$ & 1,29 & 6,22 & 0,01 & $-0,46$ \\
\hline & $\alpha_{2}$ & $-0,67$ & $-0,08$ & $-0,03$ & Vetor 2 & 0,01 & 0,00 & 1,00 & 10,24 & $-1,33$ & $-1,44$ & $-7,83$ & $-0,20$ & 0,57 \\
\hline \multirow{3}{*}{ Couro } & $\alpha_{1}$ & $-0,92$ & $-0,04$ & 0,02 & Vetor 1 & $-0,01$ & 1,00 & 0,00 & 0,00 & $-0,60$ & 0,91 & $-1,03$ & $-0,43$ & $-0,06$ \\
\hline & $\alpha_{2}$ & $-0,29$ & $-0,20$ & 0,00 & Vetor 2 & 0,00 & 0,00 & 1,00 & 0,00 & 0,82 & $-0,04$ & $-1,85$ & $-0,42$ & $-0,11$ \\
\hline & $\alpha_{3}$ & 0,91 & 0,11 & $-0,30$ & Vetor 3 & 0,00 & 0,00 & 0,00 & 1,00 & 0,02 & 0,11 & $-1,09$ & $-0,14$ & $\mathrm{i}$ \\
\hline \multirow{2}{*}{ Madeira } & $\alpha_{1}$ & $-0,58$ & 0,00 & $-0,07$ & Vetor 1 & 0,00 & 1,00 & 0,00 & $-0,23$ & $-0,63$ & $-0,12$ & $-0,93$ & 0,07 & 0,29 \\
\hline & $\alpha_{2}$ & 0,41 & $-0,25$ & $-0,01$ & Vetor 2 & 0,00 & 0,00 & 1,00 & $-0,12$ & 0,12 & $-1,07$ & $-0,48$ & 0,22 & 0,13 \\
\hline \multirow[b]{2}{*}{ Papel e Celulose } & $\alpha_{1}$ & $-0,90$ & 0,38 & $-0,10$ & Vetor 1 & $-0,01$ & 1,00 & 0,00 & 0,70 & $-0,25$ & 0,00 & 1,19 & 0,50 & $-0,21$ \\
\hline & $\alpha_{2}$ & 0,37 & $-0,29$ & $-0,02$ & Vetor 2 & $-0,02$ & 0,00 & 1,00 & 3,61 & 0,30 & $-0,85$ & 1,55 & 0,68 & $-0,36$ \\
\hline \multirow[b]{2}{*}{ Derivados de petróleo } & $\alpha_{1}$ & $-0,68$ & $-0,11$ & 0,05 & Vetor 1 & 0,01 & 1,00 & 0,00 & 0,91 & $-0,01$ & $-0,77$ & $-0,12$ & 0,35 & $-1,50$ \\
\hline & $\alpha_{2}$ & $-0,42$ & $-0,12$ & 0,38 & Vetor 2 & $-0,02$ & 0,00 & 1,00 & $-2,44$ & $-0,89$ & 0,03 & 1,98 & $-0,68$ & 1,64 \\
\hline \multirow[b]{2}{*}{ Químicos } & $\alpha_{1}$ & $-0,75$ & $-0,25$ & $-0,08$ & Vetor 1 & 0 & 1,00 & 0,00 & $-1,86$ & $-0,70$ & $-0,02$ & $-0,01$ & $-0,04$ & 0,18 \\
\hline & $\alpha_{2}$ & 0,23 & $-0,32$ & 0,02 & Vetor 2 & 0,00 & 0,00 & 1,00 & $-0,46$ & $-0,97$ & $-0,42$ & 0,43 & $-0,61$ & 0,08 \\
\hline \multirow[b]{2}{*}{ Farmoquímicos } & $\alpha_{1}$ & $-1,16$ & 0,08 & 0,00 & Vetor 1 & 0,00 & 1,00 & 0,00 & $-0,50$ & $-1,24$ & 0,29 & 0,45 & $-0,06$ & $-0,03$ \\
\hline & $\alpha_{2}$ & 0,14 & $-0,75$ & 0,17 & Vetor 2 & $-0,01$ & 0,00 & 1,00 & $-0,35$ & 0,00 & $-0,22$ & 0,24 & 0,00 & $-0,01$ \\
\hline Borracha e Plástico & $\alpha_{1}$ & $-0,85$ & 0,06 & $-0,01$ & Vetor 1 & 0,00 & 1,00 & 0,09 & $-0,72$ & $-0,58$ & $-0,07$ & 0,78 & 0,17 & 0,02 \\
\hline Minerais não metálicos & $\alpha_{1}$ & $-0,23$ & 0,04 & $-0,06$ & Vetor 1 & $-0,01$ & 1,00 & $-1,28$ & 1,66 & $-1,84$ & 0,74 & 1,46 & $-0,06$ & 0,15 \\
\hline Metalurgia & $\alpha_{1}$ & $-0,40$ & $-0,17$ & 0,10 & Vetor 1 & 0,00 & 1,00 & $-0,06$ & $-1,20$ & $-1,13$ & 0,38 & 1,64 & $-0,63$ & $-0,33$ \\
\hline \multirow{2}{*}{ Produtos de metal } & $\alpha_{1}$ & $-0,65$ & $-0,13$ & 0,00 & Vetor 1 & 0,01 & 1,00 & 0,00 & $-2,90$ & $-0,94$ & $-0,11$ & 1,32 & $-0,23$ & 0,00 \\
\hline & $\alpha_{2}$ & $-0,65$ & $-0,18$ & $-0,19$ & Vetor 2 & $-0,01$ & 0,00 & 1,00 & 1,50 & $-0,44$ & $-0,68$ & $-0,01$ & 0,12 & 0,05 \\
\hline \multirow{3}{*}{ Informática } & $\alpha_{1}$ & $-0,61$ & 0,01 & 0,00 & Vetor 1 & $-0,05$ & 1,00 & 0,00 & 0,00 & $-0,60$ & 1,94 & 2,57 & $-0,65$ & $-0,60$ \\
\hline & $\alpha_{2}$ & 0,01 & $-0,38$ & 0,03 & Vetor 2 & $-0,04$ & 0,00 & 1,00 & 0,00 & 0,13 & 2,01 & 2,27 & $-0,61$ & $-0,36$ \\
\hline & $\alpha_{3}$ & 1,36 & 1,03 & $-0,11$ & Vetor 3 & $-0,01$ & 0,00 & 0,00 & 1,00 & $-0,29$ & 0,66 & 1,48 & $-0,11$ & $-0,19$ \\
\hline \multirow[b]{2}{*}{ Máquinas elétricas } & $\alpha_{1}$ & $-0,43$ & $-0,15$ & 0,01 & Vetor 1 & 0,03 & 1,00 & 0,00 & $-7,74$ & 0,84 & $-1,06$ & 0,40 & $-0,21$ & 0,01 \\
\hline & $\alpha_{2}$ & $-0,42$ & $-0,12$ & $-0,06$ & Vetor 2 & $-0,03$ & 0,00 & 1,00 & 6,61 & $-1,78$ & 0,68 & $-0,30$ & $-0,29$ & $-0,06$ \\
\hline \multirow{2}{*}{ Máquinas e equipamentos } & $\alpha_{1}$ & $-1,39$ & $-0,02$ & $-0,04$ & Vetor 1 & 0,00 & 1,00 & 0,00 & $-1,04$ & $-0,42$ & $-0,11$ & 0,78 & 0,19 & $-0,03$ \\
\hline & $\alpha_{2}$ & $-0,21$ & $-0,19$ & 0,06 & Vetor 2 & 0,00 & 0,00 & 1,00 & $-0,81$ & 0,23 & $-0,68$ & $-0,10$ & $-0,18$ & 0,00 \\
\hline \multirow[b]{2}{*}{ Veículos } & $\alpha_{1}$ & $-0,50$ & $-0,07$ & $-0,04$ & Vetor 1 & $-0,01$ & 1,00 & 0,00 & $-0,30$ & $-0,23$ & 0,01 & 0,04 & 0,20 & 0,00 \\
\hline & $\alpha_{2}$ & $-0,19$ & $-0,25$ & $-0,01$ & Vetor 2 & 0,00 & 0,00 & 1,00 & 1,06 & 0,02 & $-0,68$ & $-0,14$ & $-0,08$ & $-0,03$ \\
\hline \multirow{3}{*}{ Outros eq. transporte } & $\alpha_{1}$ & $-1,19$ & 0,02 & $-0,01$ & Vetor 1 & 0,00 & 1,00 & 0,00 & 0,00 & $-0,38$ & 0,14 & $-0,23$ & $-0,31$ & 0,00 \\
\hline & $\alpha_{2}$ & 0,26 & $-0,42$ & $-0,01$ & Vetor 2 & 0,00 & 0,00 & 1,00 & 0,00 & $-0,03$ & $-0,58$ & 0,13 & $-0,14$ & $-0,04$ \\
\hline & $\alpha_{3}$ & 0,72 & 0,04 & $-0,21$ & Vetor 3 & 0,00 & 0,00 & 0,00 & 1,00 & $-0,24$ & 0,07 & $-0,08$ & $-0,06$ & $-0,05$ \\
\hline Móveis e Prod. diversos & $\alpha_{1}$ & $-0,34$ & $-0,05$ & $-0,05$ & Vetor 1 & $-0,02$ & 1,00 & 4,92 & $-0,23$ & $-1,37$ & $-2,54$ & 0,34 & $-0,17$ & $-0,07$ \\
\hline
\end{tabular}

Tabela B.1 - Estimativas dos vetores cointegração dos modelos setoriais VARX* 



\section{APÊNDICE C - COEFICIENTES DO REPASSE DOS CHOQUES CAMBIAIS E AOS PREÇOS DO PETRÓleo}
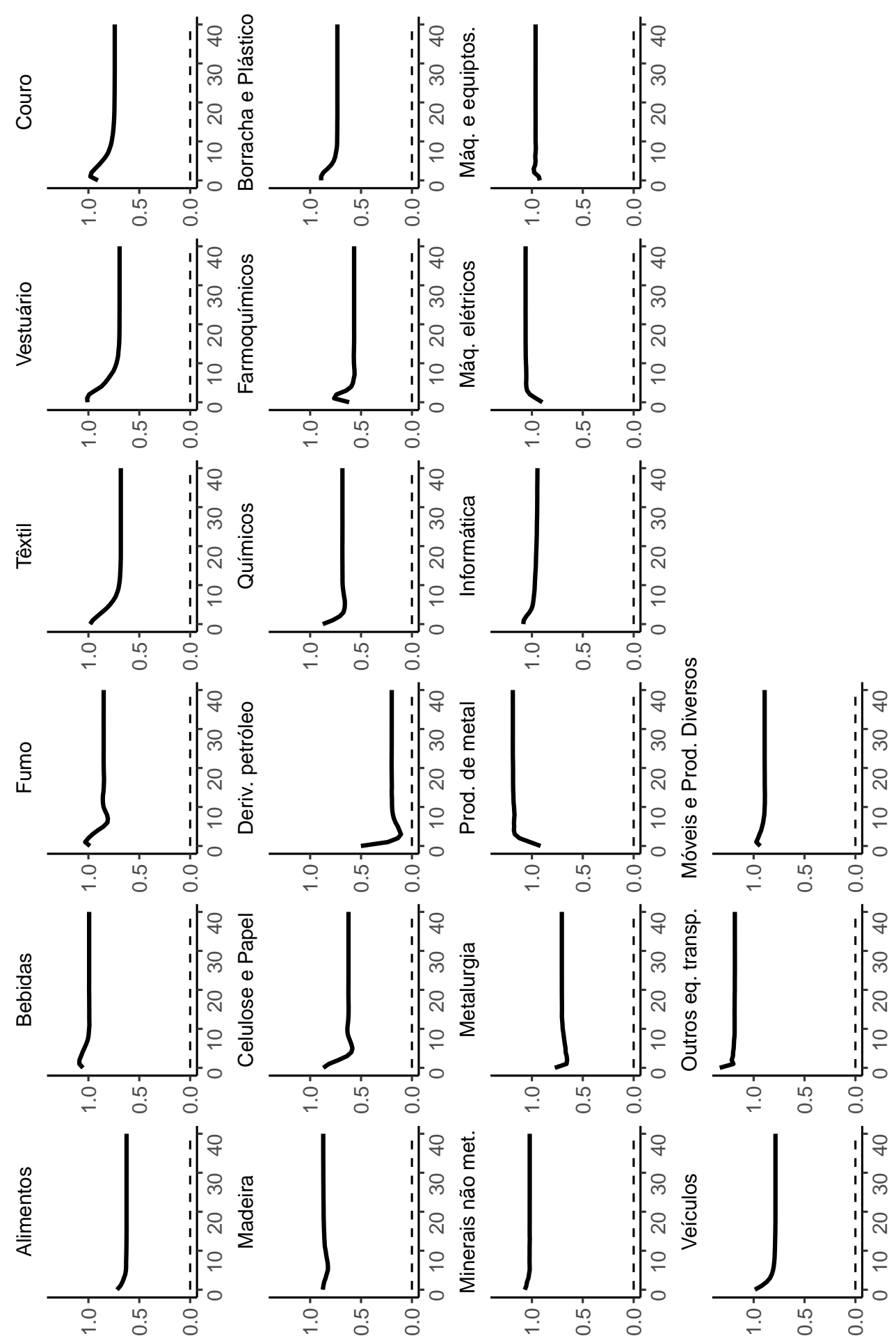

Figura C.1 - Dinâmica do repasse do choque cambial para os preços de importação 

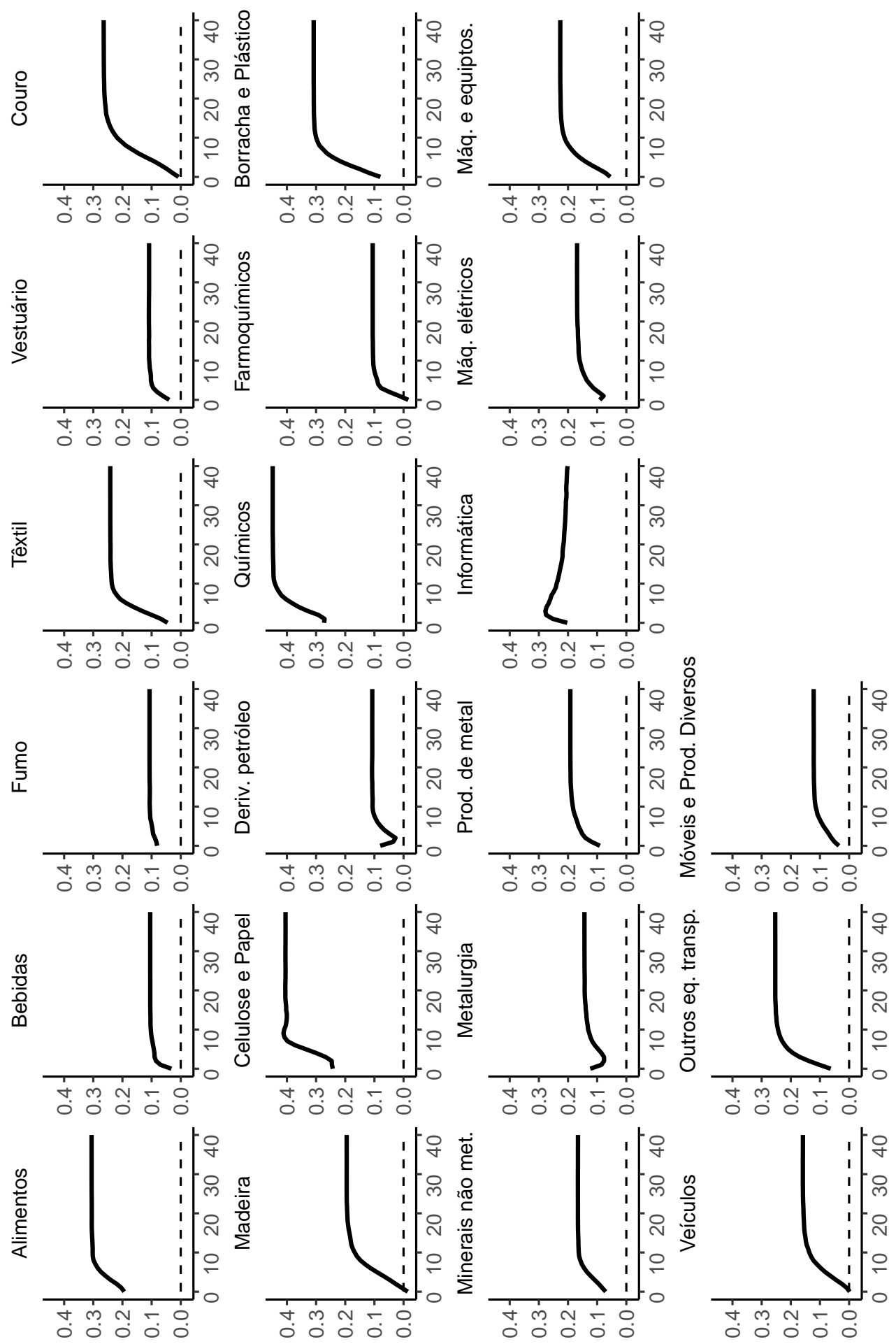

Figura C.2 - Dinâmica do repasse do choque cambial para os preços ao atacado 

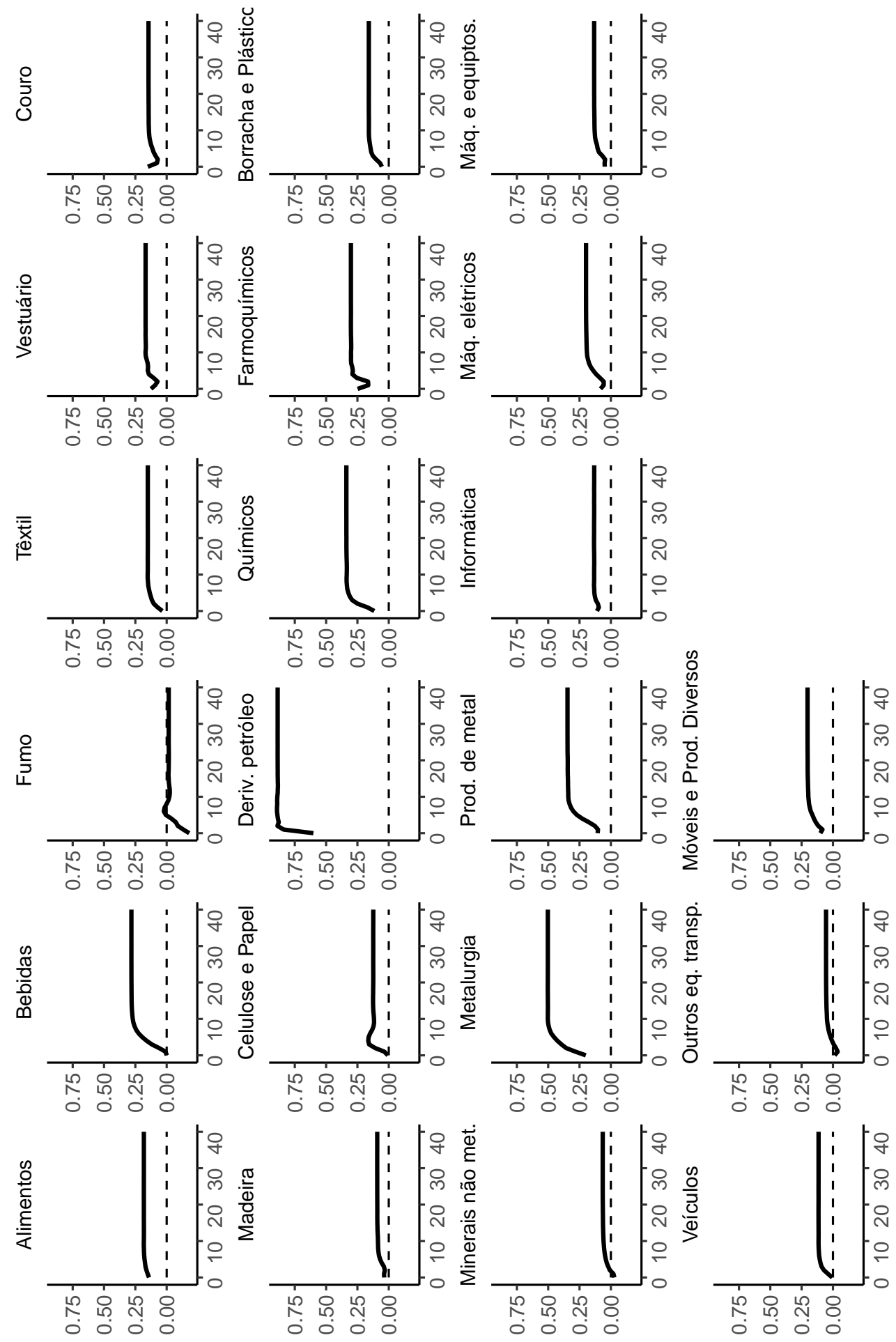

Figura C.3 - Dinâmica do repasse do choque do preço do petróleo para os preços de importação 

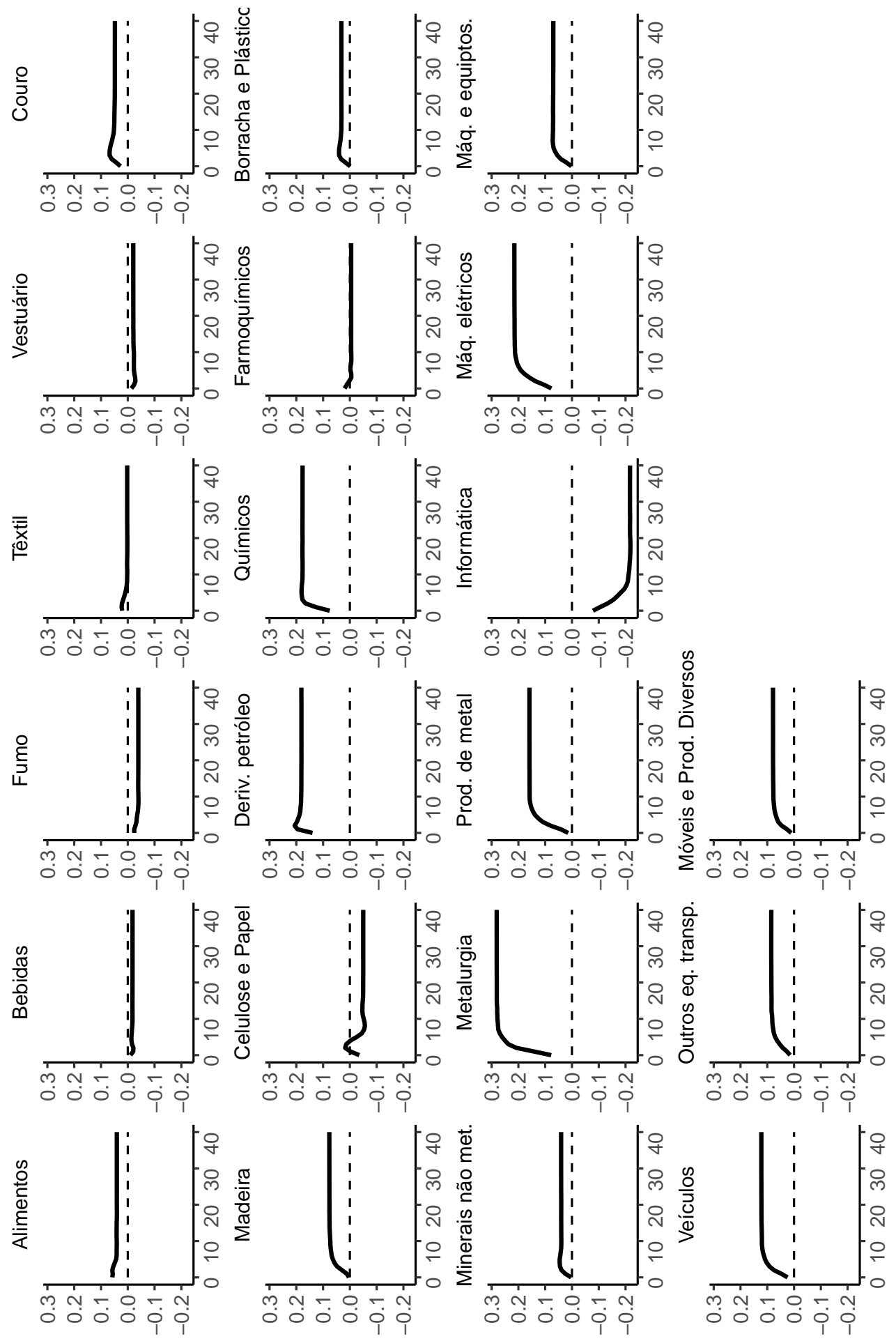

Figura C.4 - Dinâmica do repasse do choque do preço do petróleo para os preços ao atacado 